\title{
THE TOXICITY OF SILVER NANOPARTICLES
}

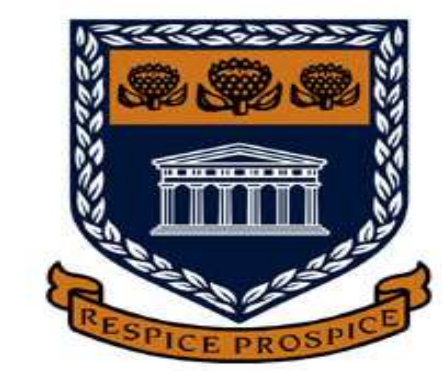

UNIVERSITY of the

WESTERN CAPE

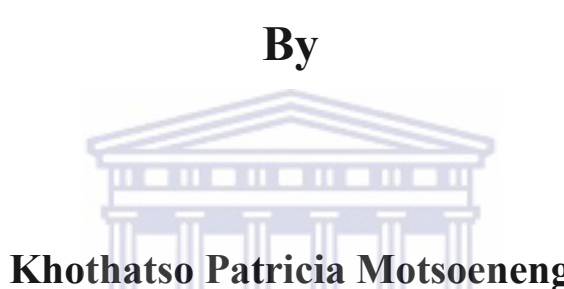

A mini thesis submitted in partial fulfilment of the requirements for the degree of Masters of Science in Nanoscience, University of the Western Cape

Supervisor: Prof Edmund Pool (Medical Bioscience Department)

Co-Supervisor: Prof Leslie Petrik (Chemistry Department)

July 2015 


\section{Abstract}

Unavailability and contamination of available water resources are major factors contributing to adverse health conditions worldwide. AgNPs present a potential strategy for water purification; however, their ability to accumulate in organs such as the kidneys, lungs and spleen is a possible source of toxicity. This study investigates the toxicity of AgNPs to Saccharomyces cerevisiae (S. cerevisiae). S. cerevisiae is an excellent model organism for assessing toxic compounds that affect eukaryotic organisms due to their ease of cultivation. AgNPs were prepared by photo-reduction of silver nitrate with OSRAM Vitalux lamp $(300 \mathrm{~W}$ and $230 \mathrm{~V})$ in the presence of stabilizing agents such as polyvinylpyrrolidone and citric acid, yielding AgNPs. The effects of varying the concentration of the stabilizing agent, time of exposure to the light source, and $\mathrm{pH}$ were investigated. The formation of AgNPs was analysed by ultra-violet spectroscopy (UV-Vis) and transmission electron microscope techniques. The results showed that the AgNPs absorbed ultra-violet radiation between 400 and $500 \mathrm{~nm}$ and TEM images showed the particles to be both spherical and needle-like in shape. The shapes of the AgNPs were largely dependent on the synthesis method applied. The toxicity of AgNPs was assessed using metabolic activity of yeast cells as biomarker and monitored with of the chromogenic assay, XTT. S. cerevisiae was introduced into different concentrations of AgNPs and incubated at $37^{\circ} \mathrm{C}$ for $72 \mathrm{~h}$. After the incubation, XTT assay was performed to assess the cell viability. The XTT results showed that high concentration of AgNPs $(100 \mu \mathrm{g} / \mathrm{mL})$ inhibited the growth of $S$. cerevisiae. The synthesis of AgNPs and the assessment of their toxicity on S. cerevisiae was thus undertaken and established in this work. 


\section{Keywords}

Silver nanoparticles (AgNPs)

Water purification

Photoreduction

Citric acid

Toxicity

S. cerevisiae

Chromogenic assay

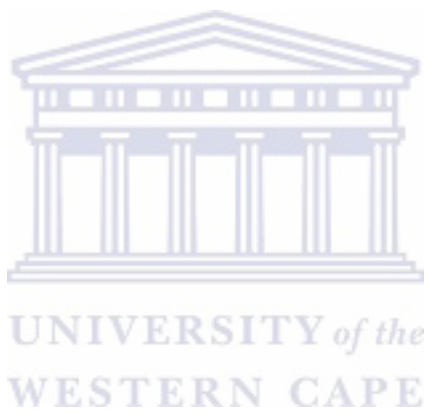




\section{DECLARATION}

I declare that "The toxicity of silver nanoparticles" is my own work that has not been submitted for any other degree or examination in any other university and that all the sources I have used or quoted have been indicated and acknowledged by complete references.

Khothatso Patricia Motsoeneng

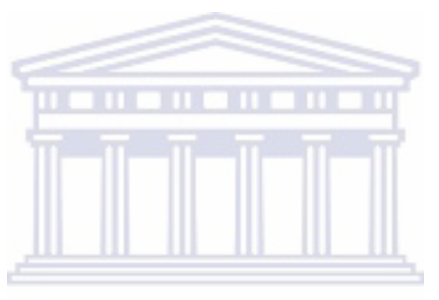

July 2015

Signed 


\section{ACKNOWLEDGEMENTS}

Firstly, I would like to give thanks to God Almighty for giving me strength and keeping me thus far.

Secondly, I would like to acknowledge my supervisor and co-supervisor: Prof Edmund Pool and Prof Leslie Petrik, for their support and readiness to impart skills and knowledge. They encouraged and challenged me to perform to the best of my potential and I am grateful for that.

Thirdly, I render many thanks to Mr Valentine Anye (University of Pretoria), for editing and proofreading this work. Your effort is highly appreciated. To my colleagues Roland, Missengue, Jimoh and everyone from Environmental and Nanoscience Research group, I say thank you for your many suggestions and inputs into this research endeavour.

I would also like to appreciate the Department of Science and Technology (DST) for funding my project and the Departments of Medical Bioscience and Chemistry at UWC, together with the University of Cape Town (UCT) for allowing me to use their equipment and resources for this work.

Fourthly, I would love to thank my mom, Makeiso Motsoeneng, for her encouraging words, prayers and support; you are the best mom ever. Special thanks to my brothers and sisters Tebello, Teboho, Keiso, Rapelang, Edisang and Thabisang; your support is highly appreciated.

Finally yet importantly, I would like to appreciate the support of my friends: Lindi, Mzwandile and Busiswa for the encouragement and support they gave me during this work. 
TABLE OF CONTENTS

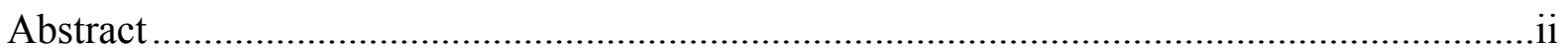

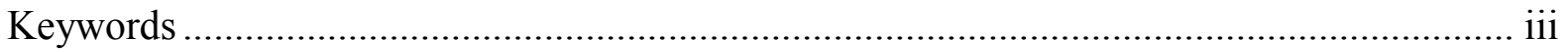

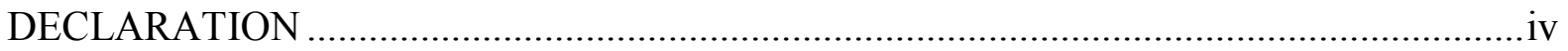

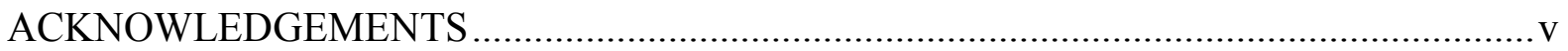

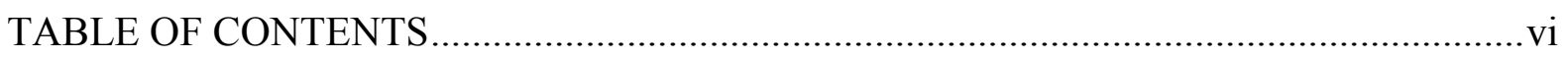

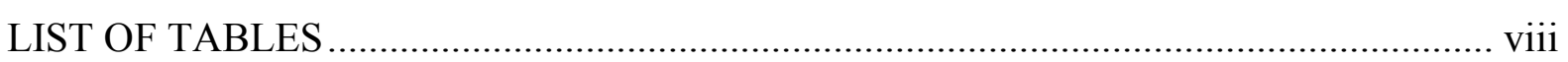

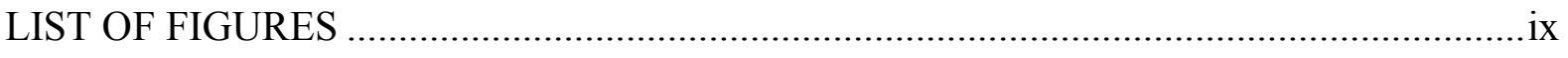

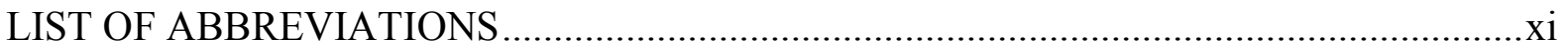

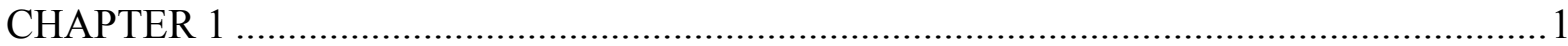

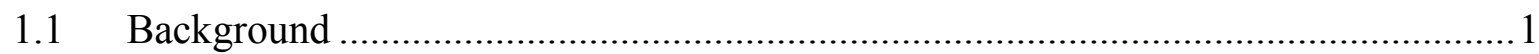

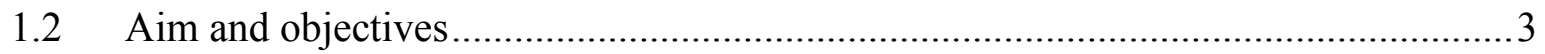

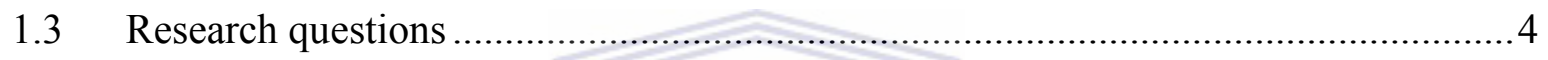

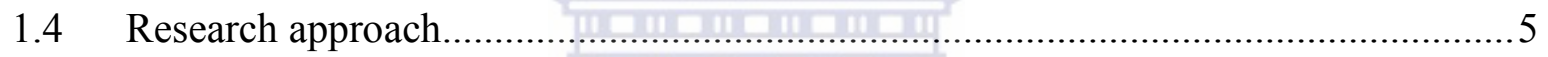

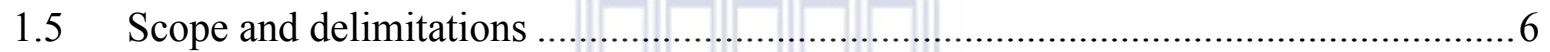

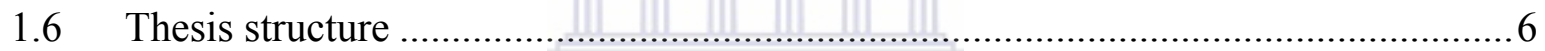

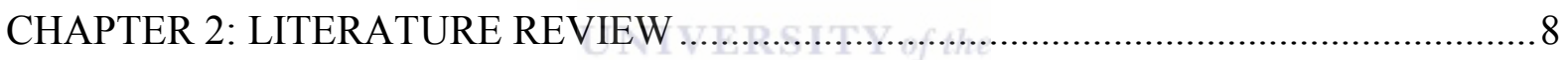

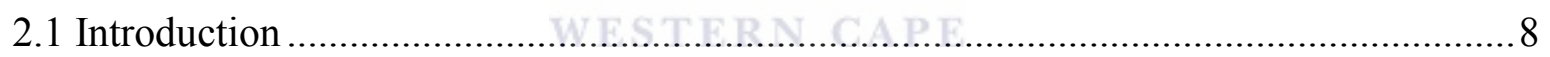

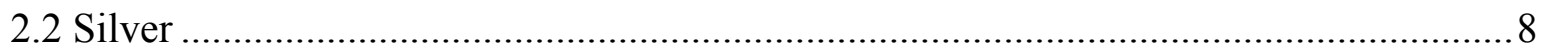

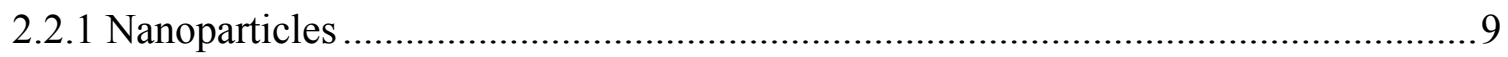

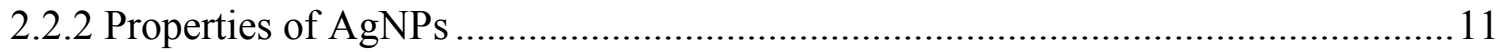

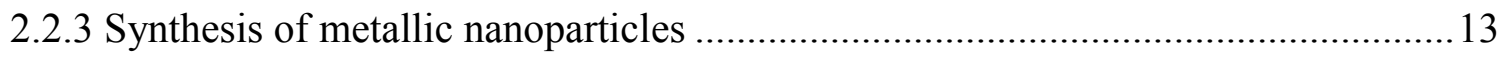

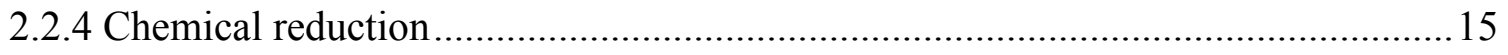

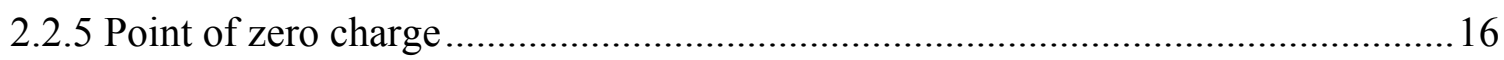

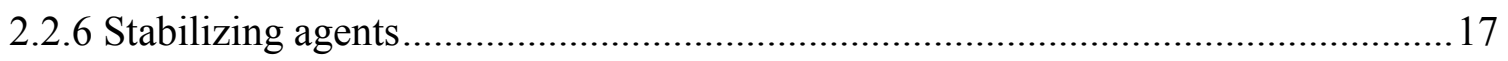

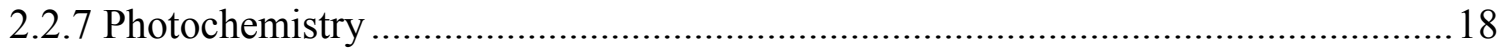

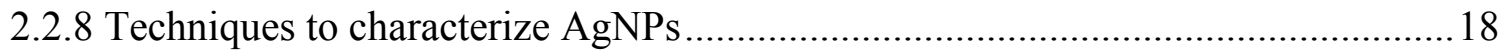

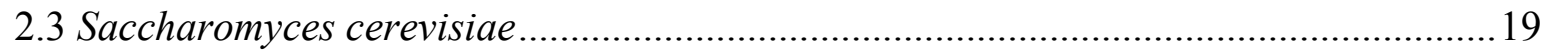

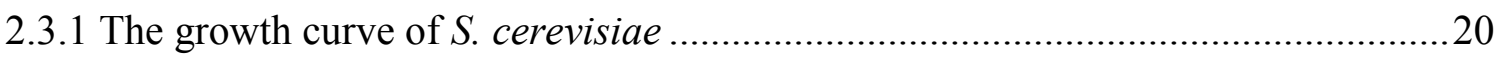

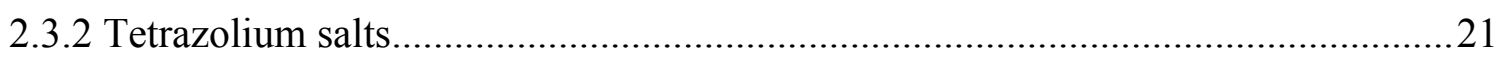

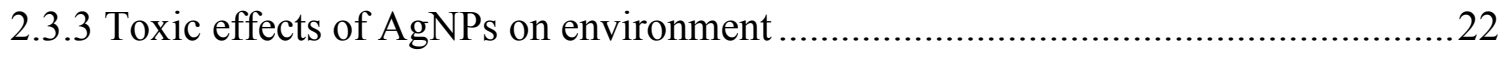

2.3.4 Effect of silver nanoparticles on the aquatic food-chain. ....................................22 


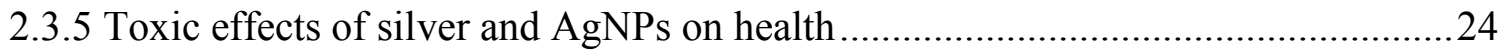

2.3.6 Silver nanoparticles, the disruptor of basal cell functions....................................26

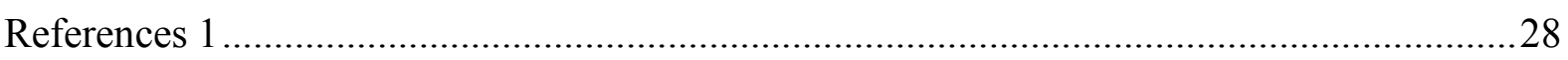

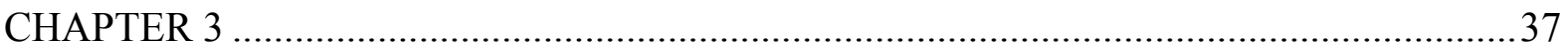

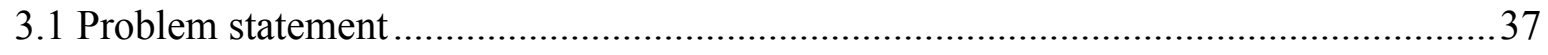

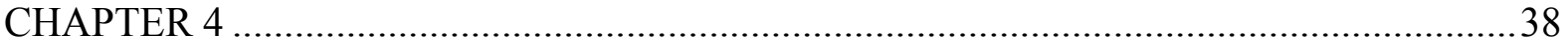

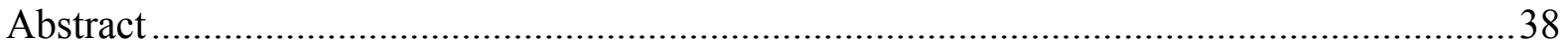

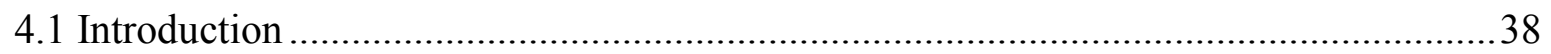

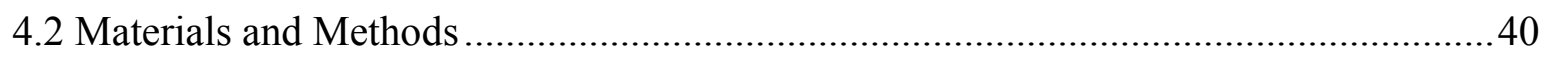

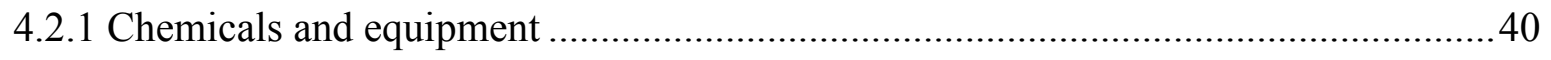

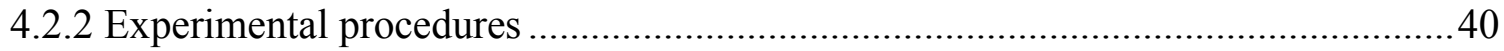

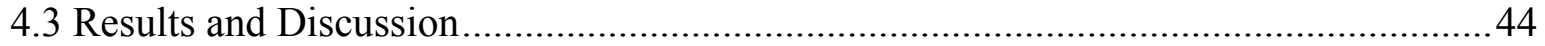

4.3.1 Silver nanoparticles prepared in the presence of PVP ..........................................4

4.3.2 Silver nanoparticles prepared in the presence of citric acid. ................................53

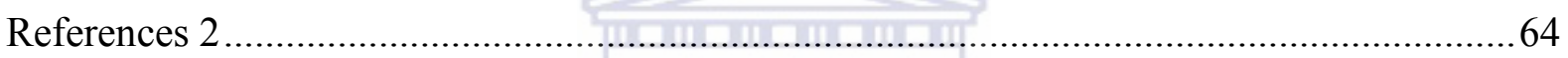

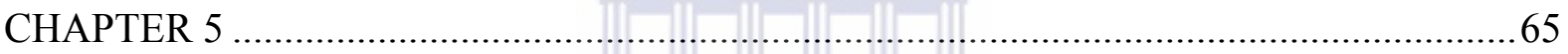

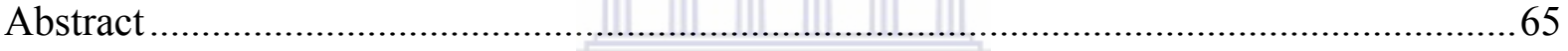

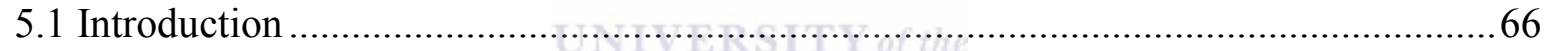

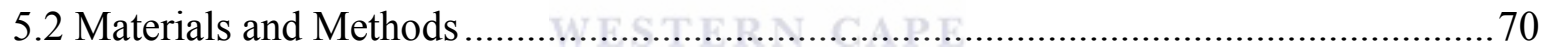

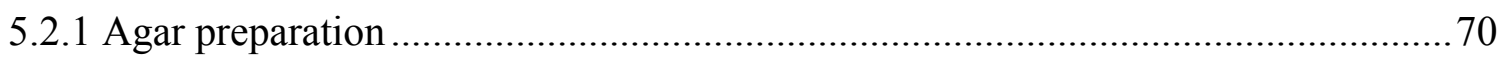

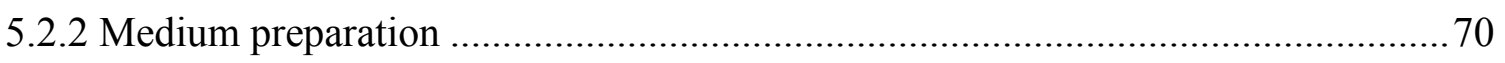

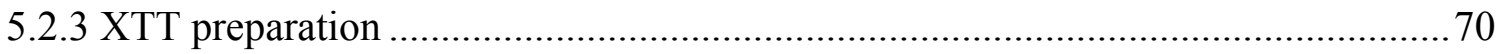

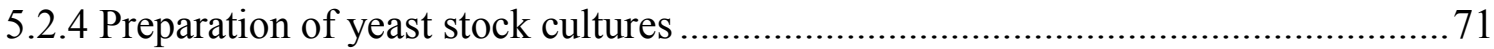

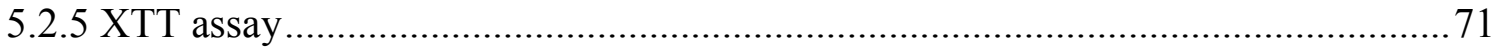

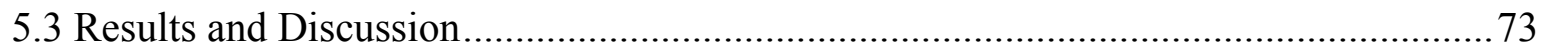

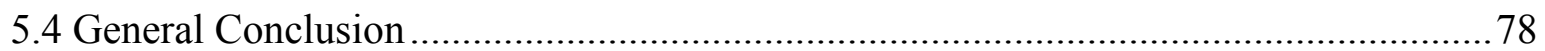

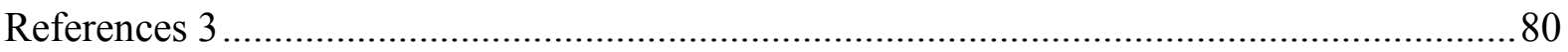




\section{LIST OF TABLES}

Table 1: Product categories with examples of products containing silver nanoparticles. The values between the brackets indicate the number of sub-categories (Panyala et al., 2008).

Table 2: List of chemicals used in this study

Table 3: Silver nanoparticles preparation under different conditions

Table 4: Silver nanoparticles used in in vitro biological experiments and their impacts (Reidy et al., 2013).

Table 5: Silver nanoparticles preparation with PVP and their size and shape.

Table 6:Preparation of silver nanoparticles with citric acid and their size and shape

Table 7: Toxicity of AgNPs prepared using PVP as dispersing agent

Table 8: Toxicity of AgNPs prepared using citric acid as dispersing agent 


\section{LIST OF FIGURES}

Figure 1: Schematic flow diagram for synthesis of AgNPs and determining their toxicity on the yeast cell.

Figure 2: The top-down approach vs. the bottom-up approach for synthesis of nanoparticles (Kildeby et al., 2005)

Figure 3: Experimental set-up for AgNP synthesis.

Figure 4: Synthesis of AgNPs using $\mathrm{AgNO}_{3}$ with varying PVP concentrations. (a) Observable colour change at 3 different PVP concentrations. (b) UV-Vis absorbance spectra of the synthesized particles. $\mathrm{A} 1, \mathrm{~A} 2$ and $\mathrm{A} 3$ represent reactions of $\mathrm{AgNO}_{3}$ with $0.4,2$ and $4 \mathrm{mg} / \mathrm{ml}$ PVP respectively. .45

Figure 5: TEM images (c) and size distribution (d) of silver nanoparticles in A1, A2 and A3..........46

Figure 6: Colour change (a); UV-Vis absorbance (b) for AgNPs in sample A4, A5 and A3.............47

Figure 7: TEM analysis of AgNPs formed at varying photolight exposure time. (c): Images and (d) size distribution of silver nanoparticles in A4, A5 and A3.

Figure 8: Synthesis of AgNPs at three different $\mathrm{pH}$ values. (a): Observable colour change at the different $\mathrm{pH}$ values 6, 9 and 10.5. (b): Corresponding UV-Vis absorbance spectra for A6, A3 and A7.

Figure 9: TEM analysis of AgNPs formed at different $\mathrm{pH}$ values. (c): TEM images and (d): size distribution of silver nanoparticles in $\mathrm{A} 6, \mathrm{~A} 3$ and $\mathrm{A} 7$.

Figure 10: Colour change and UV-Vis analysis of citric acid formed AgNPs. (a): observable colour change at different citric acid concentration; $\mathrm{B} 1, \mathrm{~B} 2$ and $\mathrm{B} 3=0.4,2$ and $4 \mathrm{mg} / \mathrm{mL}$ citric acid respectively. (b): UV-Vis absorbance spectra of B1, B2 and B3 represented respectively by blue, red and green curves.

Figure 11: TEM analysis of AgNPs formed in different concentrations $(0.4,2$ and $4 \mathrm{mg} / \mathrm{mL})$ citric acid. (c): TEM images of B1, B2 and B3. (d): size distribution of silver nanoparticles in B1, B2 and B3.

Figure 12: Visual colour observation and UV-vis analysis of the effect of light exposure time on AgNPs formation. (a): Colour change from light green (B4), to gray (B5) and brow (B3). (b): UV-vis absorbance spectrum of B4, B5 and B3.

Figure 13: TEM image analysis and particle size distribution of AgNPs formed from exposure of citric acid/ $\mathrm{AgNO}_{3}$ solution to light for 1 hour (B4), 2 hour (B5) and 3 hours (B3). (c): TEM images of B4, B5 and B3 adjusted to a $20 \mathrm{~nm}$ scale; (d): size distribution of silver nanoparticles in B4, B5 and B3.

Figure 14: Verification of the formation of AgNPs at three different $\mathrm{pH}$ values. (a): Colour change observations after $3 \mathrm{~h}$ in $\mathrm{pH} 6,9$ and 10.5 in B6, B3 and B7. 
Figure 15: TEM images and size distribution of AgNPs formed at $\mathrm{pH} 6,9$ and 10.5 after $3 \mathrm{~h}$ of exposure to light. (c): TEM images of samples from B6, B3 and B7; (d) size distribution plots of the corresponding TEM images B6, B3, B7. .62

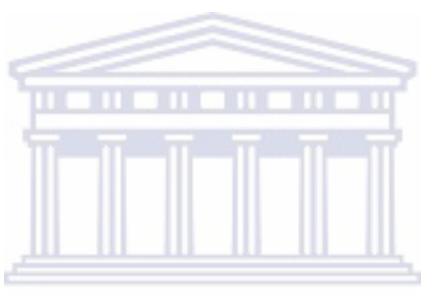

UNIVERSITY of the 


\section{LIST OF ABBREVIATIONS}

$\mathrm{AgNO}_{3} \quad$ Silver nitrate

AgNPs Silver nanoparticles

EtOH Ethanol

GSH Glutathione S-transferase

HR-TEM High Resolution-Transmission Electron Microscope

ID Identity

MEB Malt extract broth

$\mathrm{NH}_{4} \mathrm{OH} \quad$ Ammonium hydroxide

OD Optical density

PBS Potassium buffered saline

PDA Potato extract broth

PVP Polyvinylpyrrolidone

ROS Reaction oxidative species

SDS Sodium dodecyl sulfate

UV-Vis Ultra-violet

XTT 2,3-Bis(2-methyloxy-4-nitro-5-sulfophenyl)-5-[(phenylamino)

Carbonyl]-2H-tetrazolium hydroxide 


\section{CHAPTER 1}

This chapter gives a short background about water scarcity worldwide and also highlights the improvements to be made to overcome this challenge. Furthermore, the importance of this study, the problem statement, research questions, research approach with its scope, delimitations, aims and objectives are covered in this chapter. The chapter ends with a brief outline of the structure of this thesis.

\subsection{Background}

Unavailability and contamination of available water is a major health challenge globally, and in developing countries particularly (WHO, 2008). This challenge results in disease and economic dilemmas especially in marginalized communities. With extended droughts, increasing populations and competing demand from various users, the need of clean water supply has become a major necessity for governments worldwide (Savage and Diallo, 2005). Water that does not contain toxic pollutants is essential for human health. The prevalence of most enteric diseases is due to bacterial contamination of drinking water. According to the World Health Organization (WHO), approximately 1.8 million deaths and 61.9 million disability adjusted life years (DALY'S) globally are due to unsafe water, sanitation and poor hygiene. It has been estimated that $99.8 \%$ of such deaths mainly occur in developing countries with children ranking $(90 \%)$ as the first victims. Contamination of ground and surface water with pathogenic bacteria such as Escherichia coli O157:H7, Salmonella typhimurium, Shigella dysenteriae and Vibrio cholera are the major causes of diarrheal and gastrointestinal infections (Savage and Diallo, 2005). This is an indication that safe drinking water plays a huge role in human health and well-being. Infections from water are generally classified into four categories namely: water borne, water washed, water based and water 
related diseases. The first three classes are mostly associated with the lack of good water supplies.

Water borne diseases are diseases resulting from the ingestion of water contaminated with pathogens. These diseases include most enteric and diarrheal diseases caused by viruses and bacteria in water. Water washed diseases result from inadequate supply of clean water for personal hygiene and washing (Hunter et al., 2000). Water based diseases are obtained from hosts that live in water. Humans are likely to contract these kinds of diseases from ingestion or walking in contaminated water. Water related disease includes diseases distributed by insects that breed or feed near contaminated water such as malaria, dengue fever and onchocerciasis (Hunter et al., 2000).

Though several systems and techniques have been developed for wastewater treatment, these systems still do not remove all contaminants in water. The removal or inactivation of pathogenic bacteria is often the last step in wastewater treatment systems (Tiwari et al., 2008). Some techniques used for wastewater treatment involve the use of chemicals and physical agents such as chlorine and its derivatives, ultra-violet light, boiling, low frequency ultrasonic irradiation, distillation, water sedimentation and reverse osmosis. Halogens such as chlorine and bromine are used as antibacterial agents. The direct use of these halogens, however, causes problems due to the high toxicity and vapour pressure of these chemicals in pure form (Tiwari, et al., 2008). Another chemical compound, ammonium $\left(\mathrm{NH}_{4}^{+}\right)$, a common cation in water has been shown to have serious adverse effects on both human and animal health. This compound is found in wastewater and small proportions of it manage to be oxidized in water during conventional treatment in treatment plants. Coupled with the decomposition of organic matter in water, the presence of oxidized $\mathrm{NH}_{4}{ }^{+}$, reduces the amount 
of oxygen that can be dissolved by water, posing a potential detrimental consequences to aerobic biota.

Ongoing research is attempting to use AgNPs for water purification to provide safe drinking water. AgNPs are simple and inexpensive disinfection systems, which could provide safe drinking water for millions of people in areas where there are shortages of clean water (Dankovich and Gray, 2011). Several clay pot-based, water treatment systems and devices are currently being used internationally by small rural areas, which lack safe water. Although South Africa has done some exploratory work that relates to the use of these clay pots for hygiene purpose, little on evaluation of the safety of these units or improving them has been accomplished. These units can be a great empowerment tool for rural communities lacking water service. Clay pots have been used in countries such as Nicaragua and Cambodia for some time but silver, used as the antimicrobial agent is simply painted onto the surface. The incorporation of silver throughout the pot may increase water treatment efficiency (Vinka et al., 2008).

\subsection{Aim and objectives}

The aim of this study was to investigate the toxicity of AgNPs on yeast cell (S. cerevisiae).

\section{The objectives of the study are as follows:}

- To synthesize AgNPs from silver nitrate $\left(\mathrm{AgNO}_{3}\right)$ using photolight as a reducing agent.

- To characterize the synthesized AgNPs using Ultra-Violet spectroscopy (UV-Vis) and Transmission Electron Microscope (TEM).

- To examine the toxicity of silver to yeast cells and by observing the cell viability 


\subsection{Research questions}

- Does photoreduction method produce different shapes of silver nanoparticles?

- Which stabilizing agent (PVP or citric acid) produce small sizes of silver nanoparticles?

- What effects do AgNPs have on the S. cerevisiae cell?

- Is $S$. cerevisiae a good indicator for toxicity of AgNPs?

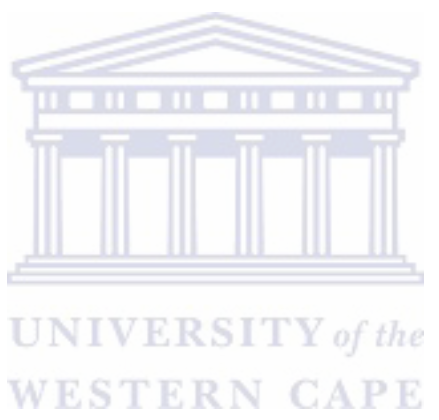




\section{$1.4 \quad$ Research approach}

The schematic flow diagram (Figure 1) presents the research approach used to synthesize AgNPs and to examine the toxicity of the synthesized AgNPs.

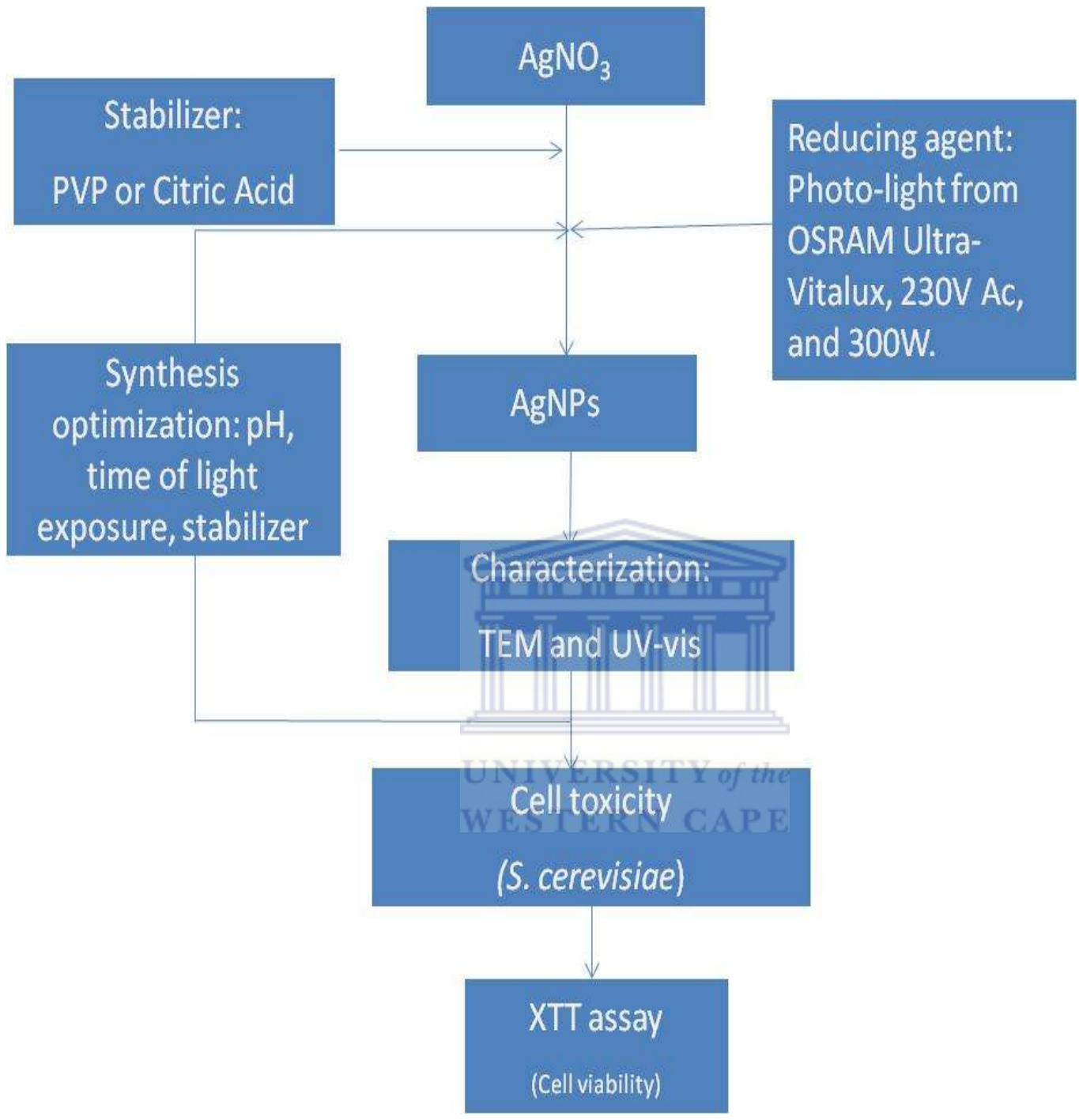

Figure 1: Schematic flow diagram for synthesis of AgNPs and determining their toxicity on the yeast cell.

AgNPs were synthesised by reducing silver nitrate $\left(\mathrm{AgNO}_{3}\right)$ with photolight (OSRAM ultravitalux, $230 \mathrm{~V}$ Ac, $300 \mathrm{~W}$ ) in the presence of PVP or citric acid as stabilizer. The obtained AgNPs were characterized by UV-Vis and TEM techniques. Optimization of nanoparticles size was achieved by varying parameters such as molar ratio, time of light exposure and $\mathrm{pH}$. The obtained AgNPs were used to investigate their toxicity on $S$. cerevisiae. Cell proliferation was investigated using XTT assays. 


\subsection{Scope and delimitations}

This study focused on the synthesis of $\mathrm{AgNPs}$ from silver nitrate $\left(\mathrm{AgNO}_{3}\right)$ using a photolight source (OSRAM ultra-vitalux, 230V Ac, 300W) as reducing agent. UV-vis and TEM were used to characterize the synthesized AgNPs. AgNPs purification could not be done and extensive characterization methods, including XDR, FTIR and SEM could not be used due to time constraints. The toxicity of these nanoparticles was investigated on $S$. cerevisiae, a model organism for assessing toxic compounds affecting eukaryotic cells. Owing to the time, financial and ethical restrictions, animal models (such as rats) could not be used for this study. The effect of AgNPs on yeast cells was investigated in this study using XTT assay and toxicity of stabilizing agents such as PVP and citric acid could not be investigated due to time limitation. It is important to note here that, this work was a mini thesis, with just a year allocated for research and writing following an intensive year of purely course work. Hence, the time limitation mentioned in this section.

\subsection{Thesis structure}

\section{Chapter-2 Literature Review and Theoretical framework}

Chapter 2 lays out the theoretical framework of this research and covers general information on the toxicity of AgNPs to microbes. The chapter also gives insights into the techniques that have been applied in characterization of synthesized nanoparticles.

\section{Chapter-3 Problem statement}

Chapter3 presents the problems of water scarcity and sanitation in rural areas. It also highlights the problems of current techniques used to purify water and suggest a way forward. 


\section{Chapter-4 Preparation and characterization of AgNPs}

Chapter 4 describes the methodology used in this work to synthesize nanoparticles and characterize them. TEM and UV-Vis were used to analyse the synthesized AgNPs. The results of the characterized AgNPs are also presented and discussed in this chapter.

\section{Chapter-5 Toxicity testing of AgNPs}

Chapter 5 outlines and describes the methodology used to assess the toxicity of AgNPs. An XTT assay was used to assess the proliferation of $S$. cerevisiae cells. Results are presented and discussed.

\section{Chapter-6 Conclusion and Recommendations}

This chapter summarized the whole study and highlights the achievements and contributions of the study. The chapter proposes away forward and aspects for further research. 


\section{CHAPTER 2: LITERATURE REVIEW}

\subsection{Introduction}

This chapter presents the literature review of this study. It will be divided into two sections. The first section will review silver ions and various methods to synthesize AgNPs and techniques used to characterize them. The second section reviews growth of S. cerevisiae, toxicity of AgNPs and the colorimetric assays used to examine cell proliferation and cell viability.

\subsection{Silver}

Silver is a naturally occurring metal, appearing most often as a mineral and is positioned as the $47^{\text {th }}$ element on the periodic table with an atomic weight of 107.8. Silver has two natural isotopes $\mathrm{Ag} 106.90$ and $\mathrm{Ag} 108.90$ with respective abundances of 52 and 48\%. This metal has been used in a variety of applications, due to its high electric and thermal conductivity (Nordberg and Gerhardsson, 1988). Ancient civilizations used silver in medicine, food containers, plates, eating utensils, cups, money, jewellery, clothes and for water disinfection.

Naturally, silver possesses antimicrobial activity towards many pathogens including bacteria, fungi, yeasts and viruses (Zhang and Sun, 2007). The silver salts like silver nitrate, have been used to treat mental illness, gastroenteritis, nicotine addiction and infectious diseases such as gonorrhea and syphilis (Gulbranson et al., 2000). Recently, silver-coated catheters are being used to stop infections (Samuel and Guggenbichler, 2004). In order to protect humans from food poisoning, AgNPs are now being put in tabletops, cutting boards, surface disinfectants and refrigerators. However, ecologists have warned that the widespread use of this powerful antimicrobial agent could have a negative impact for bacteria in natural ecosystems if released in waste streams. There is now growing evidence that as the silver metal is toxic to 
bacteria, so are AgNPs toxic to mammalian cells (Braydich-Stolle et al., 2005). In addition, AgNPs have been shown to damage liver, brain and stem cells in animal models. The overexposure of colloidal or silver salt deposits under the skin causes skin disease such as argyria or argyrosis. Argyrosis is described as a pathologic bluish-black pigment in a tissue, which results from the deposition of an insoluble albuminate of silver (Panyala et al., 2008). Silver in its bulk form, is extremely toxic to fish (Hogstrand and Wood, 1996), algae, fungi, some plants, crustaceans and bacteria such as the nitrogen fixing heterotrophic and soil forming chemolithotrophic bacteria (Eisler, 1996).

Factors such as solubility and binding specificity to a biological site influence the toxicity of silver metal. The toxic effect of metals is defined as any functional or morphological change in the body caused by consumption, injection, inhalation or absorbed drug, chemical or biological agent containing silver. Silver occurs in various forms that can affect both the environment and living things. These forms include metallic silver, silver complexes, silver salts and colloidal silver. Metallic silver dissolves in acids and forms compounds like silver nitrate (Panyala et al., 2008). Aqueous solutions of silver nitrate comprises silver in the form of hydrated silver cations. Silver cations form complexes with different organic ligands and even if these cations are still present in the molecule, the charge of the complex can still be neutral. Additionally, highly stable complex forms of silver do not dissociate in solutions or liquids (Panyala et al., 2008).

\subsubsection{Nanoparticles}

Nanoparticles are particles that have at least one dimension with a size ranging between 1 to $100 \mathrm{~nm}$. They can exist in single, aggregated or agglomerated fused forms of spherical, tubular or irregular shape. The common types of nanoparticles are dendrimers, nanotubes, 
quantum dots and fullerenes. Products with engineered nanoparticles have been in markets for decades now, and keep increasing as years go by. Nanoparticles are now being used for the manufacture of analytical tools for life sciences and biotechnology (Cui et al., 2001). Additionally, nanoparticles are applied in ultra-sensitive molecular sensing, diagnostic imaging, agents of photodynamic, wound dressings, dental-bonding agents, clothing and electronics. Despite their widespread applications, little is documented on the effects of nanoparticles on human health and the environment (Teodoro et al., 2011). This calls for deliberate investigation of the toxicity of these particles on human and environmental health to be undertaken.

\subsubsection{Silver nanoparticles}

AgNPs are nanoparticles consisting of about 20 to 15,000 silver atoms. These particles occur in various shapes; spheres, rods and cubes, and sizes, but generally are smaller than $100 \mathrm{~nm}$. AgNPs can also be produced as tubes, multifacets, wires and cubes. At the nano-scale, AgNPs have better physiochemical properties and greater biological activities compared to the regular bulk metal. This is as a result of the higher surface area per mass, permitting a larger amount of surface atoms to interact with the surroundings (Wijnhoven et al., 2009). Nowadays, AgNPs are being used in an increasing number of consumer and medical products (Table 1) (Panyala et al., 2008). 
Table 1: Product categories with examples of products containing silver nanoparticles. The values between the brackets indicate the number of sub-categories (Panyala et al., 2008).

\begin{tabular}{|c|c|c|}
\hline Categories & Subcategories & Examples \\
\hline $\begin{array}{l}\text { Personal care and } \\
\text { cosmetics }(30)\end{array}$ & $\begin{array}{l}\text { Skin care (14) } \\
\text { Oral hygiene (6) } \\
\text { Hair care (3) } \\
\text { Cleaning (2) } \\
\text { Coating (2) } \\
\text { Baby care (2) } \\
\text { Over the counter health } \\
\text { products (1) }\end{array}$ & $\begin{array}{l}\text { (Body) cream, hand sanitizer, hair care products, beauty soap, } \\
\text { face masks } \\
\text { Tooth brush, teeth cleaner, toothpaste } \\
\text { Hair brush, hair masks } \\
\text { Elimination wipes and spray } \\
\text { Make-up instrument, watch chain } \\
\text { Pacifier, teeth developer } \\
\text { Foam condom }\end{array}$ \\
\hline Textile and shoes (34) & $\begin{array}{l}\text { Clothing (28) } \\
\text { Other textiles (2) } \\
\text { Toys }\end{array}$ & $\begin{array}{l}\text { Fabrics and fibers, socks, shirts, caps, jackets, gloves, } \\
\text { underwear } \\
\text { Sheets, towels, shoe care, sleeves and braces } \\
\text { Plush toys }\end{array}$ \\
\hline Electronics (29) & $\begin{array}{l}\text { Personal care (13) } \\
\text { Household appliances }(8) \\
\text { Computer hardware }(6) \\
\text { Mobile devices (2) }\end{array}$ & $\begin{array}{l}\text { Hair dryers, wavers, ions, shavers } \\
\text { Refrigerators, washing machines } \\
\text { Notebooks, (laser) mouse, keyboards } \\
\text { Mobile phones }\end{array}$ \\
\hline $\begin{array}{l}\text { Household products/home } \\
\text { improvement (19) }\end{array}$ & $\begin{array}{l}\text { Cleaning (9) } \\
\text { Coating (4) } \\
\text { Furnishing (3) } \\
\text { Furnishing/coating (3) }\end{array}$ & $\begin{array}{l}\text { Cleaning products for bathroom, kitchen, toilets, } \\
\text { detergents, fabric softener } \\
\text { Sprays, paint supplements } \\
\text { Pillows } \\
\text { Showerheads, locks, water taps }\end{array}$ \\
\hline $\begin{array}{l}\text { Filtration, purification, neutralization, } \\
\text { sanitization (13) }\end{array}$ & $\begin{array}{l}\text { Filtration (8) } \\
\text { Cleaning (6) ERSIT) }\end{array}$ & $\begin{array}{l}\text { Air filters, ionic sticks } \\
\text { Disinfectant and aerosol sprays }\end{array}$ \\
\hline
\end{tabular}

\subsubsection{Properties of AgNPs}

AgNPs in the field of nanotechnology have gained considerable interest because of their unique properties such as good conductivity, catalytic, antifungal, anti-viral, antiinflammatory and antimicrobial activity (Panyala et al., 2008). They are effective in preventing bacterial infection and retarding infection in medical based products ranging from topical ointments and bandages for wound healing, to coated stents (Chen, 2007). Additional, AgNPs have biological properties, which are important for consumer products, textiles/fabrics, food technology and medical applications. Moreover, they have unique optical and physical properties, which are claimed to have great potential for medical applications such as drug delivery, diagnostic and imaging (Wijnhoven et al., 
2009).However, the improvements of novel AgNPs containing products is unceasingly required.

\subsubsection{Antimicrobial and anti-inflammatory properties}

AgNPs are effective killing agents for a wide spectrum of gram-negative and gram-positive bacteria (Burrell et al., 1999), including antibiotic-resistant strains (Percival et al., 2007). The gram-negative bacteria include genera such as Escherichia, Acinetobacter, Salmonella, Pseudomonas and Vibrio. Gram-positive bacteria include genera such as Listeria, Bacillus, Staphylococcus, Enterococcus and Streptococcus. The antibiotic resistant bacteria strains include vancomycin-resistant and methicillin-resistant Enterococcus faecium and Staphylococcus aureus.

Recently, it has been shown that AgNPs with diameter ranging between 5-32 nm increase the antimicrobial activity of different antibiotics (Shahverdi et al., 2007). Small nanoparticles with large surface area to volume ratio simply provide a more efficient means for antimicrobial activity even at a lower concentration. Triangularly shaped AgNPs display the strongest antimicrobial activity (Wijnhoven et al., 2009). AgNPs are more effective and fast acting fungicides against a wide spectrum of common fungi including Aspergillus, Candida, and Saccharomyces. In addition, these nanoparticles are effective against yeast isolated from bovine mastitis (Wijnhoven et al., 2009). AgNPs with diameters between 5-20 nm exhibit inhibition of HIV-1 virus replication (Sun et al., 2005) whereas, gold nanoparticles with average diameter 1-10 nm show a relatively low anti-HIV-1 activity (Elechiguerra et al., 2005). 
In animal models, AgNPs have the ability to alter the expression of matrix metalloproteinases (proteolytic enzymes that play crucial roles in different inflammatory and repair processes), suppress the expression of tumour nicrosis factor (TNF)- $\alpha$, interleukin (IL)-12, and IL-1b, and induce apoptosis of inflammatory cells (Bhol and Schechter, 2005). In addition, these nanoparticles modulate cytokines that are involved in wound healing (Wijnhoven et al., 2009).

\subsubsection{Synthesis of metallic nanoparticles}

Two methods or approaches have been widely applied to synthesized metallic nanoparticles namely, the top-down and the bottom-up approaches.

\subsubsection{Top-down approach}

The principle behind the top-down approach is to take a bulk piece of the material and change it into the desired nanomaterial (Figure 2). The fabrication techniques include cutting, grinding and etching, which have been developed to work on the nano-scale. Top-down techniques can produce nanomaterials with a size ranging between 10-100 nm (Kildeby et al., 2005). Nonetheless, top-down often results in nanomaterials with rough surfaces. These imperfect surface structures affect the physical properties and surface chemistry of the nanomaterials negatively because of high surface to volume ratio. This approach is however, important when highly complex structures are desired (Kildeby et al., 2005).

\subsubsection{Bottom-up approach}

The bottom-up or self-assembly approach refers to the construction of a structure atom-byatom, molecule-by-molecule or cluster-by cluster (Figure 2). A good example of the bottomup approach is colloidal dispersions, which are used to synthesize the nanoparticles. The sizes 
of the nanomaterials, which can be obtained through this approach, span the full nano-scale. The bottom-up approach is advantageous because of its better possibilities to obtain nanomaterials with less defects and more homogeneous chemical compositions. This is due to the mechanisms utilized in the synthesis of nanostructures that reduce the Gibbs free energy, so that the resulting nanomaterials are in a state closer to thermodynamic equilibrium (Kildeby et al., 2005).

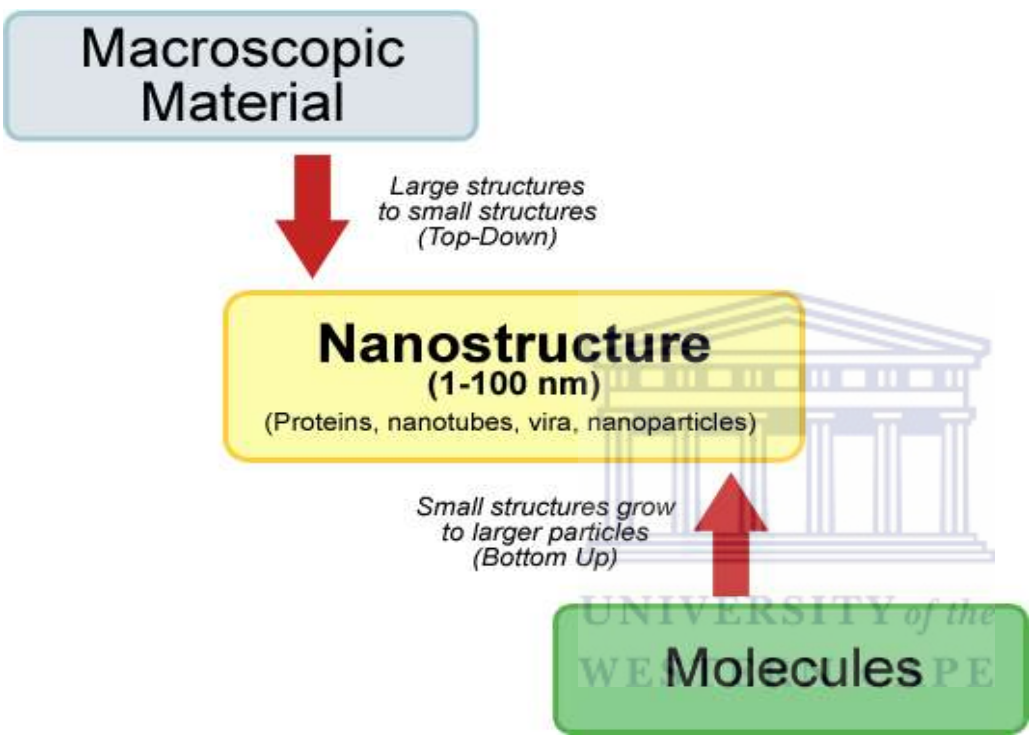

Figure 2: The top-down approach vs. the bottom-up approach for synthesis of nanoparticles (Kildeby et al., 2005)

\subsubsection{Synthesis of AgNPs}

The synthesis of AgNPs can be done using a bottom-up approach. This approach provides an opportunity to produce AgNPs in the range of 1-100 nm (Daniel and Astruc, 2004). It also gives an advantage of producing stable AgNPs compared to AgNPs produced by the topdown approach, because the nanoparticles are formed as defined crystalline structures (Balzani, et al., 2002). The stability of nanoparticles is of significance when examining and exploiting their properties. AgNPs can be synthesized by chemical reduction, photochemical reduction, metallic wire explosion, sonochemical method and polyol method (Jones et al., 
2011). The simplest and the most commonly used method for preparing metal nanoparticles is the chemical reduction of metal salts. In the following section, various synthesis methods from the literature will be reviewed.

\subsubsection{Chemical reduction}

\subsubsection{Metal salts: Hydrazine and formaldehyde}

The chemical reduction method involves the reduction of the metal salts in the presence of an appropriate capping agent, which is essential for controlling the growth of metal colloids and preventing them from agglomerating. Synthetic polymers such as polyvinylpirrolidone (PVP), polyvinylalcohol (PVA) and gelatin are often used as protecting agents. The reduction of silver nitrate with alkyl acid phosphate in the presence of gelatin can produce particle sizes of 0.1-1.0 nm. It has been shown that vinyl polymers possess better protecting characteristics over substances such as gelatin (Nersisyan et al., 2003). The reduction of pre-heated silver nitrate solution in the presence of PVP results in silver powder with a particle size of $\sim 300$ $\mathrm{nm}$. The size of these particles can be reduced to $100 \mathrm{~nm}$, if the reduction of silver nitrate is done by hydrazine in the presence of PVP. An aqueous solution of $0.01 \mathrm{M}$ silver nitrate in the presence of PVP and PVA reduced with formaldehyde permitted the formation of colloidal dispersion of silver with the particle size ranging between 7-20 $\mathrm{nm}$ (Kan-Sen and ChiangYuh, 2000). It was noted that a low concentration of initial solutions of silver with a large quantity of PVP, negativity influenced the quality of the product and efficiency of the process (Nersisyan et al., 2003).

\subsubsection{Citrate, ascorbic acid or borohydride}

Reducing agents such as citrate (Pillai and Kamat, 2004), ascorbic acid (Sondi et al., 2003) and borohydride (Ahmadi et al., 1996) are among the most widely used reductants for the 
reduction of silver nitrate in aqueous solutions. AgNPs prepared with citrate produced spherical and rod-like particles. This is because of competition of nucleation in the growth processes (Dong et al., 2009). Conversely, AgNPs prepared by borohydride produced small spherically shaped particles of less than $10 \mathrm{~nm}$ due to high reactivity of the reducing agent, which induces an explosive nucleation process. The change of reaction parameters such as molar ratio of the reductant or silver precursor, $\mathrm{pH}$, or temperature of the reactions when using citrate or borohydride, affects the nucleation and growth processes and thus the sizes of the AgNPs (Qin et al., 2010). When synthesizing gold nanoparticles by reducing $\mathrm{HAuCl}_{4}$ with citrate, variation in molar ratio of citrate/ $\mathrm{HAuCl}_{4}$ or $\mathrm{pH}$ is effective to tune the reactivity of the gold precursor (Ji et al., 2007). In addition, it is easy to mediate the growth stage and nucleation and prepare gold nanoparticles with various sizes by changing the molar ratio or $\mathrm{pH}$ of the reactions. A reasonable way to prepare AgNPs with tunable size is to choose a reductant with suitable reactivity to control the nucleation growth processes of the particles (LaMer and Dinegar, 1950).

\subsubsection{Point of zero charge}

The point of zero charge (PZC) is the most imperative surface parameter used to characterize the acid-base behaviour of solids, mainly mineral oxides in electrolytic suspensions (Vakros et al., 2002). It can be described as the $\mathrm{pH}$ value at which the metal surface charge is zero, meaning that at this $\mathrm{pH}$ the charge of the positive surface sites are equal to the charge of the negative ones (Fernández-Nieve et al., 1998). However, since this parameter has many applications, for instance in case where oxides are used as supports for preparing supported catalyst, few techniques have been established so far for its experimental determination. The widely used techniques are potentiometric titrations (PT), mass titration (MT) and the immersion techniques (IT). Potentiometric titrations measure the dependency of the 
equilibrium while mass titration determines the point of zero charge of mineral hydroxides immersed in electrolyte. The use of the immersion technique results in low accuracy $( \pm 1 \mathrm{pH}$ unit), while the mass titration technique demands quite a large amount of the solid, which may not be available. The new technique for the determination of PZC is potentiometric mass titrations technique (PMT). This technique is quite similar to the PT technique; the main difference is that in the PMT technique, the potentiometric curves are determined for three different values of the mass of the oxide immersed in the electrolyte solution, keeping constant the ionic strength of the solution (Vakros et al., 2002).

\subsubsection{Stabilizing agents}

\subsubsection{Polyvinylpyrrolidone}

Polyvinylpyrrolidone (PVP) is a linear polymer and stabilizes the nanoparticles surface via bonding with the pyrrolidone ring. In addition, PVP is water soluble, un-charged, non-toxic, and, has often been used in different medical applications (Lee Ha-Young et al., 2008). However, the PVP backbone has important hydrophobic moieties (i.e. 6 carbons per monomer unit) that are also hydrophobic, resulting in precipitation due to increase of salt concentration (Song et al., 2011). Infrared (IR) and X-ray photoelectron spectroscopic (XPS) studies have shown that oxygen and nitrogen atoms of the pyrrolidone ring can result in the PVP chain being absorbed into the surface of silver. A study by Wu et al., (2010) uncovered the existence of $\mathrm{Ag}^{+}-\mathrm{O}$ interaction, and demonstrated that the $\mathrm{Ag}^{+}-\mathrm{PVP}$ is formed through the coordination between $\mathrm{Ag}^{+}$and oxygen in the carbonyl group. This facilitates the exchange of electrons between $\mathrm{Ag}^{+}$and the adjacent $\mathrm{N}$ atom found on the pyrrolidone ring. Moreover, $\mathrm{N}$ atoms with lone pair electrons serve as an electron donor, eventually leading to the reduction of $\mathrm{Ag}^{-}$to form PVP-capped $\mathrm{Ag}$ nanoparticles (Wu et al., 2010). 


\subsubsection{Citric acid}

Citric acid is a small molecular weight carboxylic acid that is very hydrophilic and miscible in water. Additionally, citric acid is the most common organic substance in the natural environment and our daily lives (e.g., fruit juice). Citric acid keeps nanoparticles well separated with a nominal size of 10 20 nm. Therefore, developing an understanding of the mechanism as well as the effects of AgNPs capped with citrate would contribute towards evaluating the fate and impact of AgNPs in the environment matrixes (Lee et al., 2012).

\subsubsection{Photochemistry}

Photochemistry involves the use of a chemical reaction that utilizes light to initiate transformation (Hoffmann, 2008). Energy is absorbed or emitted by matter in discrete quanta called photons. The absorption of light leads to an electronic excitation from ground state to excited state. A variety of photoreactions with high selectivity, chemical yields and photon efficiencies have been developed. Due to its easy generation, control and handling, light is also considered a clean and traceless reagent. However, photochemical reactions for chemical production processes are quite rare, and most technical processes are limited to commodity chemicals (Oelgemöller and Shvydkiv, 2011).

\subsubsection{Techniques to characterize AgNPs}

Techniques such as UV-vis and TEM can be used to characterise AgNPs.

\subsubsection{Ultra-Violet-Visible spectroscopy (UV-vis)}

$\mathrm{UV}$-vis is a valuable tool for characterizing the structure of AgNPs (Guzman et al., 2012). It is widely known that Surface Plasmon Resonance (SPR), which causes shifts to longer wavelengths with increasing particle size, relate to the optical absorption spectra of metal 
nanoparticles. However, the absorbance of AgNPs depends mainly on their sizes and shapes. Generally, when the symmetry of the nanoparticles increases it leads to the decrease in the number of SPR (Guzman et al., 2012). Correlation studies of the absorption spectra of individual AgNPs with their sizes (between 40-120 nm) and shapes (triangular truncated pyramids, spheres, decahedrons and platelets) showed that spherical and roughly spherical nanoparticles, decahedral or pentagonal nanoparticles, and triangular truncated pyramids and platelets absorbed in both the blue-green and red part of the UV-Vis spectrum respectively (Mock et al., 2002).

\subsubsection{Transmission Electron Microscopy}

Transmission Electron Microscope (TEM) is a technique that enables the imaging of the crystallographic structure of a sample at an atomic scale. This technique allows the determination of nanoparticle geometry and gap size with less than $0.2 \mathrm{~nm}$ resolution. Because of its high resolution, it is a valuable tool for studying nanoscale properties of crystalline material such as semiconductors and metals. At this nanoscale, crystalline defects and individual atoms can be imaged. Since crystal structures have 3-dimensions, it is necessary to combine various views of the crystal, taken from different angles into a 3D map. TEM shows AgNPs that are spherical in shape with smooth surface morphology and it shows that the produced AgNPs are uniform in size and shape (Das et al., 2009).

\subsection{Saccharomyces cerevisiae}

S. cerevisiae is amongst the most studied species of unicellular fungi. S. cerevisiae is an excellent model organism for assessing gene regulation of more complex eukaryotic organisms (Henry and Patton, 1998). It is used to ferment sugars of rice, wheat, barley and corn to produce alcoholic beverages in the baking industry. It is also been utilized to expand 
or raise dough. S. cerevisiae is easy to cultivate, and can be genetically manipulated. It is readily available in grocery stores and inexpensive. S. cerevisiae was the first eukaryotic organism whose genome was completely sequenced, annotated and made publicly available. The availability of the complete genome sequence of this yeast made it possible to develop many novel tools for evaluating all molecular components of the cell and their interactions. Although mammalian cells share similar homologies with the yeast, some compounds assayed to be non-toxic for $S$. cerevisiae may be toxic to human cells and tissues. An example of homologous proteins in yeast and humans is the inducible multidrug resistance $A B C$ transporter pdr5p (Tutulan-Cunita et al., 2005). This transporter protein is able to export a broad range of chemically distinct compounds (Välimaa et al., 2008).

\subsubsection{The growth curve of $S$. cerevisiae}

Yeast cell division occurs by budding in which a daughter cell is initiated as an out-growth from the mother cell, followed by nuclear division, formation of cell wall and cell separation (Werner-Washburne et al., 1993). Yeast cells grow in three main phases namely; the lag phase, the exponential and the stationary phases. In the lag phase, there is no apparent growth but the cells are adapting to their new environment and synthesizing chemicals and enzymes necessary for growth (Longo et al., 1996). The exponential phase, occurs where the growth rate is at a maximum, but is kept under control by environmental factors (Werner-Washburne et al., 1993). In the stationary phase, one or more components of nutrients gets depleted, metabolism slows down and cells stop rapid division(Werner-Washburne et al., 1996; Longo et al., 1996).

Since there is an increased amount of toxic chemicals present in our daily lives, a sensitive, robust, rapid and cheap toxicity assay is needed for assessing acute toxicity in eukaryotic cells. This topic has been studied extensively and many biological toxicity tests developed. In 
addition, Bitton, (1983) has reviewed the microbial and biochemical tests for evaluating chemical toxicity especially in the aquatic environment. Since then, several models such as insect (Nascarella et al., 2003), fish (Pichardo et al., 2007), Daphnia magna (Zurita et al., 2007) and tumor cell lines (Cheung et al., 2006) have been used to evaluate the toxicity of molecules in eukaryotic cells and tissues. However, none of the above models can answer the demands for a general model, which is more accurate in predicting the effects of toxic chemicals against humans. Model organisms from various species have different sensitivities, which implies biological tests will differ more or less from one species to other and may not give general results when assessing toxicity (Codina et al., 1993). Moreover, using such biological systems to evaluate the toxicity of silver in fat-soluble (highly hydrophobic) compounds is difficult, since the presence of this compound may be underestimated (Välimaa et al., 2008).

\subsubsection{Tetrazolium salts}

The use of tetrazolium salts like WST-1, XTT and MTT, have gained grounds in cell biology for measuring the metabolic activity of various cells from mammalian to microbial origin. These salts are used as indicators of cellular proliferation and biomass for both eukaryotic and prokaryotic cells (Johnsen et al., 2002; McCluskey et al., 2005). XTT is a colourless tetrazolium salt, converted into a coloured, water soluble formazan which is derived from dehydrogenase, with succinate dehydrogenase being particularly important (Kuhn et al., 2003). Succinate dehydrogenase plays a crucial role in the supply of energy to cells. Unlike other tetrazolium salts (such as CTC and TTC), XTT forms a soluble formazan and does not need extraction.

Colorimetric methods are attractive because they possess the potential to generate clear cut end-points based on the visible colour change. Additionally, they allow for the rapid 
assessment of samples by a large number of tests for toxicity very quickly (Koban et al., 2012). The living cells reduce the tetrazole ring, which results in a coloured formazan product and can be easily assessed visually and quantified with a spectrophotometer. These assays were used to test the efficiency of antifungal drugs in killing or inhibiting the growth of Candida albicans as well as other fungi (Kuhn et al., 2003). The tetrazolium salts used in biology are aromatic derivatives of 1,2,3-tetrazole and include monotetrazoliums like 2,3bis(2-methoxy-4-nitro-5-sulfophenyl)-2H-tetrazolium-5-carboxanilide inner salt (XTT), 2(4,5-dimethyl-2-thiazolyl)- 3,5-diphenyl-2H-tetrazolium bromide (MTT) and 2-(4iodophenyl)-3-(4-nitrophenyl)-5-(2,4-disulfophenyl)-2H-tetrazolium monosodium salt (WST1) (Knight, et al., 2006). WST-1 and XTT are reduced to form a soluble coloured formazan product, capable of crossing cellular membranes.

\subsubsection{Toxic effects of AgNPs on environment}

AgNPs are generally disposed in aquatic environments during manufacturing, use or waste recycling. These disposed particles easily get absorbed by algae, which form the basis of most aquatic food. The absorbed particles can thus be easily transferred up the food chain through herbivorous crustacean, grazing fish and humans. Studies have revealed that AgNPs accumulate in the microalga Chlamydonas and transfer to the zooplanktonic crustacean, daphnia, which feed on the algae (Dash et al., 2012).

\subsubsection{Effect of silver nanoparticles on the aquatic food-chain.}

\subsubsection{Microalga (chlamydonas)}

Algae are one of the most important component of the environment and ecosystem which serve as primary producer, contributing $40 \%$ of the global productivity of biomass (Ji et al., 
2011). This component has been used as bio-fertilizer, biofuel, pollution control agent (e.g algae bioreactors), casein stabilizer as well as source of nutrition (B complex, vitamins and minerals). Only a few studies evaluated the effect of AgNPs on unicellular micro-algal growth, such as Chlamydomonas and marine diatom Thalassiosira. The reactivity of AgNPs against algal components can have an impact on algal photosynthetic enzymes. In addition, these nanoparticles have been shown to have an effect on chlorophyll content, and nuclear division leading to chromosomal aberrations and cell wall damage (Dash et al., 2012).

\subsubsection{Zooplanktonic crustacean Daphnia magna}

Daphnia magna (D. Magna), which is a freshwater filter-feeding crustacean, is considered as the most sensitive organisms used to study ecotoxicity. Since D. magna is found at the bottom of the food-chain in aquatic ecosystems, any change that can take place in its population quality or quantity can result in changes in the population of other organisms feeding on it. Although various studies have evaluated the toxicity of AgNPs in aquatic animals such as Daphnia, the distinct characteristics of nanoparticles (e.g. capping agent, preparation method, size and shape) may change their effect on living organisms (Asghari et al., 2012).

\subsubsection{Cyprinus Carpio}

The common carp Cyprinus carpio is one of the more abundant species found in the freshwater environment. Due to its large size, carp have a better capacity for resistance to pollutants compared to other laboratory fish including zebrafish and Japanese medaka. Carp species are not used to examine the effects of exposure to low-dose of pollutants. However, they are being considered as one of the most suitable models for assessing the non-fatal effects of pollutants by evaluating changes in fish physiology and histology or fluctuations in 
anti-oxidant enzyme systems (which are responsible for eliminating the oxidation stress during the early stage of the body's defensive mechanism). One impact possessed by AgNPs is the inhibition of the oxygen/carbon dioxide exchange process due to the injury of the respiration organs (gills). The study by Lee et al., (2012), has shown that the exposure of fish to AgNPs initially cause the bifurcation of the filament, and increase in mucous cells number and size, and hyperplasia of the lamella epithelium (Lee et al., 2012).

\subsubsection{Toxic effects of silver and AgNPs on health}

Silver has potential toxic effects on human health and it enters the body through several portals. Previous studies have indicated that silver ions $\left(\mathrm{Ag}^{+}\right)$cause early changes on the cell membrane permeability to potassium ion $\left(\mathrm{K}^{+}\right)$and sodium ion $\left(\mathrm{Na}^{+}\right)$at concentrations that do not limit $\mathrm{Na}^{+}, \mathrm{K}^{+}$, -ATP activity (Kone et al, 1988). Forits part, AgNPs have intensive effect on the expression and proliferation of cytokine by peripheral blood mononuclear cells (PBMCs) (Seung-hoen et al., 2006). At concentrations above $15 \mathrm{mg} / \mathrm{L}$, AgNPs have a significant cytotoxic effect on PBMCs and phyto-haemaglutinin-induced cytokine production is inhibited (Shin et al., 2007).

\subsubsection{Effects on tissues and organs}

Over-exposure to silver can cause accumulation in the liver, skin, kidney, corneas, gingival, mucous membranes, nails and the spleen (Sue et al., 2001). Silver ions have a high affinity for thiol in the liver. The accumulation of silver can have toxic effects on organs and tissues. AgNPs can bind to different organs or tissues and cause potential toxic effects like production of reactive oxygen species (ROS) and cell activation, leading to inflammation and apoptosis (Xia et al., 2006). Gopinath et al., (2008) showed that nanoparticles could easily pass through cell membranes and cause severe effects on human health. High concentrations $(>44.0 \mu \mathrm{g} / \mathrm{ml})$ 
of AgNPs are necrotic to cells, leading to fast cell membrane rupture. Furthermore, nano sized particles can easily pass through the blood-brain and blood-testes barriers due to their small size (Gopinath et al., 2008). Elemental AgNPs have been found to enter the body and be distributed throughout the body via the cardiovascular system. Further, systematic and pulmonary distribution of inhaled ultra-fine elemental AgNPs in rats were found in the lungs immediately after the end of the exposure and a significant amount in the blood system, liver, kidney, spleen, heart and brain.

\subsubsection{Effects on central nervous system}

Silver is spread heterogeneously in the central nervous system (CNS). It can enter the system through the blood-brain barrier and accumulate in the large motoneurones of the brainstem and spinal cord, and in neurons found in the cerebellar nuclei and glia. The biological halflife of silver in the central nervous system is longer than in other body organs and can ultimately cause toxic outcomes on the CNS (Panyala et al., 2008).

\subsubsection{Respiratory effects}

The respiratory system is a major organ that allows the entry of nanoparticles. Particles larger than nanoparticles are generally trapped by a microcilliary system in the respiratory tract. Ultra-fine particles like nanoparticles unfortunately, simply bypass the microcillary system and are deposited directly in the alveolar space (Chen, 2007). At the alveolar region these nanoparticles can be submersed into the surfactant lining of alveoli producing surface radicals and reactive oxygen species (ROS) which are harmful to the surfaces of alveoli. Some studies indicated that exposure of nanoparticles in lung epithelial cells and also in alveolar microphage cells induces oxidative stress. The toxic effects of nanoparticles are due to their intensive catalytic activity. Due to large surface area and oxidative properties, AgNPs can 
produce highly reactive species like ROS in the intra-alveolar spaces. Through the interactions with the surfaces of alveoli, silver can cause irritation in the respiratory tract (Panyala et al., 2008).

\subsubsection{Argyria and argyrosis}

Argyria occurs when metallic silver is deposited under skin and abdominal viscera causing it to turn ashen-grey (irreversible pigmentation) while argyrosis is the pigmentation of the eyes (Brandt and Park, 2005). These two cases are caused by placing silver-containing materials into the body or skin or by use of medicines containing silver. Argyria and argyrosis maybe localized or generalized. The localized argyria is commonly caused by the direct contact of silver and substances containing silver. Small particles can enter though sweat glands or needle punctures. However, the most affected areas are mucous membranes, eyes and hands. The symptoms of generalized argyria include pigmentation on the skin, eyes, face, $\mathrm{V}$ of the neck, bald scalp, waist, hands, nails and forearms (Brandt and Park, 2005). Light microscopy has revealed fine granules clustered together in the periadnexal basement membrane and dermal elastic fibres. Additionally in generalized argyria, the degree of slate-grey cutaneous discolouration differs from barely perceptible to pronounced silver that contains granules deposit in and around cutaneous adnexal structures. These granules were shown to consist of silver sulphide (Panyala et al., 2008).

\subsubsection{Silver nanoparticles, the disruptor of basal cell functions.}

In vitro studies have revealed that AgNPs are able to enter cells through phagocytosis or passive diffusion through cell membrane. Once the AgNPs are in the cell cytoplasm, they appear in intracellular vesicles and are able to enter organelles such as mitochondria and nuclei. The entrance of AgNPs and their toxic potential in a cell depends on their sizes. A 
study by Wei et al., (2010) showed that silver micro-particles $(2-20 \mu \mathrm{m})$ did not gain entry in mouse fibroblast cells, whereas AgNPs with the diameter of 50-100 nm were found inside the same cell. On the other hand, studies comparing different sizes of AgNPs have shown smaller particle to be more cytotoxic (Whitacre, 2013).

The treatment of rat alveolar microphages with hydrocarbon coated spherical AgNPs with the primary size of $15 \mathrm{~nm}$ increased ROS and depleted glutathione S-transferase (GST) level. However, this could result from AgNPs reacting with GST-maintenance enzyme leading to an increase in ROS levels and the accompanied depletion of GST levels producing oxidative stress.ROS are responsible for activating the cascade leading to programmed cell death (apoptosis). Apoptosis result from moderate oxidative stress while severe stress results in necrosis. Necrosis is associated with inflammation and can be characterized by swelling and lysing of cells, whereas apoptosis is an active cellular process that leads to morphological cell changes (e.g. cell shrinkage, membrane blebbing, nuclear condensation, DNA fragmentation) and to the formation of apoptotic bodies that are engulfed by phagocytic cells (Whitacre, 2013). 


\section{References 1}

1. Ahmadi, T.S., Wang, Z.L., Green, T.C., Henglein, A. and El-Sayed, M.A. Shapecontrolled synthesis of colloidal platinum nanoparticles. Science. (1996); 272: 19241925.

2. Asghari, S., Johari, S.A., Lee, J.H., Kim, Y.S., J, Y., Choi, H.J., Moon, M. and Yu, I.J. Toxicity of various silver nanoparticles compared to silver ions in Daphnia magna. Journal of Nanobiotechnology. (2012); 10:1-14.

3. Balzani, V., Credi, A and Venturi, M. The Bottom-Up approach to molecular-level devices and machines. Chemistry European Journal. (2002); 8: 5525-5532.

4. Bhol, K.C and Schechter P.J. Topical nanocrystalline silver cream suppresses inflammatory cytokines and induces apoptosis of inflammatory cells in a murine model of allergic contact dermatitis. Br Journal of Dermatology. (2005); 152:1235-1242.

5. Bitton, G. Bacterial and biochemical tests for assessing chemical toxicity in the aquatic environment: A review. CRC Critical Review and Environmental Control. (1983); 13: 51-67.

6. Brandt, D., Park, B., Hoang, M. and Jacobe, H.T. Argyria: secondary to ingestion of home made silver solution. Journal of American Academy Dermatology. (2005); 53: 105107.

7. Braydich-Stolle, L., Hussain, S., Schlager, J.J. and Hofmann, M.C. In vitro cytotoxicity of nanoparticles in mammalian germ-line stem cells. Toxicological Science. (2005); 88: $412-419$.

8. Burrell, R.E., Heggers, J.P., Davis, G.J. and Wright, J.B. Efficacy of silver-coated dressings as bacterial barriers in a rodent burn sepsis model. Wounds. (1999); 11:64-71. 
9. Chen, $\mathrm{X}$ and Schluessener H.J. Nanosilver: A nanoproduct in medical application. Toxicology Letter. (2007); 176: 1-12.

10. Cheung, R.Y., Rauth, A.M., Ronaldson, P.T., Bendayan, R. and Wu, X.Y. In vitro toxicity to breast cancer cells of microsphere-delivered mitomycin $\mathrm{C}$ and its combination with doxorubicin. Journal of Biopharmaceutical. (2006); 62: 321-331.

11. Codina, J.C., Perez-Garcia, A., Romero, P. and de Vicente, A. A. Comparison of microbial bioassays for the detection of metal toxicity. Architecturer Environmental Contamination Toxicology. (1993); 25: 250-254.

12. Cui, Y., Wei, Q., Park, H. and Lieber, C. Nanowire nanosensors for highly sensitive and selective detection of biological and chemical species. Science. (2001); 293: 1289-1292.

13. Daniel, M.C and Astruc, D. Gold nanoparticles: assembly, supramolecular chemistry, quantum-size-related properties, and applications toward biology, catalysis, and nanotechnology. Chemical Revolution. (2004); 104: 293-346.

14. Dankovich, T.A. and Gray, D.G. Bacterial paper impregnated with silver nanoparticles for point-of-use water treatment. Environmental Science and Technology. (2011); 45:1992-8.

15. Das, R., Nath, S. S., Chakdar, D., Gope, G. and Bhattacharjee R. Preparation of silver nanoparticles and their characterization. Journal of Nanotechnology. (2009); 49: 1-5.

16. Dash, A., Singh, A.P., Chaudhary, B. R. Singh, S. K and Dash, D. Effect of Silver Nanoparticles on Growth of Eukaryotic Green Algae. Nano-Microbiology Letter. (2012); 4: $158-165$.

17. Dong, X., Ji, X., Wu, H., Zhao, L., Li, J. and Yang, W. Shape control of silver nanoparticles by stepwise citrate reduction. Journal of Physical Chemistry. (2009); 113: 6573-6576. 
18. Eisler, R. A review of silver hazards to plants and animals. $4^{\text {th }}$ Int. Conf. transport, fate and effects of Silver in the environment, Madison, Wisconsin. (1996); 143-144.

19. Elechiguerra, J. L., Burt, J. L., Morones, J. R., Camacho-Bragado, A., Gao, X., Lara, H.H. and Yacaman, M. J. Interaction of silver nanoparticles with HIV-1. Journal of Nanobiotechnology. (2005); 3: 1-8

20. Fernández-Nieves, A., de las Nieves, F. J. and Richter, C. Point of zero charge for a TiO2/water interface. Progress in colloid and polymer science. (1998); 110: 21-24.

21. Gopinath, P., Gogoi, S.K., Chattopadhyay, A. and Gosh, S.S. Implications of silver nanoparticles induced cell apoptosis for in vitro gene therapy. Journal of Nanobiotechnology. (2008); 19: 1-13.

22. Gulbranson, S. H., Hud, J. A. and Hansen, R. C. Argyria following the use of dietary supplements containing colloidal silver protein. Cutis. (2000); 66: 373-376.

23. Guzman, M., Dille, J. and Godet, Stéphane. Synthesis and antibacterial activity of silver nanoparticles against gram-positive and gram-negative bacteria. Nanomedicine: Nanotechnology, Biology and Medicine. (2012); 8:37-45.

24. Henry, S. A. and Patton-Vogt, J. L. Genetic regulation of phospholipid metabolism: yeast as a model eukaryote. Progress of nucleic acid research molecular biology. (1998); 61: $133-79$.

25. Hoffmann, N. Photochemical reactions as key steps in organic synthesis. Chemistry Review. (2008); 108: 1052-1103.

26. Hogstrand, C. and Wood, C.M. The toxicity of silver to marine fish. 4th International conference. Transport, fate and effects of silver in the environment Madison, Wisconsin. (1996), pp 109-112.

27. Hunter, P. R., J. M. Colford, M. W., LeChevallier, S. and Binder, P.S. Panel on waterborne diseases. Emerging Infectious Diseases Journal. (2000); 7: 544-545. 
28. Ji, J., Long, Z. and Lin, D. Toxicity of oxides nanoparticles to the green algae Chlorella spieces. Chemical Engineering Journal. (2011); 170: 525-530.

29. Ji, X., Song, X., Li, J., Bai, Y., Yang, W. and Peng, X. Size control of gold nanocrystals in citrate reduction: the third role of citrate. Journal of American Chemistry Society. (2007); 129: 13939-13948.

30. Johnsen, A. R., Bendixen, K. and Karlson, U. Detection of microbial growth on polycyclic aromatic hydrocarbons in microtiter plates by using the respiration indicator WST-1. Applied Environmental Microbiology. (2002); 68: 2683-2689.

31. Jones, M. R., Osberg, K. D., Macfarlane, R. J., Langille, M. R and Mirkin, C. A. Templated techniques for the synthesis and assembly of plasmonic nanostructures. Chemical Revolution. (2011); 111: 3736-3827.

32. Kan-Sen, C. and Chiang-Yuh, R. Synthesis of nanosized silver particles by chemical reduction method. Materials Chemistry and Physics. (2000); 64: 241-246.

33. Kildeby, N. L., Andersen, O. Z., Roge, R.E., Petersen, T. L. and Riis, J. F. Silver nanoparticles. Institute for Physics and Nanotechnology - Aalborg University. (2005); 914.

34. Knight, S. A. B. and Dancis, A. Reduction of 2,3-bis(2-methoxy-4-nitro-5-sulfophenyl)2H-tetrazolium-5-carboxanilide inner salt (XTT) is dependent on CaFRE10ferric for Candida albicans grown in unbuffered media. Microbiology. (2006); 152:2301-2308.

35. Koban, I., Matthes, R., Hübner, N., Welk, A., Sietmann, R., Lademann, J., Kramer, A. and Kocher, T. XTT assay of ex vivo saliva biofilms to test antimicrobial influences. GMS Hospital Hygiene Interdisciplinary. (2012); 7: 1-10.

36. Kone, B. C., Kaleta, M. and Gullans, S. R. Silver ion (Ag+)-induced increases in cell membrane $\mathrm{K}+$ and $\mathrm{Na}+$ permeability in the renal proximal tubule: Reversal by thiol reagents. Journal of Member Biology. (1988); 102: 11-19. 
37. Kuhn, D. M., Balkis, M., Chandra, J., Mukherjee, P. K. and Ghannoum M. A. Uses and Limitations of the XTT Assay in studies of candida growth and metabolism. Journal of Clinical Microbiology. (2003); 41: 1-4.

38. LaMer, V. K. and Dinegar, R. H. Theory, production and mechanism of formation of monodispersed hydrosols. Journal of American Chemistry Society. (1950); 72: 48474854.

39. Lee, B., Duong, C. N., Cho, J., Lee, J., Kim, K., Seo, Y., Kim, P., Choi, K. and Yoon, J. Toxicity of citrate-capped silver nanoparticles in common carp (Cyprinus carpio). Journal of Biomedicine and Biotechnology. (2012); 12: 1-14.

40. Lee, Ha-Young., Lee, Sang-Hoon., Xu, C., Xie, J and Lee, Jin-Hyung. Synthesis and characterization of PVP-coated large core iron oxide nanoparticles as an MRI contrast agent. Nanotechnology. (2008); 19: 1-6.

41. Longo, V. D., Gralla, E.B and Valentine, J. S. Superoxide Dismutase Activity Is Essential for Stationary Phase Survival in Sacharomyces cerevisiae. The Journal of Biological Chemistry. (1996); 271: 12275-12280.

42. McCluskey, C., Quinn, J. P. and McGrath, J. W. An evaluation of three new-generation tetrazolium salts for the measurement of respiratory activity in activated sludge microorganisms. Microbiology Ecology. (2005); 49: 379-387.

43. Mock, J. J., Barbic, M., Smith, D. R., Schultz, D. A. and Schultz, S. Shape effects in plasmon resonance of individual colloidal silver nanoparticles. Journal of Chemical Physics. (2002); 116: 6755-60.

44. Nascarella, M. A., Stoffolano, J. J. G., Stanek III, E. J., Kostecki, P. T. and Calabrese, E. J. Hormesis and stage specific toxicity induced by cadmium in an insect model, the queen blowfly, Phormia regina Meig. Environmental Pollution. (2003); 124: 257-262. 
45. Nersisyan, H. H., Lee, J. H., Son, H. T., Won, C. W. and Maeng, D. Y. A new and effective chemical reduction method for preparation of nanosized silver powder and colloid dispersion. Materials Research Bulletin.(2003); 3: 8949-956.

46. Nordberg, G. and Gerhardsson, L. S. (1988). Handbook on toxicity of inorganic compounds. Marcell Dekker. New York. pp 619-624.

47. Oelgemöller M. and Shvydkiv O. Recent advances in microflow photochemistry. Molecules. (2011); 16:7522-7550.

48. Panyala, N. R., Pena-Mendez, E. M. and Havel, J. Silver or silver nanoparticles: a hazadours threat to the environment and human health? Journal of Applied Biomedicine. (2008); 6: 117-129.

49. Percival, S. L., Bowler, P. G. and Dolman. J. Antimicrobial activity of silver-containing dressings on wound microorganisms using an in vitro biofilm model. International Wound Journal. (2007); 4:186-191.

50. Pichardo, S., Jos, A., Zurita, J. L., Salguero, M., Cameán, A. M. and Repetto, G. Acute and sub-acute toxic effects produced by microcystin-YR on the fish cell lines RTG-2 and PLHC-1. Toxicology In-Vitro. (2007); 21: 1460-1467.

51. Pillai, Z. S. and Kamat, P. V. What factors control the size and shape of silver nanoparticles in the citrate ion reduction method? Journal of Physical Chemistry. (2004); 108: $945-951$.

52. Qin, Y., Ji, X., Jing, J., Liu, H., Wu, H. and Yang, W. Size control over spherical silver nanoparticles by ascorbic acid reduction. Physicochemical Engineering Aspects. (2010); 372:172-176.

53. Samuel, U. and Guggenbichler, J. P. Prevention of catheter-related infections: the potential of a new nano-silver impregnated catheter. International Journal of Antimicrobiology. (2004); 23:75-78. 
54. Savage, N and Diallo M. S. Nanomaterials and water purification: Opportunities and challenges. Journal of Nanoparticle Research. (2005); 7: 331-342.

55. Seung-heon S., Mi-kyung, Y. and Jeung-kyu K. The effects of nanosilver on the proliferation and cytokine production in peripheral blood mononuclear cells. Japanese Journal of Rhinology. (2006); 45:269.

56. Shahverdi, A. R., Fakhimi, A., Shahverdi, H. R. and Minaian S. Synthesis and effect of silver nanoparticles on the antibacterial activity of different antibiotics against Staphylococcus aureus and Escherichia coli. Nanomedicine. (2007); 3:168-171.

57. Shin, S. H., Ye, M. K., Kim, H. S. and Kang, H. S. The effects of nano-silver on the proliferation and cytokine expression by peripheral blood mononuclear cells. International Immunopharmacology. (2007); 7: 1813-1821.

58. Sondi, I., Goia, D. V. and Matijevic, E. Preparation of highly concentrated stable dispersions of monodispersed silver nanoparticles. Journal of Colloid Interface Science. (2003); 260: 75-81.

59. Song, J. E., Phenrat, T., Marinakos, S., Xiao, Y., Liu, J., Wiesner, M. R., Tilton. R. D. and Lowry, G. V. Hydrophobic interactions increase attachment of gum arabic- and PVPcoated Ag nanoparticles to hydrophobic surfaces. Environmental Science and Technology. (2011); 45: 5988-5995.

60. Sue, Y. M., Lee, J. Y., Wang, M. C., Lin, T. K., Sung, J. M. and Huang, J. J. Generalized argyria in two chronic hemodialysis patients. American Journal of Kidney Dischemistry. (2001); 37: 1048-1051.

61. Sun, R.W., Chen, R., Chung, N. P., Ho, C. M., Lin, C. L. and Che, C. M. Silver nanoparticles fabricated in Hepes buffer exhibit cytoprotective activities toward HIV-1 infected cells. Chemistry Communication (Camb). (2005); 41: 5059-5061. 
62. Teodoro, J. S., Simões, A. M., Duarte, F. V., Rolo A. P., Murdoch R. C., Hussain S.M. and Palmeira, C. M. Assessment of the toxicity of silver nanoparticles in vitro: A mitochondrial perspective. Toxicology in vitro. (2011); 25: 664-670.

63. Tiwari, D. K., Behari, J. and Sen, P. Application of nanoparticles in waste water treatment. World Applied Science Journal. (2008); 3: 417-433.

64. Tutulan-Cunita, A. C., Mikoshki, M., Mizunuma, M., Hirata, D. and Miyakawa, T. Mutational analysis of the multidrug resistance ABC transporter Pdr5p with altered drug specificity. Genes Cells. (2005); 10: 409-420.

65. Vakros, J., Kordulis, C. and Lycourghiotis, A. Potentiometric mass titrations: a quick scan for determining the point of zero charge. Chemical Communication. (2002); 22: $1980-1981$.

66. Välimaa, A. L., Kivistö, A., Virta, M. and Karp, M. Real-time monitoring of non-specific toxicity using a Saccharomyces cerevisiae. Reporter System. Sensors. (2008); 8: 64336447.

67. Werner-Washburne, M., Braun, E., Johnston, G. C. and Singer, R. A. Stationary phase in the yeast Saccharomyces cerevisiae. Microbiology Review. (1993); 57:383.

68. Werner-Washburne, M., Braun, E. L., Crawford, M. E and Vickie M. Peck. Stationary phase in Saccharomyces cerevisiae. Molecular Microbiology. (1996); 19: 1159-1166.

69. Whitacre, D. M. Reviews of Environmental Contamination and Toxicology. Springer. (2013); 223, 84-86.

70. WHO, "Guidelines for Drinking-water quality" (2008) Available [Online]: http://www.who.in/water sanitation health/dwq/fulltext.pdf (2010, 06/08).

71. Wijnhoven, S.W.P., Peijnenburg, W.J.G.M., Herberts, C. A., Hagens, W.I., Oomen, A.G. and Heugens, E. Nano-silver-a review of available data and knowledge gaps in human and environmental risk assessment. Nanotoxicology, (2009); 3: 109-138. 
72. Wu, C., Mosher, B. P., Lyons, K. and Zeng T. Reducing ability and mechanism for polyvinylpyrrolidone (PVP) in silver nanoparticles synthesis. Journal of Nanoscience Nanotechnology. (2010); 10: 2342-7.

73. Xia, T., Kovochich, M., Brant, J., Hotze, M. and Sempf, J. Comparison of the abilities of ambient and manufactured nanoparticles to induce cellular toxicity according to an oxidation stress paradigm. Nano Letters. (2006); 8: 1794-1807.

74. Zhang, Y. and Sun, J. A Study on the bio-safety for nano-silver as anti-bacterial materials. China Journal of Medical Instrument. (2007); 1: 35-38.

75. Zurita, J.L., Jos, A., del Peso, A., Salguero, M., Cameán, A.M., López-Artíguez M. and Repetto, G. Toxicological assessment of indium nitrate on aquatic organisms and investigation of the effects on the PLHC-1 fish cell line. Scientific Total Environmental. (2007); 387: 155-165. 


\section{CHAPTER 3}

\subsection{Problem statement}

AgNPs are simple and less expensive nanomaterials. They possess antimicrobial activity that could have a negative impact on the naturally occurring microbial population when released in wastewater streams. These nanoparticles are highly toxic to mammalian cells and have been shown to damage the brain, liver and stem cells. Prolonged exposure of colloidal silver or silver salts under the skin can cause diseases. AgNPs in bulk form are extremely toxic to fish, algae, some plants, crustaceans, fungi and bacteria like the nitrogen fixing heterotrophic and soil forming chemolithotrophic bacteria. In physiological media, silver is able to release ions that interact with cell components and thus induce harmful effects on the cell. The study by Benn et al, (2008) has shown that silver can leak easily into wastewater treatment services and kill aquatic organisms in lakes and streams. In terms of potential effects on aquatic ecosystems, effective techniques for water purifications need to be developed to minimize AgNPs leaching into the environment. To minimize leaching, the Swedish Environmental Protection Agency (SEPA) has protested against the application of nano-silver in washing machines as an antimicrobial because AgNPs contaminated wastewater from the machines may leach into the environment. Additionally, the United State Environmental Protection Agency (USEPA) has decided to regulate the application of nanotechnology. Farmers are concerned that the antimicrobial activity of AgNPs will affect the beneficial bacteria found in soils. Despite their growing shares on the market, risks associated with exposure to AgNPs have not been researched adequately (Wijnhoven et al., 2009). Therefore, there is a great need to investigate the toxicity of AgNPs in details. 


\title{
CHAPTER 4
}

\section{Photochemical synthesis of silver nanoparticles and their characterization}

\begin{abstract}
The photoreduction of silver ions by citrate or PVP was used in this study to synthesize silver nanoparticles. Silver nitrate was photoreduced with light from an OSRAM Vitalux lamp (300 $\mathrm{W}$ and $230 \mathrm{~V}$ ) in the presence of a stabilizing agent (PVP or citric acid), to yield AgNPs after about 10 min. The particles displayed excellent long-term stability. The effects of varying the concentration of stabilizing agent, time of exposure to light source, and $\mathrm{pH}$ were investigated. Characterization of the AgNPs was taken using UV-Vis and TEM techniques. UV-Vis results showed that the AgNPs absorbed UV-radiation between 400-500 nm and TEM images revealed the particles to be spherical and needle-like in shape. The shapes depended on synthesis conditions applied. AgNPs were therefore, successfully synthesized and characterized in this work.
\end{abstract}

\subsection{Introduction}

The synthesis of nanoparticles is an interesting field in solid-state chemistry. Due to their small sizes, nanoparticles display novel properties, which differ from the properties of the bulk material. The chemical reactivity of small metallic particles is strongly dependent on particle size. For the preparation of metal particles, protective agents have been used during the reduction of metal ions. Water-soluble polymers such as poly (vinyl alcohol), poly (Nvinylpyrrolidone), and poly (methyl vinyl ether) have been used as protective agents (Huang et al., 1996). Many methods are used to synthesize AgNPs with various morphologies including nanowires, nanoparticles, nanotubes and nanoplates. Silver ions from silver nitrate are often adopted because they show high flexibility in the formation of AgNPs. In addition, 
this route is straight forward and low-cost (Chen et al., 2011). Energy sources for silver ion precipitation from silver nitrate can be from light irradiation, or thermal heat. The basic mechanisms involved are photothermal, photochemical (lamp or laser) and solvo-thermal reductions. A laser light, due to its exceptional capability in local processing and patterning, has attracted growing interest in producing AgNPs lately (Chen et al., 2011).In this work, AgNPs were synthesized by reducing silver ions with OSRAM Vitalux lamp (300 W and 230 $\mathrm{V}$ ) in the presence of PVP or citric acid (figure 3). The synthesized AgNPs were characterized by TEM and UV-Vis techniques.

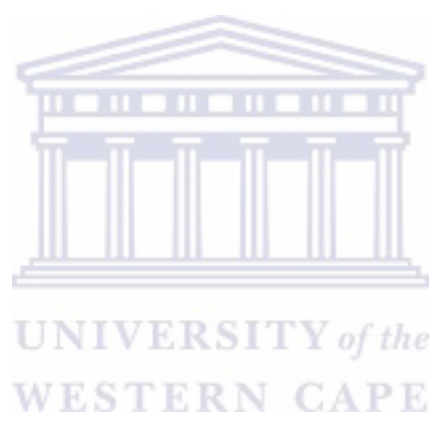




\subsection{Materials and Methods}

\subsubsection{Chemicals and equipment}

The list of chemicals with their suppliers and purity used in this study are presented in Table 2, and the equipment used during experiment are shown in Figure 4.

Table 2: List of chemicals used in this study

\begin{tabular}{lll}
\hline Chemicals & Suppliers & Purity
\end{tabular}

\begin{tabular}{llc}
\hline Silver nitrate & Kimix Chemicals & $99.8 \%$ \\
Polyvinylpyrrolidone & Sigma-Aldrich & $99.0 \%$ \\
Citric acid & Sigma-Aldrich & $100 \%$ \\
Ammonium hydroxide & Sigma-Aldrich & $25 \%$ \\
\hline
\end{tabular}

\subsubsection{Experimental procedures}

\subsubsection{Preparation of AgNPs}

For the synthesis of AgNPs, PVP or citric acid solution was prepared as shown in Table 3. The solutions were labelled $\mathrm{A} 1$ to $\mathrm{A} 7$ and $\mathrm{B} 1$ to $\mathrm{B} 7$ for $\mathrm{PVP}$ or citric acid reactions respectively. $10 \mathrm{~mL}$ of PVP or citric acid solution was poured into a $50 \mathrm{~mL}$ beaker and the $\mathrm{pH}$ parameter adjusted to 6,9 or 10.5 , using either $1 \mathrm{M} \mathrm{NH}_{4} \mathrm{NO}_{3}$ or $1 \mathrm{M}$ citric acid (Note: $\mathrm{pH}$ 9 was kept constant from (A1/B1 to $\mathrm{A} 5 / \mathrm{B} 5) . \mathrm{AgNO}_{3}$ solution $(10 \mathrm{~mL})$ was added to the PVP or citric acid solution. The mixture was then exposed to the light source (OSRAM Vitalux lamp at $300 \mathrm{~W}$ and $230 \mathrm{~V}$ ) at a height of $25 \mathrm{~cm}$ for 1,2 or $3 \mathrm{~h}$ with continuous stirring. Figure 4 shows the set-up of the experiment. Sample A3/ B3 (Table 3) will be used to compare the $\mathrm{UV}-\mathrm{Vis}$ results of time and $\mathrm{pH}$ parameters. 

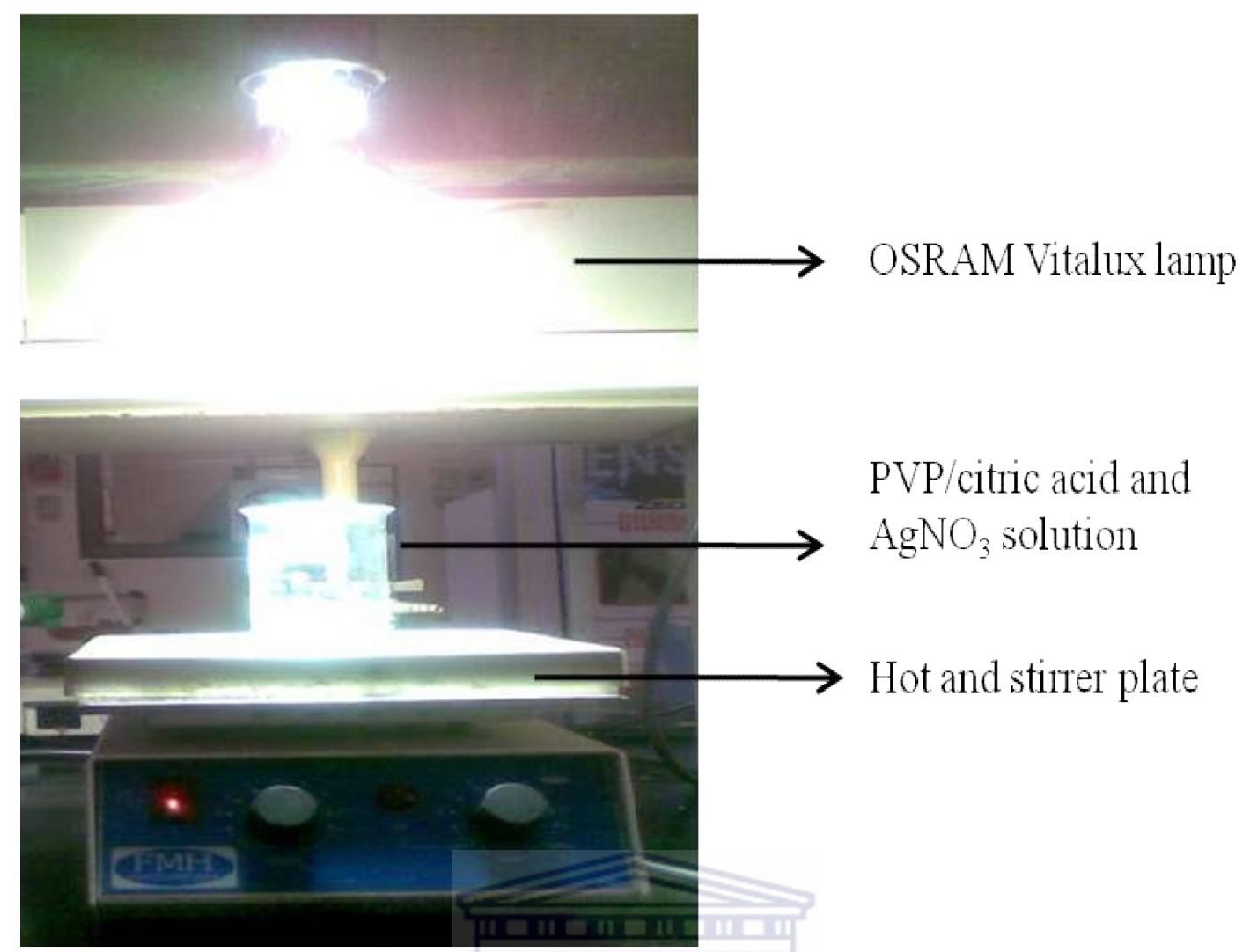

Figure 3: Experimental set-up for AgNP synthesis.

UNIVERSITY of the

WESTERN CAPE 
Table 3: Silver nanoparticles preparation under different conditions

\begin{tabular}{lllll}
\hline Sample & $\mathrm{AgNO}_{3}$ & $\mathrm{PVP} /$ citric & Time & $\mathrm{pH}$ \\
ID & & acid & \\
& $(\mathrm{mg} / \mathrm{mL})$ & & (hour) & \\
& & $(\mathrm{mg} / \mathrm{mL})$ &
\end{tabular}

\begin{tabular}{lllll}
\hline A1/B1 & 0.4 & $\mathbf{0 . 4}$ & 3 & 9 \\
A2/B2 & 0.4 & 2 & 3 & 9
\end{tabular}

$\begin{array}{lllll}\text { A3/B3 } & 0.4 & 4 & 3 & 9 \\ & & & & \\ \text { A4/B4 } & 0.4 & 4 & 1 & 9\end{array}$

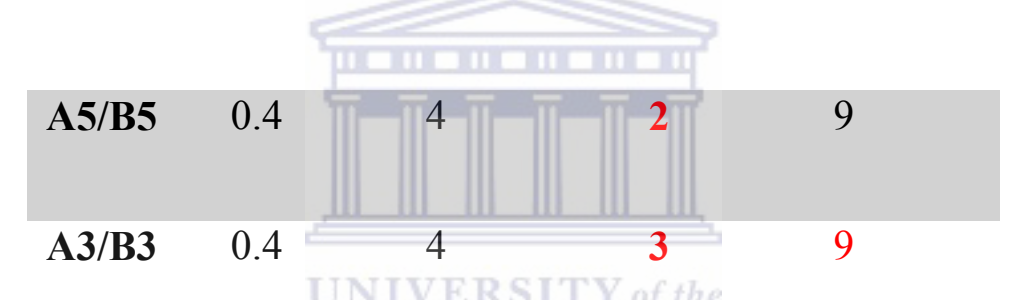

$\begin{array}{lllll}\text { A6/B6 } & 0.4 & 4 & 3 & 6 \\ \text { A3/B3 } & 0.4 & 4 & 3 & 9\end{array}$

\begin{tabular}{lllll} 
A7/B7 & 0.4 & 4 & 3 & 10.5 \\
& & & & \\
\hline
\end{tabular}

Table 3 presented the samples ID (A1 to A7 or B1 to B7) and applied synthesis conditions. The synthesized AgNPs were analysed by UV-Vis and TEM techniques. The red values represent the parameters that were varied to synthesize the nanoparticles. 


\subsubsection{Characterization of synthesized silver nanoparticles}

AgNPs were analysed by UV-Vis, using a quartz cuvette with a $1 \mathrm{~cm}$ path length. A $1.5 \mathrm{~mL}$ of de-ionised water was transferred into the cuvette and used as blank for the spectrophotometer used. The AgNPs were analysed by transferring $1.5 \mathrm{~mL}$ of the sample into a cuvette and measuring its absorbance reading at $\mathrm{OD}_{600}$ with the spectrophotometer.

For further analysis of the AgNPs samples, TEM micrographs were obtained using TEG Technai F20 micro-analyser. A $1 \mu \mathrm{L}$ aliquot of each AgNPs sample was placed on a carbon coated copper grid and kept under vacuum desiccation for a few minutes to dry. After drying, the copper grids were loaded onto a specimen holder. The TEM images of AgNPs samples were captured. Image $J$ software was used to determine the particle size from which particle size distribution was plotted.

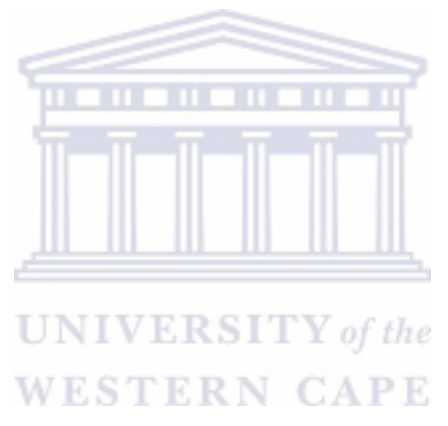




\subsection{Results and Discussion}

This section presents the results and discussion of the characterization of the synthesized AgNPs made with either PVP or citric acid as a dispersing agent. The effect of varying parameters such as concentration of dispersing agent, time of light exposure and $\mathrm{pH}$ are presented and discussed. The colour, size and shape of synthesized AgNPs are also discussed in this section.

\subsubsection{Silver nanoparticles prepared in the presence of PVP}

AgNPs were synthesized with PVP as dispersant according to the method described in section 4.2 Table 3. The following parameters were varied systematically: molar ratio of dispersant, time exposure to light source, and $\mathrm{pH}$. All samples were exposed to the light for 1 , 2 or $3 \mathrm{~h}$ and $\mathrm{pH}$ was fixed at 9 or varied between 6 to 10.5 (Table 3 ). UV-Vis was used to determine the size and the shape of nanoparticles and TEM images confirmed the size and their corresponding particle size distribution. Please note AgNPs colour change and UV-Vis figures are labelled (a) and (b) while TEM images and particle size distribution figures are labelled (c) and (d) respectively.

\subsubsection{Influence of the concentration of PVP on AgNPs formation}

Samples A1, A2 and A3 were obtained by respectively adding $0.4,2$ and $4 \mathrm{mg} / \mathrm{mL}$ of PVP to $0.4 \mathrm{mg} / \mathrm{mL}$ silver nitrate solution and exposing under photolight for $3 \mathrm{~h}$ at a $\mathrm{pH}$ of 9 . UV-Vis and TEM were used to analyse samples A1, A2 and A3. 


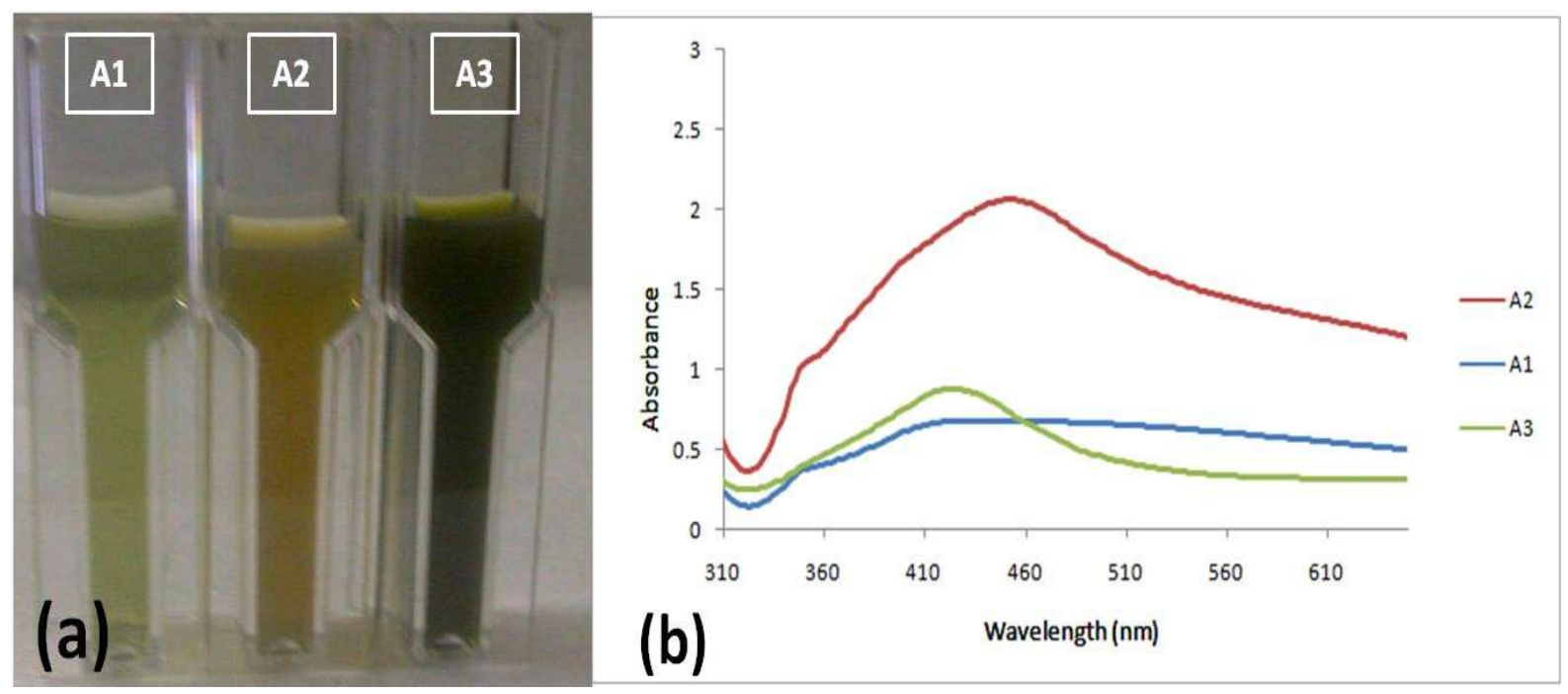

Figure 4: Synthesis of $\mathrm{AgNPs}$ using $\mathrm{AgNO}_{3}$ with varying PVP concentrations. (a) Observable colour change at 3 different PVP concentrations. (b) UV-Vis absorbance spectra of the synthesized particles. $\mathrm{A} 1, \mathrm{~A} 2$ and $\mathrm{A} 3$ represent reactions of $\mathrm{AgNO}_{3}$ with $0.4,2$ and $4 \mathrm{mg} / \mathrm{mL}$ PVP respectively.

Figure 4(a) illustrates the colour change of silver nitrate and PVP solution to three shades of green (light green for A1 (0.4 mg/mL PVP), yellowish for A2 (2 mg/mL PVP) and deep green for A3 (4 mg/mL PVP) after light exposure. The change of colour indicates the synthesis of AgNPs and the different colour indicated different particle sizes and shapes.

The formation of AgNPs was further confirmed by the UV-Vis in Figure 4(b) (a valuable tool for characterizing the structures of AgNPs). Sample A1 showed a large band with low absorbance at about $430 \mathrm{~nm}$ and a shoulder at $380 \mathrm{~nm}$, while A2 gave a band at $450 \mathrm{~nm}$ with highest absorbance compared to A1 and A3. The broadness of the peak in sample A1 indicates particles size distribution and the shift of absorption peak from $430 \mathrm{~nm}$ to $450 \mathrm{~nm}$ (longer wavelength) indicates bigger particle size (Brause et al., 2002). By increasing the concentration of the dispersing agent, the wavelength of sample A3 gave a band with high absorbance, which was blue-shifted to $420 \mathrm{~nm}$ indicating small particle sizes. The low absorbance observed in $\mathrm{A} 1$ indicated that with the molar ratio $\mathrm{AgNO}_{3}$ : PVP of 0.4:0.4, fewer AgNPs were formed. There were much more synthesized AgNPs with the molar ratio $\mathrm{AgNO}_{3}$ : 
PVP of 0.4:2 (A2) and 0.4:4 (A3). These observations suggest that the dispersing agent (PVP) should be in excess to ensure the synthesis of spherically shaped AgNPs.
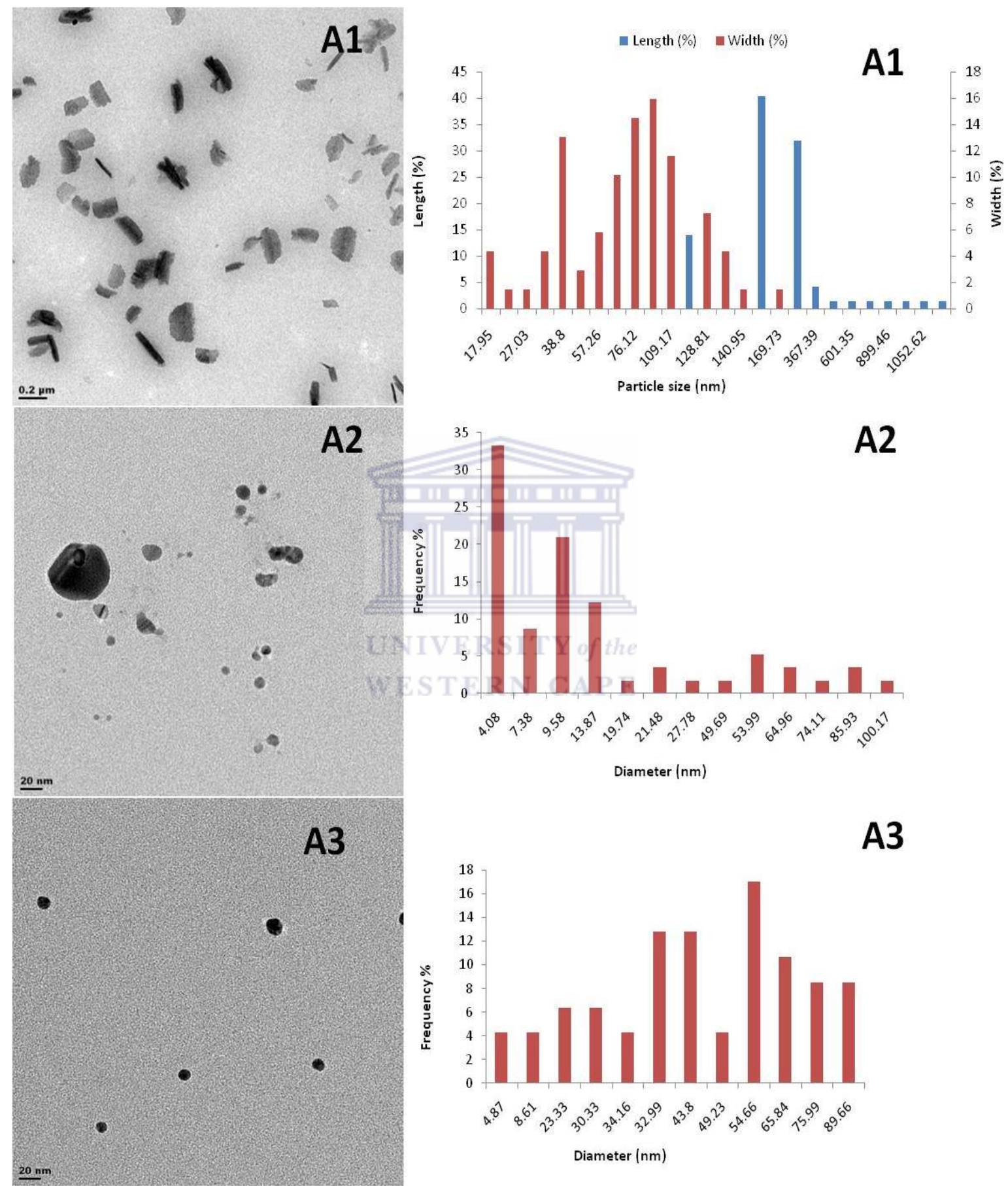

\section{(c) (d)}

Figure 5: TEM images (c) and size distribution (d) of silver nanoparticles in A1, A2 and A3. 
The size and morphology of AgNPs were investigated using TEM analysis. TEM images and their size distribution are shown in Figure 5 (c) and (d). The particle size distribution of sample A1 was presented (length and width) due to its needle-like shape in Figure 5 (d). Sample A1 gave an average length of about $150 \mathrm{~nm}$ and average width of around $90 \mathrm{~nm}$. Samples A2 and A3 have an average particle size of $4.08 \mathrm{~nm}$ and $54.66 \mathrm{~nm}$, respectively. It can be observed from TEM particle size that in sample A2 most of the nanoparticles were sized below $20 \mathrm{~nm}$ while A3 nanoparticles were sized between 30-60 nm. According to particle size distribution, the conditions applied to prepare A2 seemed to work the best compared to A1 and A3 because of its small particle size.

\subsubsection{Influence of light exposure time on the formation of silver nanoparticles.}

Samples A4, A5 and A3 were obtained by exposing silver ions and PVP solution to photolight for 1, 2 and $3 \mathrm{~h}$, respectively. A visual colour change was observed. UV-vis and TEM were used to investigate the sizes and shapes of the synthesized AgNPs.

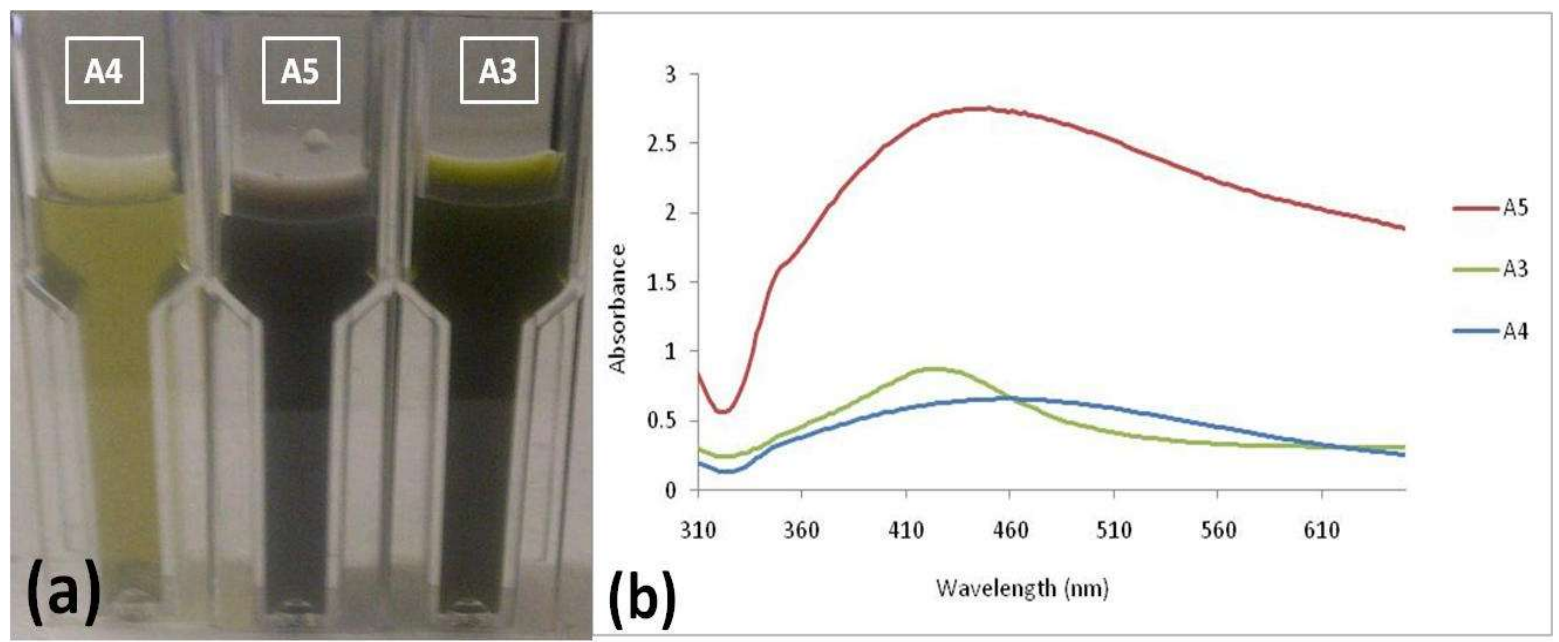

Figure 6: Colour change (a); UV-Vis absorbance (b) for AgNPs in sample A4, A5 and A3. 
In figure 6 (a), an observable colour change from the colourless solution of PVP with silver nitrate to yellow, black and deep green for samples A4, A5 and A3, respectively was obtained. The change of colour indicates the potential formation of AgNPs. The colourless solution of PVP with silver nitrate, when exposed to light for $1 \mathrm{~h}$ resulted in a yellow colour, which indicates the initiation of AgNPs formation. As the time of reaction increases to $2 \mathrm{~h}$, the colour changes from yellow to black, and from black to green with further increase in exposure time to $3 \mathrm{~h}$. The results of Figure 6 (a) correlates to those obtained by Shameli et al, (2012) using phytosynthesis method.

The UV-vis spectrum obtained in Figure 6 (b) showed that with 1 h (A4) of light exposure there was low absorbance at a wavelength of about $460 \mathrm{~nm}$. By increasing the time of light exposure to $2 \mathrm{~h}$ (A5), the absorbance band shifted to the shorter wavelength (blue shift) of $430 \mathrm{~nm}$ indicating small particles size. After increasing the time of light exposure to $3 \mathrm{~h}, \mathrm{~A} 3$ showed a well-defined surface plasmon band centered at a wavelength of about $420 \mathrm{~nm}$. Previous studies by Huang et al., (1999) using a photochemical reduction method showed that the increase of time exposure caused the absorbance peak to gradually shift towards shorter wavelengths. There is a similar trend observed with the results presented in Figure 6 (b) as it could be seen that by increasing the time of light exposure, the absorbance band blueshifted from 460 (A4) to 430 (A5) $\mathrm{nm}$ and A3 has also blue-shifted from 430 (A5) to 420 (A3) nm. 

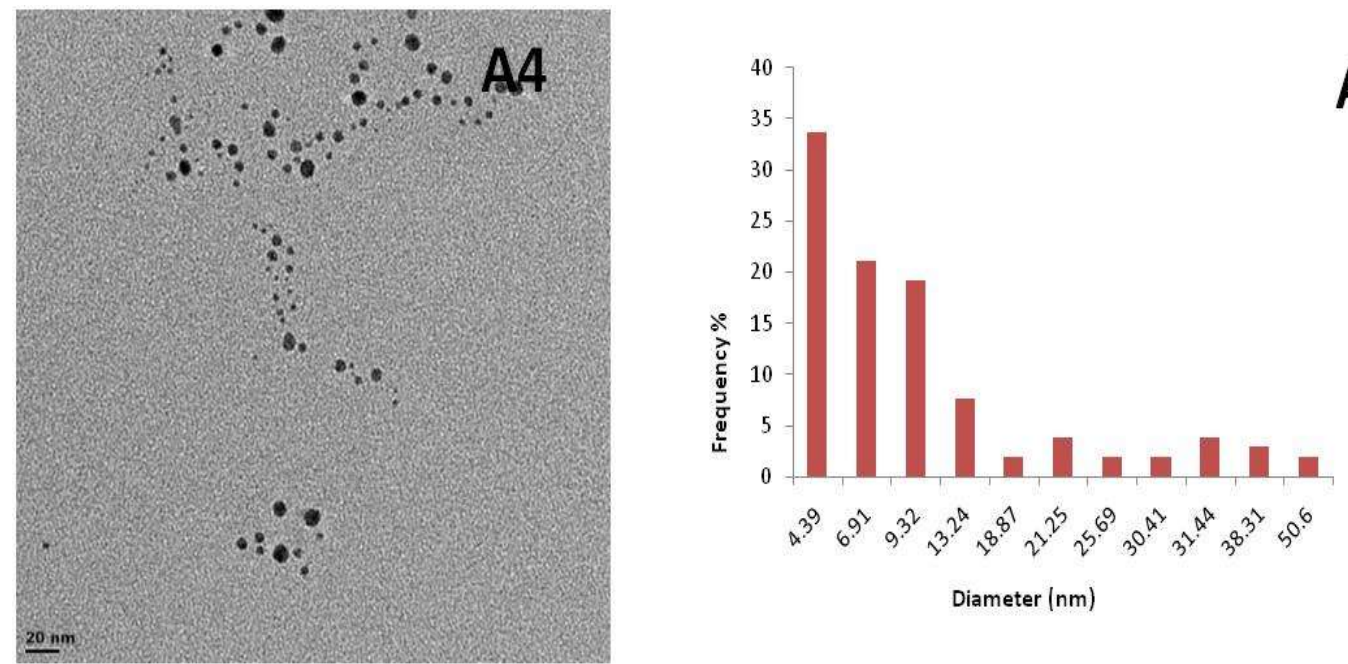

A4

A5

A5

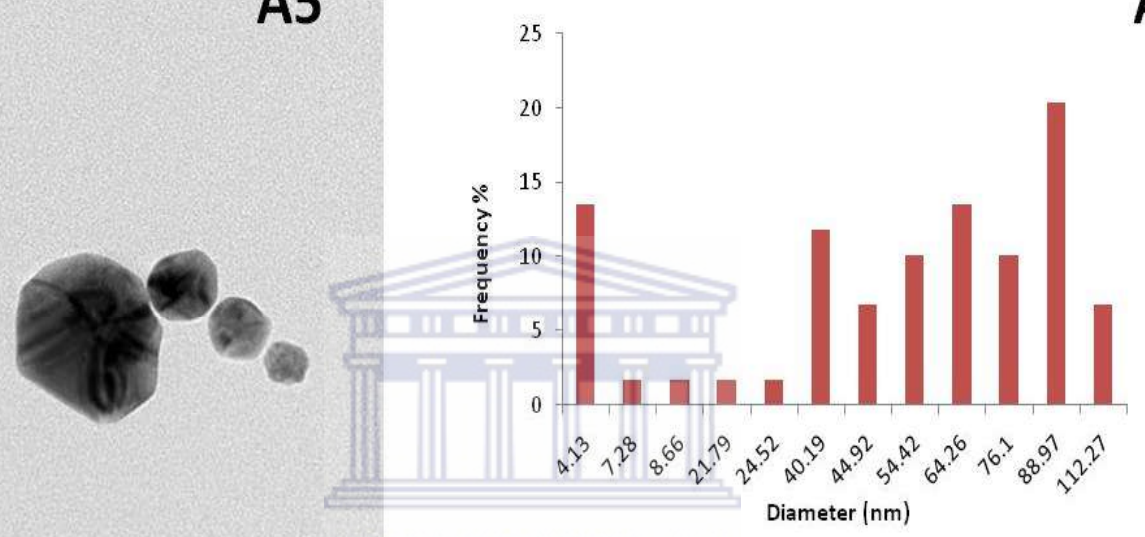

$\underline{20 \mathrm{~mm}}$
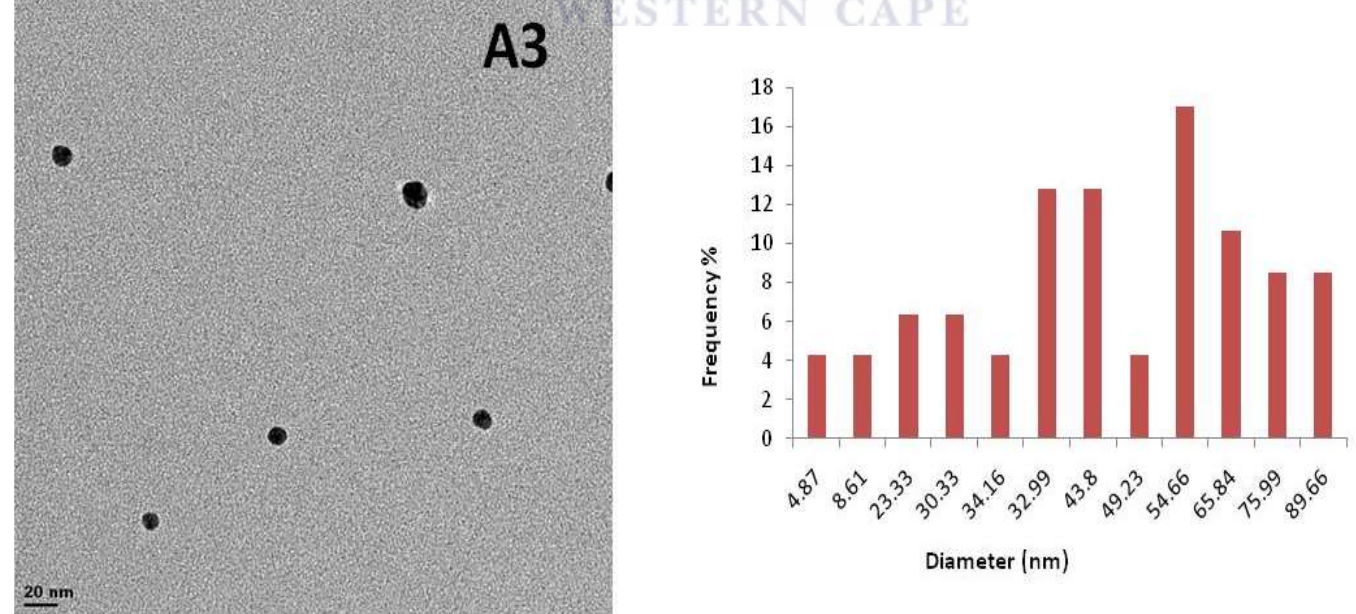

(c)

(d)

Figure 7: TEM analysis of AgNPs formed at varying photolight exposure time. (c): Images and (d) size distribution of silver nanoparticles in A4, A5 and A3. 
The TEM images and their corresponding particle size distribution of AgNPs at different time are presented in Figure 7 (c) and (d). Sample A4, A5 and A3 have mean particles size of 4.39 $\mathrm{nm}, 88.97 \mathrm{~nm}$ and $54.66 \mathrm{~nm}$, respectively. Sample A5 has shown the largest particles size decahedron shape. In comparison with TEM and particle size distribution, A4 resulted in small size and widely dispersed AgNPs while A5 and A3 produced bigger particle sizes.

\subsubsection{Influence of $\mathrm{pH}$ on the formation of silver nanoparticles}

The last parameter that was varied was $\mathrm{pH}$ to assess its influence on AgNP formation. The PVP solution was adjusted to $\mathrm{pH}$ 6, 9 and 10.5 as indicated in Table 3 for samples A6, A3 and A7. After adjusting the $\mathrm{pH}$ of PVP, silver nitrate solution was added and the solution was exposed to light for $3 \mathrm{~h}$. Different colour changes were observed when varying $\mathrm{pH}$. UV-Vis and TEM were used to characterise samples A6, A3 and A7 as shown in figure 8 and 9, respectively.

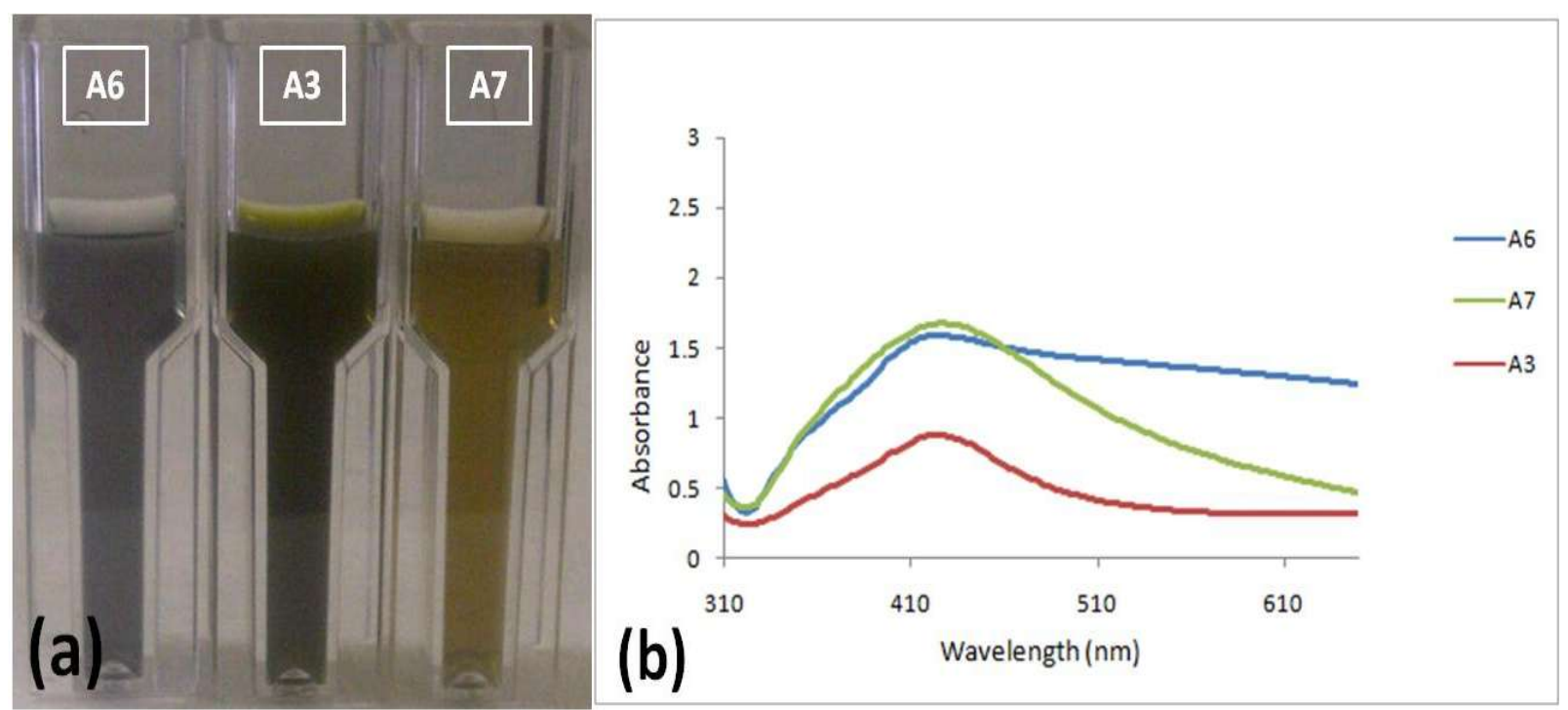

Figure 8: Synthesis of AgNPs at three different $\mathrm{pH}$ values. (a): Observable colour change at the different $\mathrm{pH}$ values 6, 9 and 10.5. (b): Corresponding UV-Vis absorbance spectra for A6, A3 and A7. 
The colour change in Figure 8 (a) was observed after exposing silver nitrate and PVP solution to light with an adjusted $\mathrm{pH}$ of 6,9 and 10.5 for A6, A3 and A7, respectively. The colourless solution of silver nitrate and PVP changed to gray, deep green and yellow (A6, A3 and A7) respectively. The change in colour is the initial indication of the formation of AgNPs.

The UV-Vis absorption spectrum was further used to confirm the formation of AgNPs as shown in Figure 8 (b). The pH adjustment to 6 (A6), which is known as circum neutral pH gave an absorbance band at $420 \mathrm{~nm}$, indicating suppression of large nanoparticle formation. The alkaline $\mathrm{pH}$ of 9 (A3) and 10.5 (A7) showed a well-defined surface plasmon band centered at around $430 \mathrm{~nm}$, which clearly indicated the synthesis of nanoparticles. The observations showed that by increasing the $\mathrm{pH}$ from neutral to alkalinity the absorbance band has red shifted from $420 \mathrm{~nm}$ to $430 \mathrm{~nm}$ indicating big particles sizes. Using photolight as a reducing agent, the low $\mathrm{pH}$ of 6 (A6) produced a shoulder band shifting to the shorter wavelength with very small nanoparticles, while high $\mathrm{pH}$ of 9 and 10.5 produced well defined AgNPs UV spectrums with larger sized nanoparticles. High $\mathrm{pH}$ level produces large number of nanoparticles with a smaller surface area (Vanaja et al., 2013; Qin et al., 2010). The $\mathrm{pH}$ is considered as one of the factors that influence the synthesis of nanoparticles, as the size and the shape of nanoparticles are dependent on the $\mathrm{pH}$ of the solution (Vanaja et al., 2013). The observations showed that sample A6 (circum neutral $\mathrm{pH}$ ) produces the best AgNPs compared to alkaline $\mathrm{pH}(\mathrm{pH} 9$ and 10.5). 


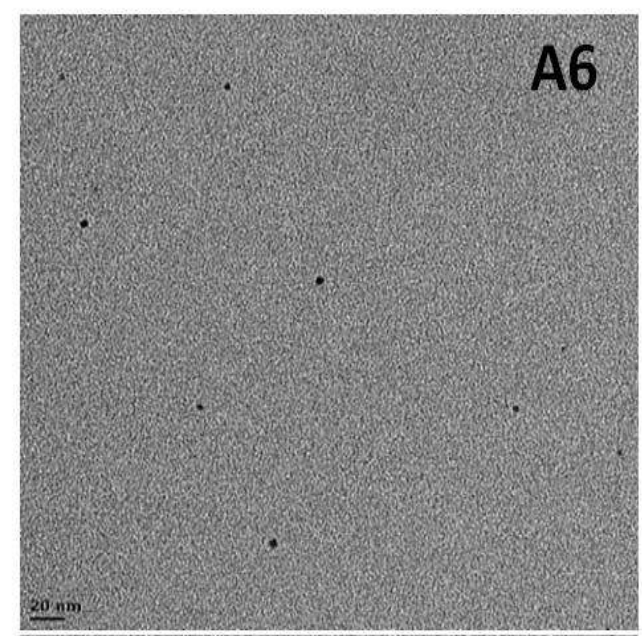

A6
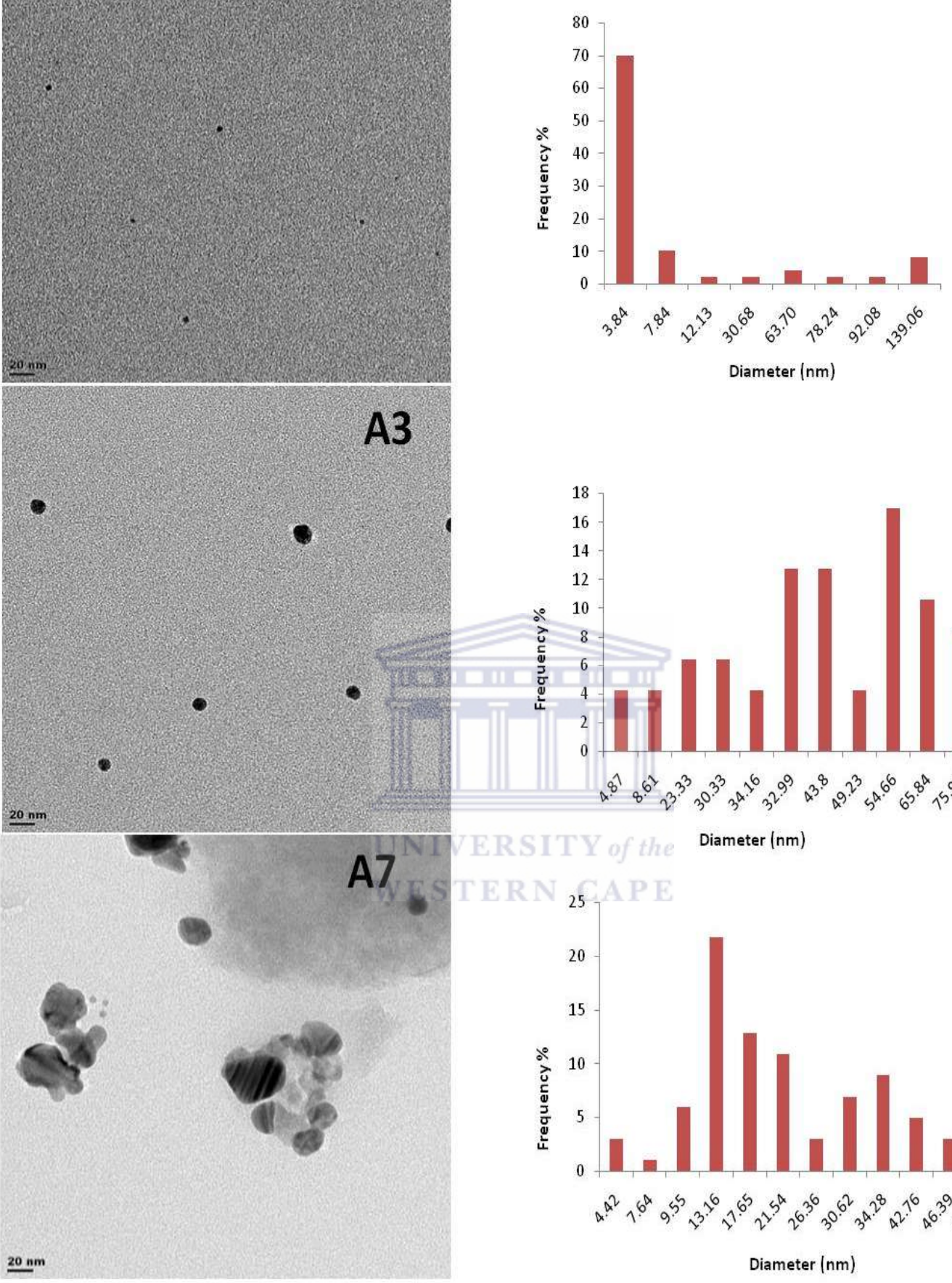

A3

(c)

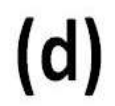

Figure 9: TEM analysis of AgNPs formed at different $\mathrm{pH}$ values. (c): TEM images and (d): size distribution of silver nanoparticles in A6, A3 and A7. 
For further characterization of the results obtained in Figure 8 (b), TEM analysis was used to determine the size and morphology of AgNPs, as shown in Figure 9 (c). TEM images showed that in the case of A6 the particles are spherical in shape and very uniform in size and smaller than $7 \mathrm{~nm}$. The particle size distributions are shown in Figure 9 (d), where sample A6 has an average particle size of $3.48 \mathrm{~nm}, \mathrm{~A} 3$ and A7 have average particles size of $54.66 \mathrm{~nm}$ and $13.16 \mathrm{~nm}$, respectively. Using the photolight synthesis, the observations in Figure 9 (d) shows that increase in $\mathrm{pH}$ increases the size of AgNPs.

\subsubsection{Silver nanoparticles prepared in the presence of citric acid.}

Silver nanoparticles were synthesized with citric acid as dispersant as described in section 4.2 Table 3. The following parameters were varied systematically: molar ratio of dispersant, exposure time to light and $\mathrm{pH}$ of citric acid. The samples were exposed to the light for 1, 2 or $3 \mathrm{~h}$ and $\mathrm{pH}$ was set at 9 and then varied to 6 and 10.5 (Table 3). UV-Vis analysis was used to determine the size and shape of nanoparticles formed and TEM was used to confirm the size and corresponding particle size distribution of the particles. Please note AgNPs colour change and UV-Vis figures are labelled (a) and (b) while TEM images and particle size distribution figures are labelled (c) and (d) respectively.

\subsubsection{Influence of citric acid concentration on AgNPs formation}

Samples B1, B2 and B3 (Figure 10 (a)), were obtained from three different concentrations of citric acid: $0.4,2$ and $4 \mathrm{mg} / \mathrm{mL}$ at the same $\mathrm{pH}$. The citric acid solutions were added separately to silver nitrate solution and exposed to photolight for $3 \mathrm{~h}$ per sample. UV-Vis and TEM analysis were used to analyse samples (Figure 10). 


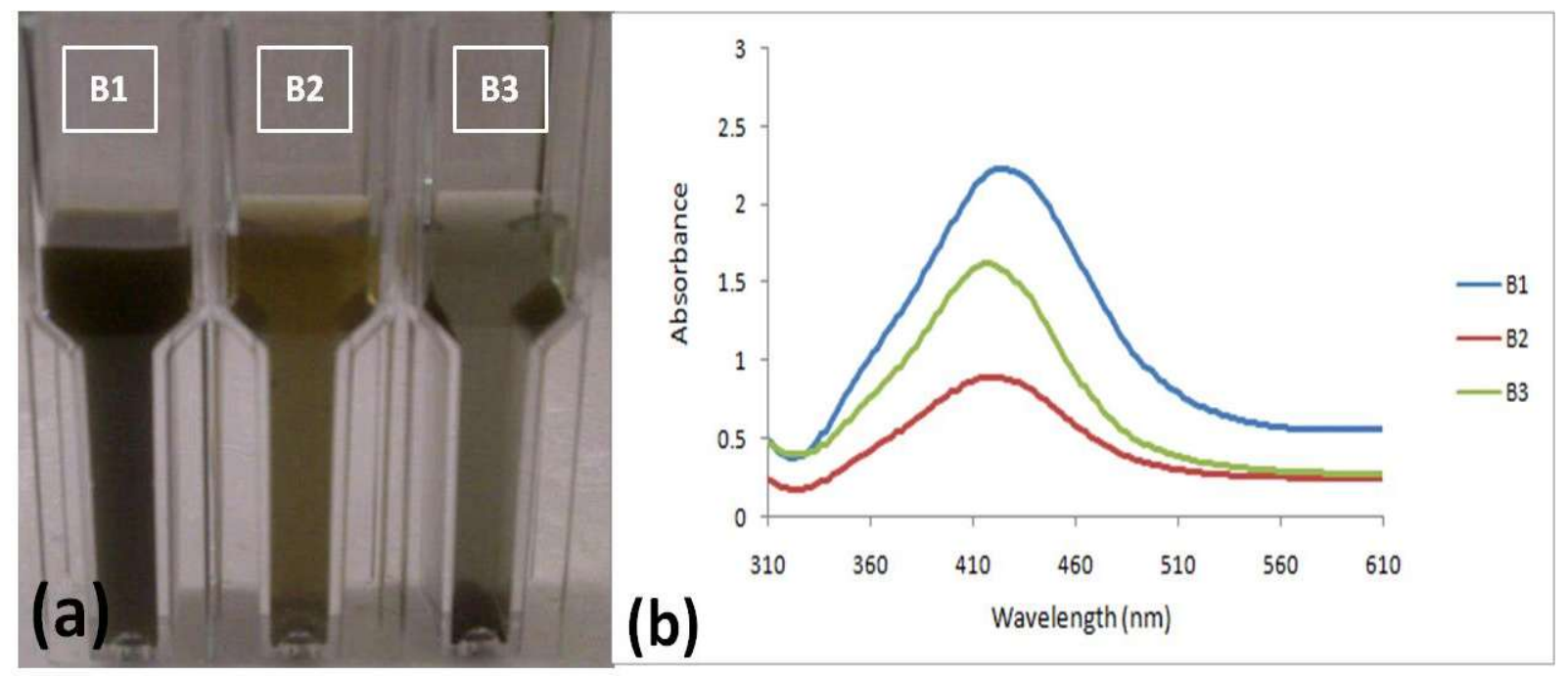

Figure 10: Colour change and UV-Vis analysis of citric acid formed AgNPs. (a): observable colour change at different citric acid concentration; B1, B2 and B3 $=0.4,2$ and $4 \mathrm{mg} / \mathrm{mL}$ citric acid respectively. (b): UV-Vis absorbance spectra of $\mathrm{B} 1, \mathrm{~B} 2$ and $\mathrm{B} 3$ represented respectively by blue, red and green curves.

Figure 10 (a), showed the colour change of the solution at different concentrations of citric acid with silver nitrate reduced by light. The colourless citric acid/silver nitrate solution gradually turns brownish (B1), light brown (B2) and gray (B3) in 0.4, 2 and $4 \mathrm{mg} / \mathrm{mL}$ citric acid respectively. The colour change indicated the initial formation of AgNPs and it was confirmed by UV-vis (Figure $10 \mathrm{~b}$ ) and TEM analysis (Figure 11).

UV-Vis both confirmed the formation of AgNPs and estimated their sizes and shapes. Sample B1 with a molar ratio of 0.4 to 0.4 of $\mathrm{AgNO}_{3}$ to citric acid, showed an absorbance band at a wavelength around $430 \mathrm{~nm}$, an absorbance of averagely large nanoparticles. As the molar ratio of citric acid to $\mathrm{AgNO}_{3}$ increased to 2:0.2 (B2), and 4:0.2 (B3), the absorbance band wavelength decreased from $430 \mathrm{~nm}$ to 420 and $412 \mathrm{~nm}$ respectively. This is a precise indication that the higher the citric acid concentration the smaller and smoother the nanoparticles become. The sizes of these particles were further verified using TEM analysis (Figure 11). 

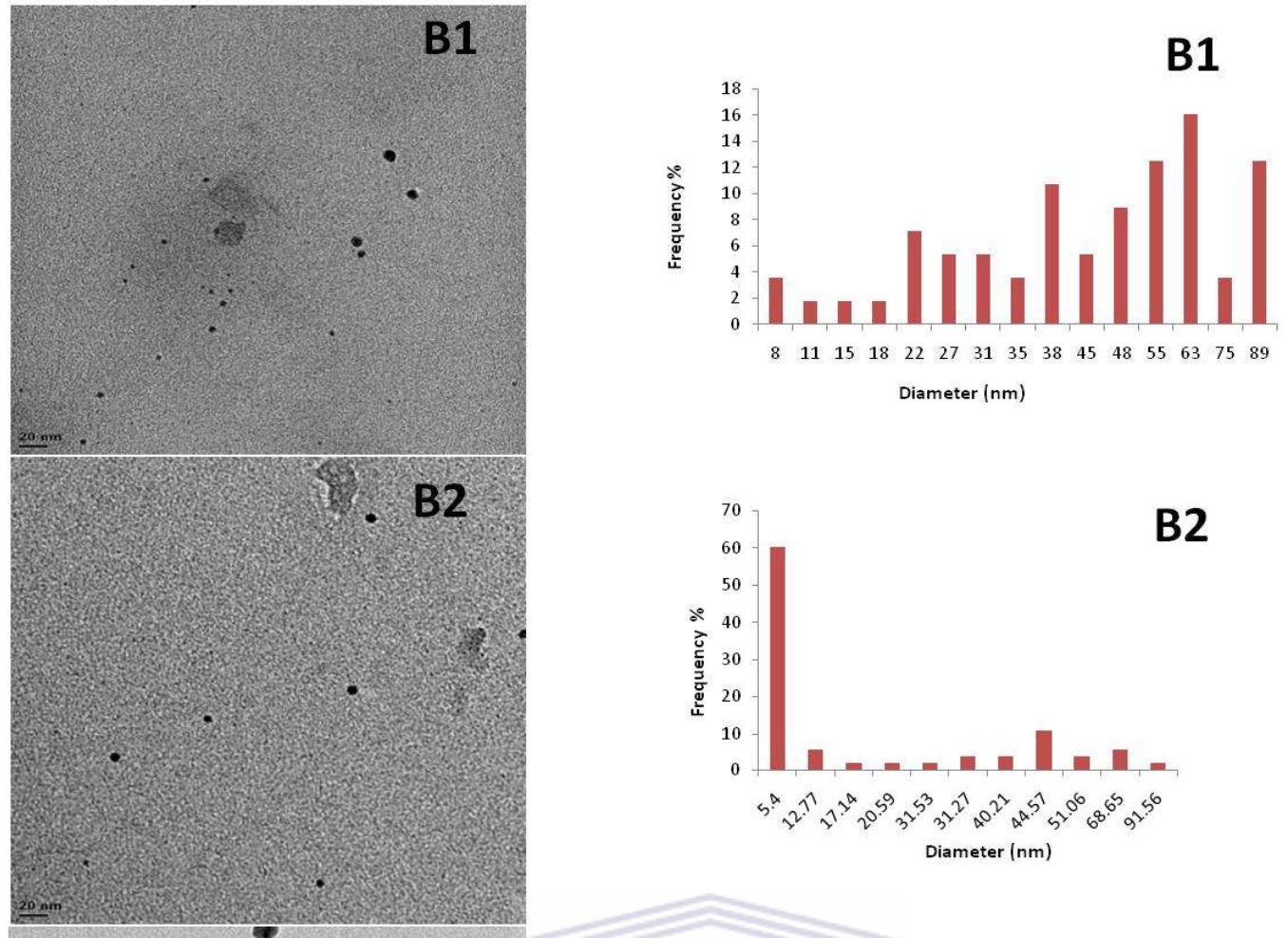

B2

B3

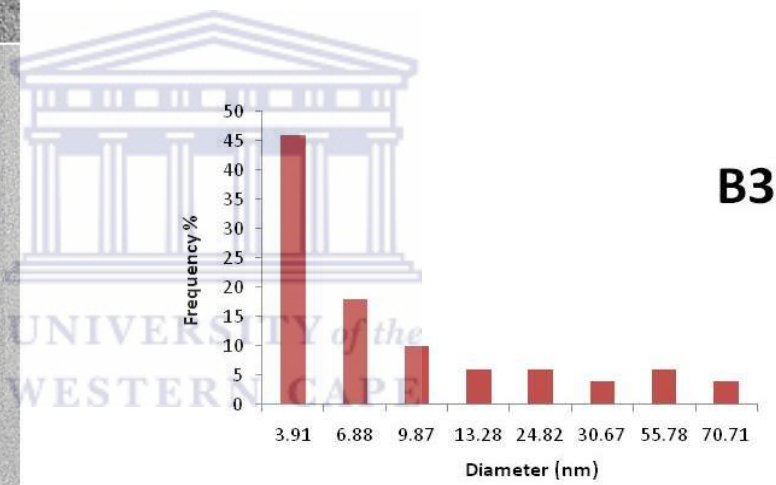

(c)

(d)

Figure 11: TEM analysis of AgNPs formed in different concentrations $(0.4,2$ and $4 \mathrm{mg} / \mathrm{mL})$ citric acid. (c): TEM images of B1, B2 and B3. (d): size distribution of silver nanoparticles in B1, B2 and B3.

TEM images in Figure 11 (c) showed that the nanoparticles were mainly of spherical shapes but of different sizes as expected for the three different concentrations of citric acid concentrations B1, B2 and B3. Though visual observation of the images (c) may suggest that B3 has the largest sizes, the size distribution analysis actually suggest as expected that B3 has the smallest particles sizes. Figure 11 (d) represents the particle size distribution of AgNPs, where sample B1 had a mean particle size of $63 \mathrm{~nm}$. Sample B2 and B3 had a mean particle 
size of 5.4 and $3.91 \mathrm{~nm}$, respectively. Though visual observation of the images in Figure 11 (c) may suggest contrarily, namely that B3 has the largest sizes, the particle size distribution results in Figure 11 (d) confirms as expected that B3 has the smallest particles. This size distribution results correspond perfectly with the UV-Vis analysis (Figure 11 (c)) as the UVVis absorbance reading for B1, B2 and B3 blue-shifted from $430 \mathrm{~nm}$ to $420 \mathrm{~nm}$ and to 412 $\mathrm{nm}$ indicating a corresponding decrease in particle sizes. These results clearly suggest that the concentration of the dispersing agent citric acid is inversely proportional to the sizes of AgNPs formed in $\mathrm{agNO}_{3} /$ citric acid reaction at constant $\mathrm{pH}$.

\subsubsection{Influence of the time of light exposure on the formation of AgNPs.}

Energy is transferred in the form of photons of light and the number of photons that interact with a sample may have a large effect on the outcome of the reaction. In this analysis, the effect of exposing light on the formation of AgNPs was verified by exposing three different samples B4, B5 and B3 to the same light source for different duration of time namely 1, 2 and 3 hours (Section 4.2). The effects of the exposure of the same concentration of silver ions and citric acid solution in B4, B5 and B3 to light for 1,2 or $3 \mathrm{~h}$, respectively were monitored first by observing the visual colour difference, and then analysing by UV-vis and TEM. A visual colour change to a light green, gray and brown solution was observed for the respective exposure times (Figure 12 (a). Figure 12 (b) shows a UV-vis spectrum of the samples and Figure 13 shows a TEM analysis of the sample. 


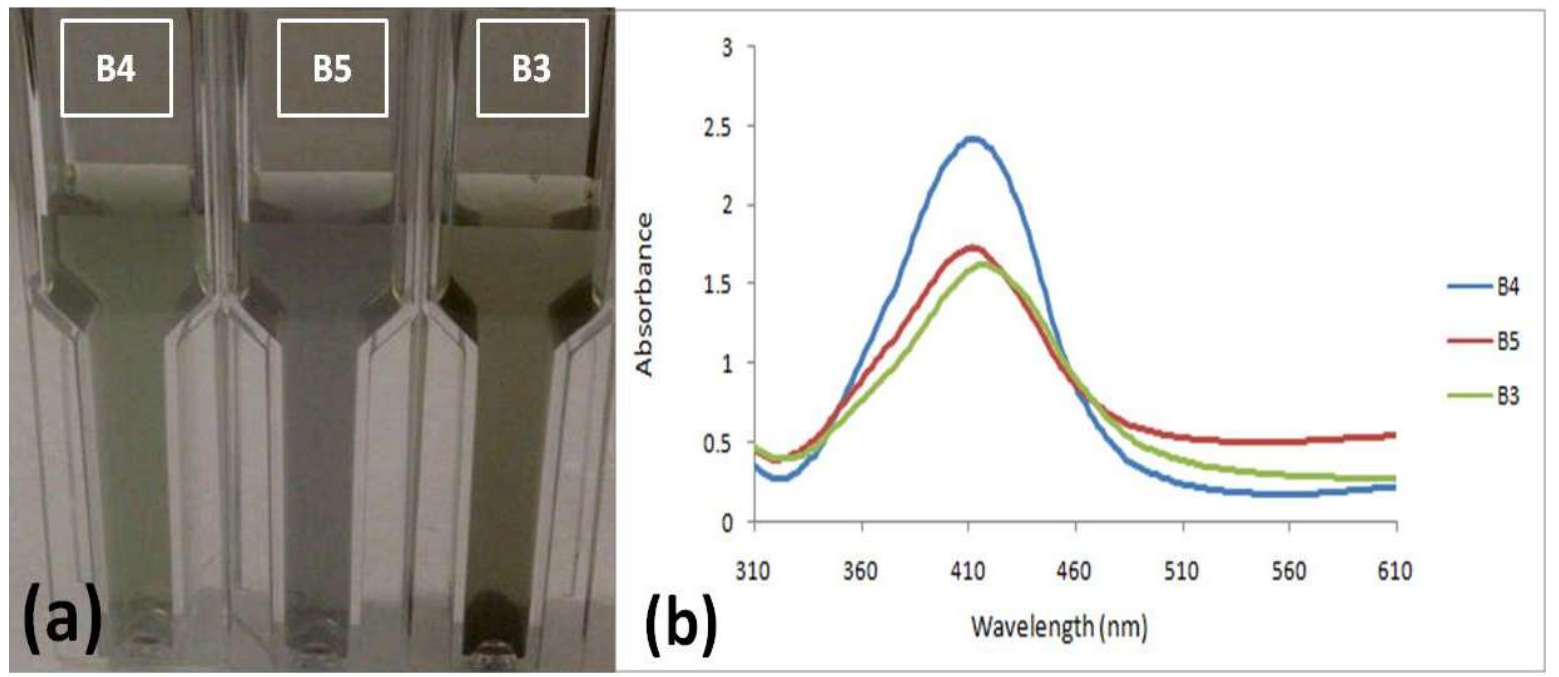

Figure 12: Visual colour observation and UV-vis analysis of the effect of light exposure time on AgNPs formation. (a): Colour change from light green (B4), to gray (B5) and brow (B3). (b): UV-vis absorbance spectrum of B4, B5 and B3.

Figure 12 (a) shows the first indication of the formation of AgNPs, a colour change from the colourless citric acid/ $\mathrm{AgNO}_{3}$ solution to light green, gray and brown solutions as a result of exposure to the same amount of light at different durations of time. The observations suggest a definite effect of amount of light on the formation of AgNPs. The spectrum shows that B4 absorbs at highest wavelength of about $420 \mathrm{~nm}$, B5 at about $412 \mathrm{~nm}$ and B3 at about $415 \mathrm{~nm}$. This changes in wavelength suggest that largest size nanoparticles were formed after $1 \mathrm{~h}$ and that further exposure to light refines the particles to smaller sizes but and over exposure to light starts causing the particles to increase in size again. Hence an optimized amount of light is needed to obtain AgNPs of a particular size. UV-vis absorbance spectrum of the samples shows that the particles absorb the greatest amount of light after exposure to light for an hour (420 nm in B4). Further exposure, however, results in a decrease in the wavelength of length of light absorbed (412 nm in B5 after $2 \mathrm{~h}$ ). Counter intuitively, further exposure rather changes the absorbance wavelength to the increasing direction from $412 \mathrm{~nm}$ in $\mathrm{B} 5$ after 2 hours to $415 \mathrm{~nm}$ after 3 hours in B3. When correlating nanoparticles absorbance wavelength to particle size distribution it shows that the largest particles are formed 
immediately at the beginning of reaction exposure to light. These particles decrease in size to optimum particle size at a particular light energy absorbance after which the particles start deforming and increasing in size again. This preposition was verified by TEM as recorded in Figure 13

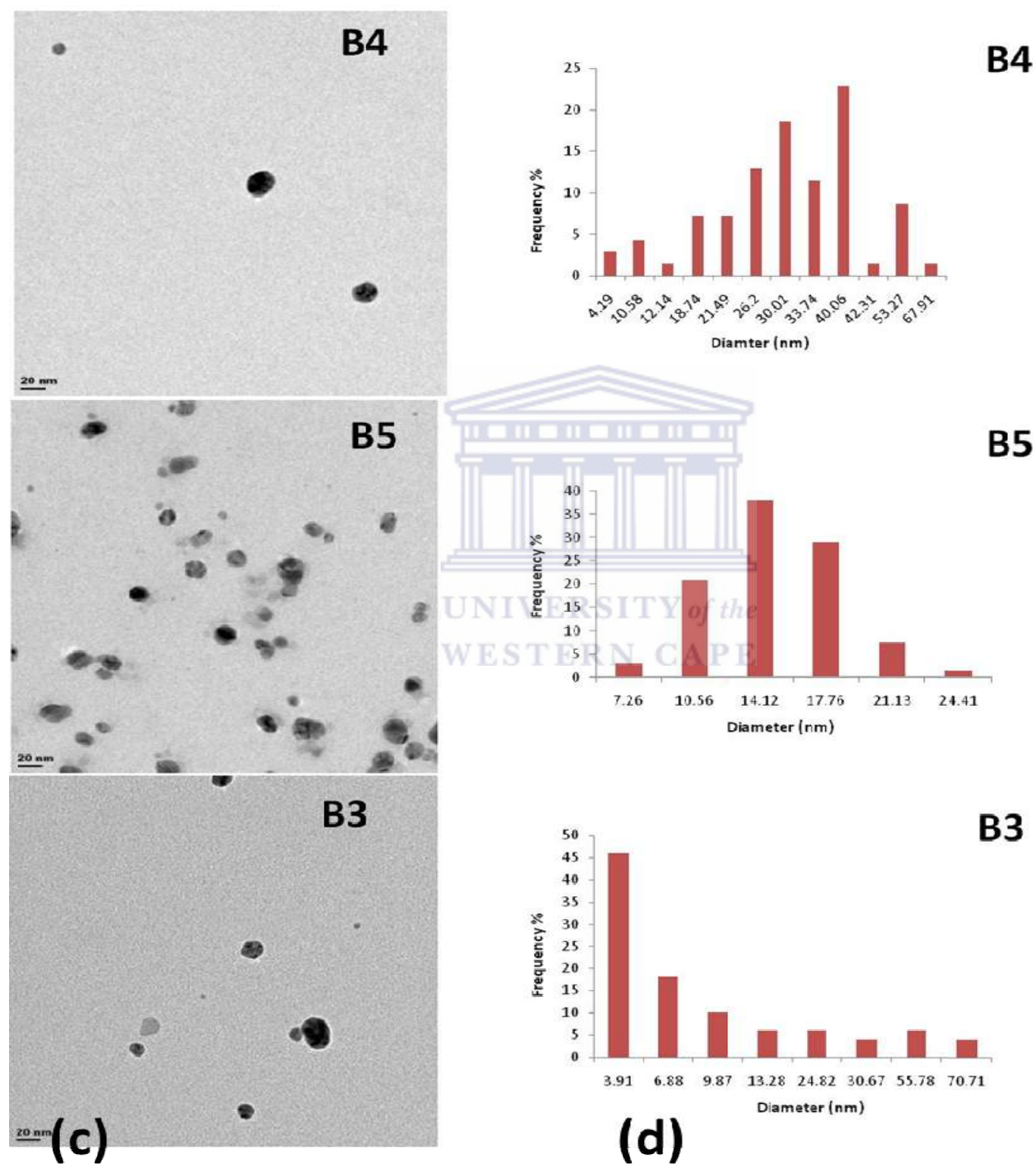

Figure 13: TEM image analysis and particle size distribution of AgNPs formed from exposure of citric acid/ $\mathrm{AgNO}_{3}$ solution to light for 1 hour (B4), 2 hour (B5) and 3 hours (B3). (c): TEM images of B4, B5 and B3 adjusted to a $20 \mathrm{~nm}$ scale; (d): size distribution of silver nanoparticles in B4, B5 and B3. 
TEM images presented in Figure 13 (c) showed spherically shaped AgNPs in all samples (B4, B5 and B3) and nanoparticles were highly distributed in B4 and B3, while B5 showed slightly agglomeration of AgNPs. The images (c) show sparsely distributed spherical particles in B4 and B5 but slightly agglomerated particles in B3. The average size distribution (d) indicates that the particle sizes decreased with an increase in exposure time. This is not directly in agreement with the UV-vis observation that there is an initial decrease of particle size with exposure time, which started to increase after a certain light exposure. The images are in line with the UV-vis observations in Figure 12 as there is a clear indication that the particle sizes at the beginning of light exposure are larger in size compared to those obtained after two hours of light exposure. It can be seen that $2 \mathrm{~h}$ exposure time was the optimum exposure time as there are a good number of particles formed and of small sizes. Agglomeration of the particles at this time suggest that too many have formed and potentially calls for the adjustment of the reactant concentrations or the solution's $\mathrm{pH}$. Further exposure at $3 \mathrm{~h}$ shows disappearance and increase in size of the particles, an observation that correlates once again with the UV-vis observation and which, therefore calls one to, always be precise with the amount of light and time of exposure when nanoparticles of a particular size and quantity are desired. Readings from the size distribution plots of Figure 13 (d) agree perfectly with the observation in the Figure 13 (c) image of B4 and B5 showing a mean particle size of $40.06 \mathrm{~nm}$ in B4 and $14.12 \mathrm{~nm}$ in B5. However, there is a sharp disagreement between the observation in B5 and B3 where UV-vis and TEM images suggest a reverse in observation i.e. an increase in particle sizes from B5 to B3. The mean particle size according to the plot in Figure 13 (c) further decreases from $14.12 \mathrm{~nm}$ to $3.91 \mathrm{~nm}$. This abnormality may be attributed to the disrupted, irregular and changing structures of the particles as experimental time proceeds. However, this observation calls for further verification. 


\subsubsection{Effect of $\mathrm{pH}$ on the formation of AgNPs}

The $\mathrm{pH}$ of a solution is the measure of the hydrogen ion or hydronium ion content of the solution. $\mathrm{pH}$ effects reactions in very different ways. In this section, the effect of $\mathrm{pH}$ on the formation of $\mathrm{AgNPs}$ using citric acid and $\mathrm{AgNO}_{3}$ was investigated. The citric acid solution was adjusted using $3 \mathrm{M} \mathrm{NaOH}$ to $\mathrm{pH}$ 6, 9 or 10.5 for samples B6, B3 and B7 (Table 3). The same concentration of citric acid was added to each of the citric acid solutions in B6, B3 and B7 and the solution exposed to light for $3 \mathrm{~h}$. Like in previous sections, colour change was monitored as indication of AgNPs formation and UV-vis and TEM analysis were used to investigate the sizes and shapes of the particles. Figures 14 and 15 document the outcomes of these investigations.

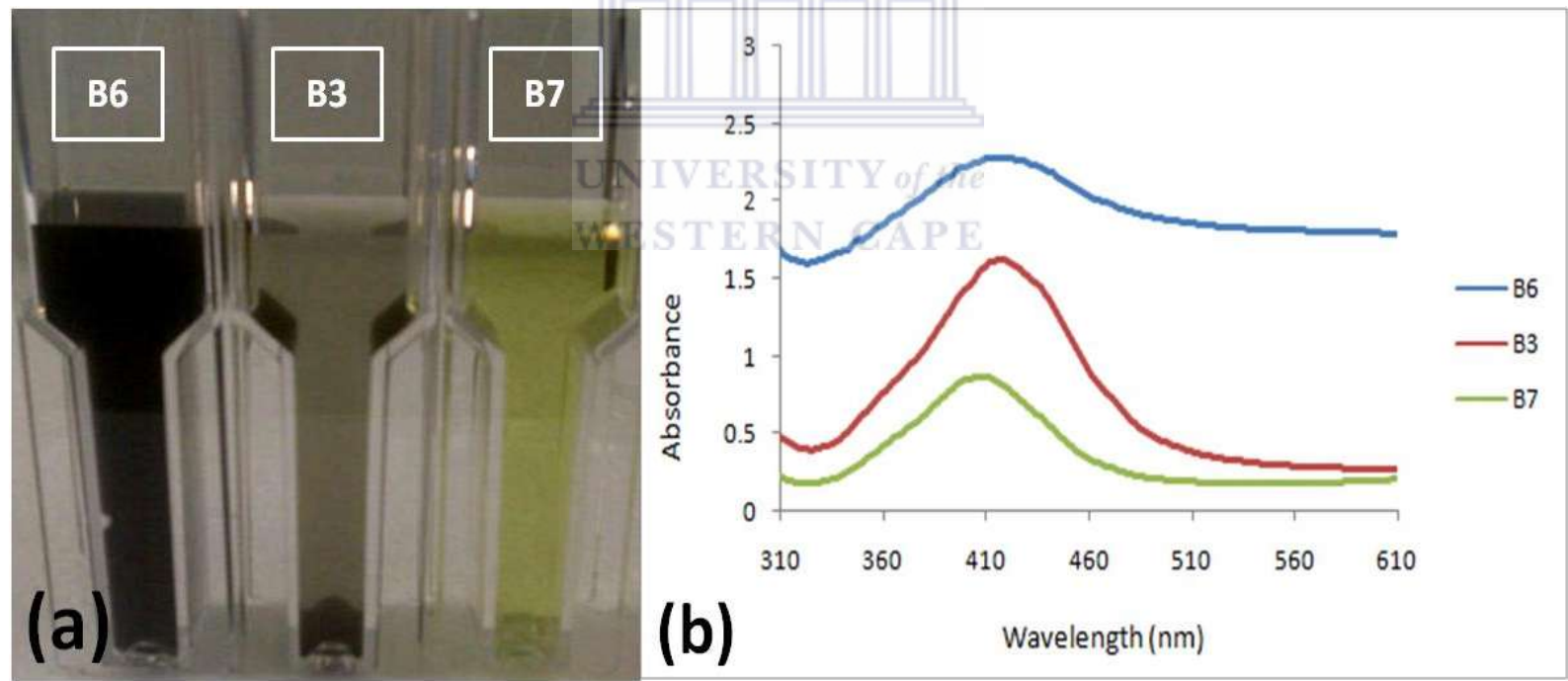

Figure 14: Verification of the formation of AgNPs at three different $\mathrm{pH}$ values. (a): Colour change observations after $3 \mathrm{~h}$ in $\mathrm{pH} 6,9$ and 10.5 in $\mathrm{B} 6, \mathrm{~B} 3$ and $\mathrm{B} 7$.

As expected, $\mathrm{pH}$ variations definitely influenced the formation of AgNPs. The colour changes, from the colourless citric acid/ $\mathrm{AgNO}_{3}$ solution to black in $\mathrm{B} 6$, gray in $\mathrm{B} 3$ and yellow in B7 after $3 \mathrm{~h}$ of exposure to light. (b) UV-Vis absorbance spectrum of the AgNPs formed in B6, B3 and B7. The spectrum shows that B7 and B3 absorb UV-radiation of the 
same wavelength, $413 \mathrm{~nm}$ although B6 also shows a broader spectrum curve. B7 for its part, showed the absorbance of a slightly shorter wavelength at $410 \mathrm{~nm}$. Hence higher $\mathrm{pH}$ values favoured formation of smaller and well defined AgNPs. It was observed that increasing the $\mathrm{pH}$ from weak acid point at $\mathrm{pH} 6$ to a strong basic point at 9 and 10.5 resulted in the fine tuning of the broad spectrum curve observed for $\mathrm{B} 6(\mathrm{pH}$ 6) to a narrower symmetrical curve for $\mathrm{B} 3$ and $\mathrm{B} 7$ at $\mathrm{pH} 9$ and 10.5 respectively. $\mathrm{B} 6$ and $\mathrm{B} 3$, though different in the broadness and symmetry of the absorbance curve, do absorb UV of the same wavelength $413 \mathrm{~nm}$, indicating that there is no significant difference between AgNPs formed at pH 6 and pH9. The narrower and more symmetrical spectral curves of B3 and B7, however indicate that more well-defined and smooth particles are formed at these higher $\mathrm{pH}$ values. Also there is a slight shift in the UV absorbance at $\mathrm{pH} 10.5$ to $410 \mathrm{~nm}$ indicating that the particles are not only well defined but are also smaller in size. The results suggest that $\mathrm{pH}$ values above 9 are good for AgNPs formation. These observations were further verified by TEM analysis as recorded in Figure 15. 


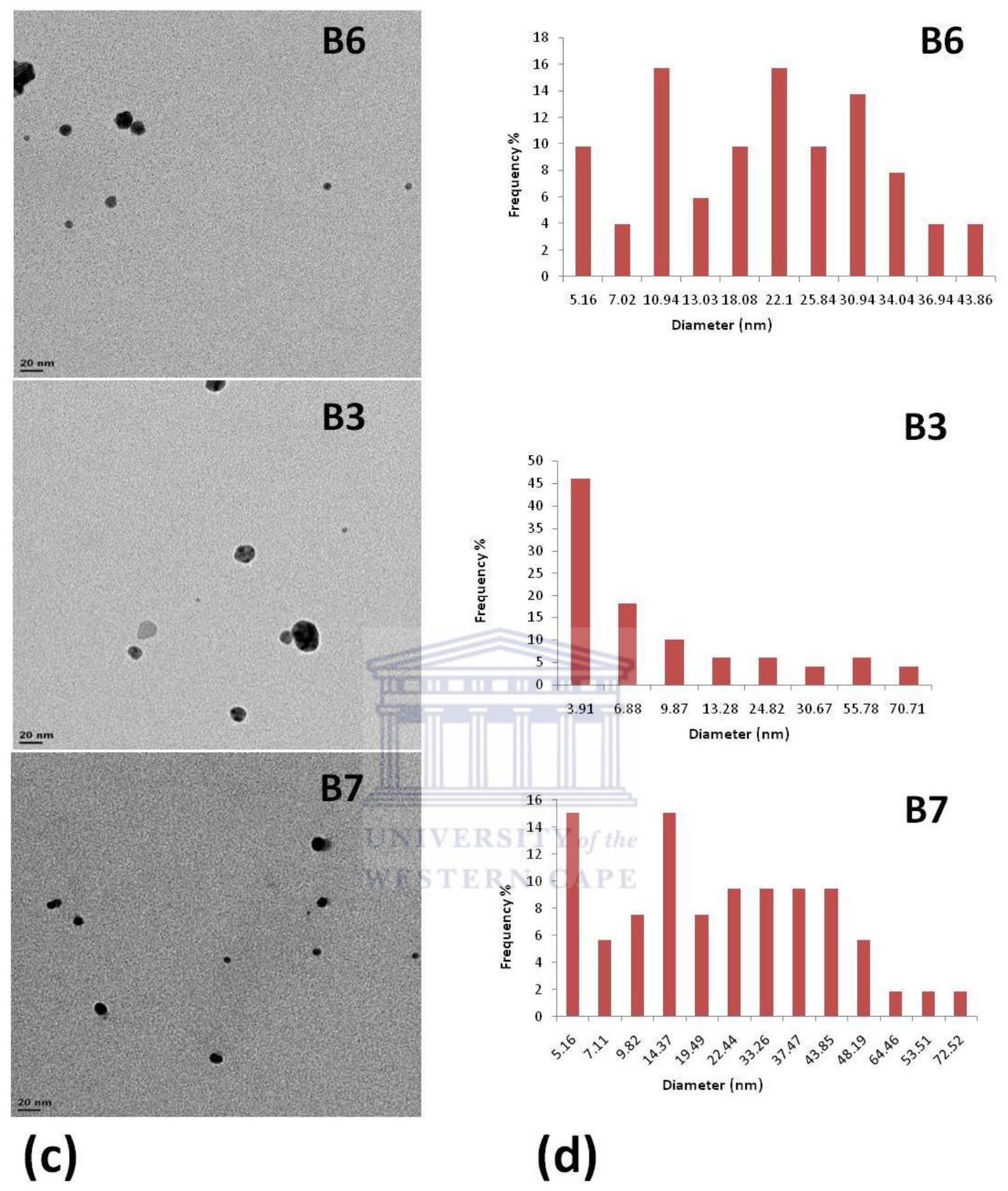

Figure 15: TEM images and size distribution of AgNPs formed at $\mathrm{pH} 6,9$ and 10.5 after $3 \mathrm{~h}$ of exposure to light. (c): TEM images of samples from B6, B3 and B7; (d) size distribution plots of the corresponding TEM images B6, B3, B7.

The TEM images presented in Figure 15 (c) show that the particles obtained are spherical in shape, with sizes in the $100 \mathrm{~nm}$ range. The TEM images and their size distribution also reveal that, the mean diameter of B6 was $10.9 \mathrm{~nm}, \mathrm{~B} 3$ was $3.91 \mathrm{~nm}$ and $\mathrm{B} 7$ was between $5.16 \mathrm{~nm}$ 
and $48.19 \mathrm{~nm}$. The results here do not agree with the suggestion of the UV-vis observations namely, B7 and B3 absorbed UV at the same wavelength hence, potentially have particles of the same size, and B7 absorbs at a lower wavelength of $410 \mathrm{~nm}$ hence, smaller size particles.

The inconsistency and non-correlation between UV-vis suggestion and TEM size distribution calls for a further investigation of the experiments and their application in preparing of nanoparticles. Nonetheless, these instruments were used to confirm the formation of AgNPs and to individually characterize them. These particles would be used in the next section of this work to investigate their toxicity on the eukaryotic unicellular yeast, $S$. cerevisiae, as a model to postulate the effect of the particles on eukaryotes cells in general.

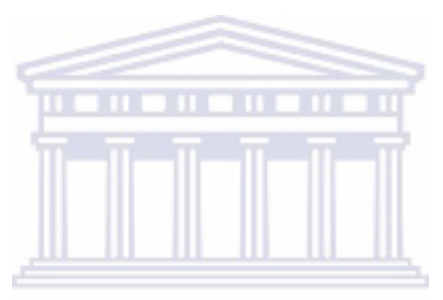

UNIVERSITY of the 


\section{References 2}

1. Huang, H. H.,Ni, X. P., Loy, G. L., Chew, C. H., Tan, K. L., Loh, F. C., Deng, J. F. and $\mathrm{Xu}, \mathrm{G}$. Q. Photochemical formation of silver nanoparticles in poly $(\mathrm{N}-$ vinylpyrrolidone). Langmuir, (1996); 12:909-912.

2. Qin, Y., Ji, X., Jing, J., Liu, H., Wu, H. and Yang W. Size control over spherical silver nanoparticles by ascorbic acid reduction. Colloids and Surfaces A: Physicochemical Engineering Aspects. (2010); 372: 172-176.

3. Shameli, K., Ahmad, M. B., Jazayeri, S. D., Shabanzadeh, P., Sangpour, P., Jahangirian, H. and Gharayebi, Y. Investigation of antibacterial properties silver nanoparticles prepared via green method. Chemistry Central Journal, (2012); 6:73.

4. Vanaja, M., Gnanajobitha, G., Paulkumar, K., Rajeshkumar, S., Malarkodi, C. and Annadurai, G. Phytosynthesis of silver nanoparticles by Cissus quadrangularis: influence of physicochemical factors. Journal of Nanostructure in Chemistry, (2013); 3:17.

5. Brause, R., Moeltgen, H. and Kleinermanns, K. Characterization of laser ablated and chemically reduced silver colloids in aqueous solution by UV/VIS spectroscopy and STM/SEM microscopy. Applied Physics B. (2002); 75:711-716. 


\title{
CHAPTER 5
}

\section{The assessment of toxicity of silver nanoparticles using Saccharomyces cerevisiae} as bio-indicator.

\begin{abstract}
Silver nanoparticles (AgNPs) are commonly used in consumer products to prevent the undesirable growth of bacteria, fungi and algae. The release of these nanoparticles from consumer and household products into waste-water streams and further into the environment may pose a threat to non-target organisms, such as natural microbes and aquatic organisms. The aim of this study was to investigate the toxicity of AgNPs using the yeast, Saccharomyces cerevisiae (S. cerevisiae). The toxicity of AgNPs was assessed using cell metabolic activity as biomarker. Metabolic activity was monitored using XTT chromogenic assays. S. cerevisiae was incubated with Malt Extract Broth (MEB) containing different concentrations of AgNPs at $37^{\circ} \mathrm{C}$ for $24 \mathrm{~h}$. After the incubation, XTT assays were performed to assess the cell proliferation. The XTT results showed that high concentration of AgNPs inhibit the growth of $S$. cerevisiae. The data obtained also showed that different methods applied in synthesizing AgNPs results to particles with different toxicity potentials. Data also showed that the degree of toxicity is dependent on the shape and size of the nanoparticles.
\end{abstract}

Keywords: AgNPs, toxicity, S. cerevisiae, XTT assay 


\subsection{Introduction}

The distinctive chemical and physical properties of silver nanoparticles make them excellent candidates for antimicrobial activity (Jun Sung, et al., 2007). In addition, their antimicrobial and anti-inflammatory properties also make them good candidates for many purposes in the medical field (Panyala et al., 2008). However, the release of silver nanoparticles into the environment is a potential thread to both aquatic and non-aquatic life (Reidy et al., 2013). Studies and reports suggest that silver nanoparticles cause adverse effects in humans (Prabhu and Poulose, 2012). It is estimated that tonnes of silver nanoparticles are released from industrial wastes and it is believed that the toxicity of silver in the environment is due to free silver ions in the aqueous phase. The effect of free silver ions on human and animals, when ingested include permanent bluish-gray colouration of the eyes or the skin (Panyala et al., 2008). Exposure to soluble silver nanoparticles may lead to kidney and liver damage, and to changes in the morphologies of blood cells.

Hassain et al., (2005) assessed the in vitro toxicity of several nanoparticles, including silver nanoparticles (15 and $100 \mathrm{~nm}$ ) on a rat liver derived cell line (BRL 3A).After $24 \mathrm{~h}$ of exposure, the mitochondrial function and membrane integrity (measured as Lactose Dehydrogenase (LDH) leakage) were significantly decreased. The LDH leakage was a result of the dose of AgNPs and was more severe for $100 \mathrm{~nm}$ than $15 \mathrm{~nm}$ particles. Evaluation with visual microscopy indicated that not all nanoparticles accumulated in the cell, some remained associated with membranes. All tested nanoparticles $\left(\mathrm{Fe}_{3} \mathrm{O}_{4}, \mathrm{Al}, \mathrm{MoO}_{3}\right.$, and $\left.\mathrm{MnO}_{2}\right)$ appeared to be less toxic than AgNPs. The observed cytotoxicity was due to oxidative stress, as indicated by the detection of intracellular glutathione (GSH) depletion, reduced potential of mitochondrial membrane and increased ROS levels (Hussain et al., 2005). Similar concentration-dependent cytotoxicity was observed when the same AgNPs were introduced on a mouse cell line, with spermatogonial stem cell characteristics under study (Braydich- 
Stolle et al., 2005). In another study, AgNPs $(\sim 30 \mathrm{~nm})$ were again classified amongst the most cytotoxic nanoparticles compared to $\mathrm{TiO}_{2}, \mathrm{Fe}_{2} \mathrm{O}_{3}, \mathrm{Al}_{2} \mathrm{O}_{3}, \mathrm{ZrO}_{2}$ and $\mathrm{Si}_{3} \mathrm{~N}_{4}$. These particles were tested on marine alveolar macrophage cell line, human alveolar macrophage cell line and epithelial lung cell line (Soto et al., 2005, 2007). Silver nanoparticles aggregates are said to be more toxic than asbestos used for house roofing (Hussain et al., 2005). By using human alveolar epithelia cell line (A549), metallic nanoparticles ( $\mathrm{Ag}, \mathrm{TiO}_{2}, \mathrm{Ni}, \mathrm{Zn}$ and Al) were shown to induce variable levels of cellular toxicity in a dose dependent manner. In addition, neuroendocrine cells were found to be sensitive to the cytotoxic activity of silver nanoparticles (15 nm) (Hussain et al., 2005). Table 4 summarises the impact of AgNPs on various cell lines (Reidy et al., 2013).

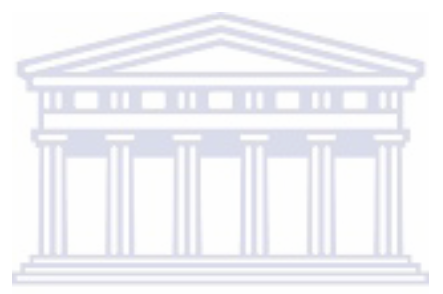


Table 4: Silver nanoparticles used in in vitro biological experiments and their impacts (Reidy et al., 2013).

\begin{tabular}{|c|c|c|c|c|c|c|}
\hline Study & Shape & Size $(\mathrm{nm})$ & Coating & IC50 & Organism & Main outcomes \\
\hline $\begin{array}{l}\text { Arora etal ., } \\
2009\end{array}$ & spherical & $7-20$ & Not stated & $\begin{array}{l}61 \mu \mathrm{\mu g} / \mathrm{mL} \\
\text { (fibroblasts) } \\
\text { and } \\
449 \mu \mathrm{\mu g} / \mathrm{mL} \\
\text { (livercel I) }\end{array}$ & $\begin{array}{l}\text { primary } \\
\text { fibroblasts } \\
\text { and primary liver } \\
\text { cells from Swiss } \\
\text { albinomice }\end{array}$ & $\begin{array}{l}\text { Silver nanoparticles present in mitochondria and cytoplasm } \\
\text { Silver nanoparticles trigger cellular antioxidant mechanism }\end{array}$ \\
\hline $\begin{array}{l}\text { Braydich Stolle } \\
\text { etal .,2010 }\end{array}$ & spherical & $\begin{array}{l}10,15,25-30 \\
80 \mathrm{~nm}\end{array}$ & $\begin{array}{l}\text { Hydrocarbon, } \\
\text { polysac charide }\end{array}$ & Not provided & $\begin{array}{l}\begin{array}{l}\text { mouse } \\
\text { spermatogonial } \\
\text { stem cells }\end{array} \\
\end{array}$ & $\begin{array}{l}\text { Size and coating dependent decline in cells proliferation at } \\
\text { concentrations } \\
=10 \mathrm{\mu g} / \mathrm{mL} \text { (via disruption of GDNF/Fyn kinase signalling) } \\
\text { ROS production and/or apoptosis did not seem to play a major role } \\
\text { Particle coating was degraded upon interaction with the intracellular } \\
\text { Small-sized nanoparticles }(10 \quad-25 \mathrm{~nm} \text { ) are more likely to promote } \\
\text { apoptosis or the production of ROS }\end{array}$ \\
\hline $\begin{array}{l}\text { Trickler etal ., } \\
2010\end{array}$ & Spherical & $\begin{array}{l}28.3 \pm 9.6 \\
47.5 \pm 5.6 \\
102.2 \pm 32.8\end{array}$ & PVP & $\begin{array}{l}\text { Not assessed } \\
\text { (above } \\
\text { concentrations } \\
\text { used) }\end{array}$ & $\begin{array}{l}\text { primaryfat brain } \\
\text { microvessel } \\
\text { endothelial cells SITY of the } \\
\text { (rBMEC) T E RN CA }\end{array}$ & $\begin{array}{l}\text { Cytotoxic - size-dependent } \\
\text { Pro-inflammatoryresponses (IL } \quad-1 \beta \text {, TNF } \alpha \text { and PGE2 release) } \quad \text { - size and } \\
\text { Blood -brain barrier permeability } \quad \text { - size-dependent increase, probably } \\
\text { Correlated withincreased immunotoxicity. }\end{array}$ \\
\hline $\begin{array}{l}\text { Bouwmeester } \\
\text { et al ., } 2011\end{array}$ & spherical & $\begin{array}{l}20 \pm 2,34 \pm 3, \quad 61 \\
\pm 5,113 \pm 8\end{array}$ & Not stated & $\begin{array}{l}\text { Not provided, } \\
\text { but below } \\
\text { concentrations } \\
\text { studied } \\
(5 \mu \mathrm{g} / \mathrm{mL})\end{array}$ & $\begin{array}{l}\text { Caco }-2 \text { and } \mathrm{M}- \\
\text { cells } \\
\text { co -culture }\end{array}$ & $\begin{array}{l}6 \%-17 \% \text { of the silver nanoparticles were dissolved to ions } \\
\text { The amount of silver ions that passed the Caco - } 2 \text { cell barrier was eq ual } \\
\text { for the silver ion and nanoparticle exposures } \\
\text { Silver nanoparticles caused changes in gene expression in a range of } \\
\text { stress responses including oxidative stress, endoplasmatic stress } \\
\text { response, and apoptosis } \\
\text { Observed effects of the silver nanoparti cles are likely exerted by the } \\
\text { silver ions that are released from the nanoparticles }\end{array}$ \\
\hline $\begin{array}{l}\text { Foldbjerg } \\
\text { et al .2011 }\end{array}$ & Not stated & $\begin{array}{l}60-70 \text { (depending } \\
\text { on method) } \\
149 \pm 37 \text { in } \\
\text { medium }\end{array}$ & $\begin{array}{l}\text { Qtrate, PVP, } \\
\text { gum arabic }\end{array}$ & " $5 \mathrm{\mu g} / \mathrm{mL}$ & $\begin{array}{l}\bullet \\
\dot{1}\end{array}$ & $\begin{array}{l}\text { Strong correlation between the levels of ROS and mitochondrial damage } \\
\text { and } \\
\text { Earlyapoptosis } \\
\text { DNA damage induced by ROS }\end{array}$ \\
\hline
\end{tabular}


Colorimetric assays for cellular viability have been found to be suitable tools in the study of eukaryotic cell activity. A mainstay of such techniques is the use of tetrazolium salts, which have evolved since the description of the 3-(4, 5-dimethylthiazol-2-yl)-2, 5diphenyltetrazolium bromide (MTT) assay (Kuhn et al., 2003; Mosmann, 1983). The synthesis of 2,3-bis(2-methoxy-4-nitro-5-sulfophenyl)-5-[(phenylamino)carbonyl]-2H-tetrazolium hydroxide (XTT) has proved to be useful, since the water solubility of the formazan product enabled the simplification of assay performance. The MTT and XTT methods have been employed as assays for yeast viability due to their easy utilization (Kuhn et al., 2003). The aim of this study was to evaluate the effects of various AgNPs on cell viability of $S$. cerevisiae using the XTT assay.

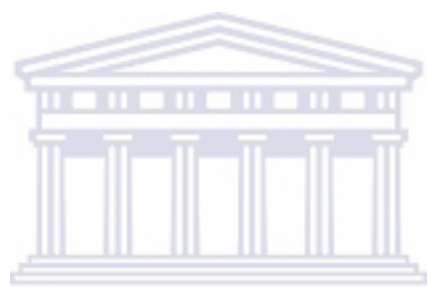




\subsection{Materials and Methods}

\subsubsection{Agar preparation}

Potato Detrose agar (PDA) (Sigma-Aldrich)was prepared by adding $500 \mathrm{ml}$ of water into a bottle containing $19.5 \mathrm{~g}$ of PDA and homogenized by mixing. It was then sterilized in an autoclave at $121^{\circ} \mathrm{C}$ for $20 \mathrm{~min}$. Immediately after autoclaving, the agar was allowed to cool down to room temperature (tilting the bottle to avoid solidification). The agar was poured into sterile petri dishes and allowed to cool down until the agar solidified. The plates were then stored at $4{ }^{\circ} \mathrm{C}$.

\subsubsection{Medium preparation}

Malt extract broth (MEB) (Thermo Scientific) was prepared by adding $500 \mathrm{ml}$ of water into a bottle containing $10 \mathrm{~g}$ of MEB and the mixture homogenised. Thereafter, $100 \mathrm{ml}$ of MEB was transferred into an Erlenmeyer flask and the rest of the broth was transferred into test tubes. The broth was then sterilized in an autoclave at $115^{\circ} \mathrm{C}$ for $10 \mathrm{~min}$. The autoclaved medium was cooled to room temperature. The $100 \mathrm{ml}$ broth in an Erlenmeyer flask was used for the yeast inoculation and the test tubes were stored at $4{ }^{\circ} \mathrm{C}$ for further use.

\subsubsection{XTT preparation}

2,3-Bis(2-methyloxy-4-nitro-5-sulfophenyl)-5-[(phenylamino)carbonyl]-2H-tetrazolium hydroxide (XTT) assays was purchased from Roche diagnostic in South Africa. XTT together with its capping reagent were incubated at room temperature to thaw. One millilitre of XTT was transferred into $2 \mathrm{ml}$ Eppendorf tube and $20 \mu \mathrm{l}$ of capping reagent added. The reagents were mixed and were ready to be used in an experiment. 


\subsubsection{Preparation of yeast stock cultures}

An autoclaved swab was dipped into instant baker's yeast containing viable $S$. cerevisiae cells and inoculated into $100 \mathrm{ml}$ of sterile MEB in an Erlenmeyer flask. The broth was incubated overnight at $37^{\circ} \mathrm{C}$. Four PDA plates (labelled 1-4) were streaked with $S$. cerevisiae from the overnight culture and incubated overnight at $37^{\circ} \mathrm{C}$. S. cerevisiae colonies were then picked up from each incubated plate and streaked out into new PDA agar plates. The plates were incubated overnight at $37^{\circ} \mathrm{C}$. After that, a single colony was picked and inoculated into $30 \mathrm{ml}$ of MEB and incubated for $24 \mathrm{~h}$ at $37^{\circ} \mathrm{C}$. After $24 \mathrm{~h}$ of incubation, the cells were transferred into $50 \mathrm{ml}$ tubes and centrifuged for 5-10 min (ensuring that the yeast cells accumulated at the bottom of the tube). The supernatant was discarded and the yeast cell pellet was resuspended with $10 \mathrm{ml}$ of sterile water and $50 \%$ glycerol was added to prevent the cells from fracturing. The yeast stock was stored at $4{ }^{\circ} \mathrm{C}$.

\subsubsection{XTT assay}

Yeast stock $(100 \mu \mathrm{l})$ was added to $10 \mathrm{ml}$ of MEB and incubated overnight at $37^{\circ} \mathrm{C}$. Doubling dilutions of AgNPs in $10 \%$ MEB were prepared to give $1 \mathrm{ml}$ of each of the following AgNP concentrations: $0.78,1.56,3.125,6.25,12.5,25,50$ and $100 \mu \mathrm{g} / \mathrm{ml}$. A negative control tube containing $0.1 \%$ Sodium Dodecyl Sulfate (SDS) in $10 \%$ MEB was also prepared. The yeast cells $(100 \mu 1)$ were added thereafter to all tubes, including controls. The tubes were incubated for $74 \mathrm{~h}$ at $37^{\circ} \mathrm{C}$. After the incubation and centrifugation, the supernatant was discarded and the pellet washed with $1000 \mu \mathrm{l}$ sterilized water. The cell pellet was resuspended in $1 \mathrm{ml}$ of distilled water after which $50 \mu 1$ of the resuspended cells was transferred to a 96 well plate. Filtered water and $0.1 \%$ SDS solutions were also used as controls. The XTT solution (Section 5.2.3) was added in each well and the initial Optical Density (OD) readings were taken using a plate reader at $450 \mathrm{~nm}$. The plate was incubated for $24 \mathrm{~h}$ at $37^{\circ} \mathrm{C}$ and $\mathrm{OD}$ readings were 
again recorded. The change in OD at $450 \mathrm{~nm}$ over the $24 \mathrm{~h}$ period was calculated and used to determine the percentage metabolic activity of the cells. The percentage metabolic activity was calculated using the formula:

Percentage metabolic activity $=($ Change in absorbance of the sample) $/$ (change in absorbance

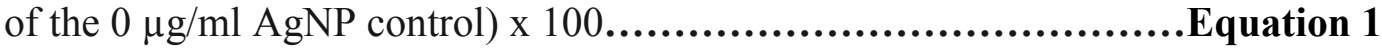

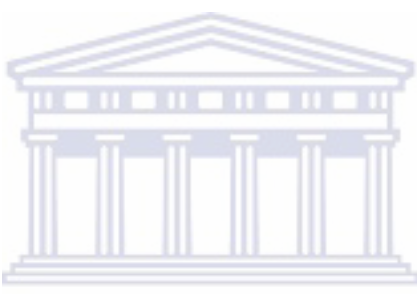

UNIVERSITY of the 


\subsection{Results and Discussion}

\section{Synthesis of silver nanoparticles}

In order to assess the toxicity of AgNPs to S. cerevisiae, AgNPs were synthesised according to the protocols described in chapter 4 . The nanoparticles were then characterized using UVVis and TEM. The results of optimization of synthesis condition showed that $\mathrm{pH}$, light exposure time, concentration and type of dispersing agents produce AgNPs of different sizes and shapes. The different AgNPs synthesized in this work were used in their crude form i.e. without purifying, to investigate the toxicity of AgNPs on S. cerevisiae.

Tables 4 (A1 to A7) and 5 (B1 to B7) summarize the protocol used to prepare AgNPs by changing three parameters: molar ratio, light exposure time and $\mathrm{pH}$. They also summarize the TEM results in terms of their different shapes and sizes and particle size distribution. 
Table 5: Silver nanoparticles preparation with PVP and their size and shape.

\begin{tabular}{|c|c|c|c|c|c|}
\hline $\begin{array}{l}\text { Sample } \\
\text { ID }\end{array}$ & Silver nanoparticles preparation & $\begin{array}{l}\text { Ratio AgNO3: } \\
\text { PVP }\end{array}$ & $\mathrm{pH}$ & Shape & $\begin{array}{l}\text { Particle size } \\
\text { distribution }(\mathrm{nm})\end{array}$ \\
\hline A1 & $\begin{array}{l}0.4 \mathrm{mg} / \mathrm{mL} \text { of PVP was adjusted to } \mathrm{pH} 9 \text { using } 1 \mathrm{M} \mathrm{NH}_{4} \mathrm{NO}_{3} \text { and } 1 \mathrm{M} \text { citric acid. } \\
0.4 \mathrm{mg} / \mathrm{mL} \text { of } \mathrm{AgNO}_{3} \text { was added into } \mathrm{PVP} \text { solution. The mixture was then exposed to } \\
\text { the light ( OSRAM Vitalux lamp ) for } 3 \mathrm{~h}\end{array}$ & 01:01 & 9 & Needle-like & $39-170$ \\
\hline A2 & $\begin{array}{l}2 \mathrm{mg} / \mathrm{mL} \text { of PVP was adjusted to } \mathrm{pH} 9 \text { using } 1 \mathrm{M} \mathrm{NH}_{4} \mathrm{NO}_{3} \text { and } 1 \mathrm{M} \text { citric acid. } \\
0.4 \mathrm{mg} / \mathrm{mL} \text { of } \mathrm{AgNO}_{3} \text { was added into PVP solution. The mixture was then exposed to } \\
\text { the light ( OSRAM Vitalux lamp ) for } 3 \mathrm{~h}\end{array}$ & $01: 05$ & 9 & Spherical & $5-14$ \\
\hline A3 & $\begin{array}{l}4 \mathrm{mg} / \mathrm{mL} \text { of } \mathrm{PVP} \text { was adjusted to } \mathrm{pH} 9 \text { using } 1 \mathrm{M} \mathrm{NH}_{4} \mathrm{NO}_{3} \text { and } 1 \mathrm{M} \text { citric acid. } \\
0.4 \mathrm{mg} / \mathrm{mL} \text { of } \mathrm{AgNO}_{3} \text { was added into PVP solution. The mixture was then exposed to } \\
\text { the light ( OSRAM Vitalux lamp ) for } 3 \mathrm{~h}\end{array}$ & 01:10 & 9 & Spherical & $33-66$ \\
\hline A4 & $\begin{array}{l}4 \mathrm{mg} / \mathrm{mL} \text { of } \mathrm{PVP} \text { was adjusted to } \mathrm{pH} 9 \text { using } 1 \mathrm{M} \mathrm{NH}_{4} \mathrm{NO}_{3} \text { and } 1 \mathrm{M} \text { citric acid. } \\
0.4 \mathrm{mg} / \mathrm{mL} \text { of } \mathrm{AgNO}_{3} \text { was added into PVP solution. The mixture was then exposed to } \\
\text { the light ( OSRAM Vitalux lamp ) for } 1 \mathrm{~h}\end{array}$ & $01: 10$ & 9 & Spherical & $5-13$ \\
\hline A5 & $\begin{array}{l}4 \mathrm{mg} / \mathrm{mL} \text { of PVP was adjusted to } \mathrm{pH} 9 \text { using } 1 \mathrm{M} \mathrm{NH}_{4} \mathrm{NO}_{3} \text { and } 1 \mathrm{M} \text { citric acid. } \\
0.4 \mathrm{mg} / \mathrm{mL} \text { of } \mathrm{AgNO}_{3} \text { was added into PVP solution. The mixture was then exposed to } \\
\text { the light ( OSRAM Vitalux lamp ) for } 2 \mathrm{~h}\end{array}$ & $01: 10$ & 9 & Decahedrons & $40-89$ \\
\hline A6 & $\begin{array}{l}4 \mathrm{mg} / \mathrm{mL} \text { of PVP was adjusted to } \mathrm{pH} 6 \text { using } 1 \mathrm{M} \mathrm{NH}_{4} \mathrm{NO}_{3} \text { and } 1 \mathrm{M} \text { citric acid. } \\
0.4 \mathrm{mg} / \mathrm{mL} \text { of } \mathrm{AgNO}_{3} \text { was added into PVP solution. The mixture was then exposed to } \\
\text { the light ( OSRAM Vitalux lamp ) for } 3 \mathrm{~h}\end{array}$ & 01:10 & 6 & Spherical & 4 \\
\hline A7 & $\begin{array}{l}4 \mathrm{mg} / \mathrm{mL} \text { of PVP was adjusted to } \mathrm{pH} 10.5 \text { using } 1 \mathrm{M} \mathrm{NH}_{4} \mathrm{NO}_{3} \text { and } 1 \mathrm{M} \text { citric acid. } \\
0.4 \mathrm{mg} / \mathrm{mL} \text { of } \mathrm{AgNO}_{3} \text { was added into PVP solution. The mixture was then exposed to } \\
\text { the light ( OSRAM Vitalux lamp ) for } 3 \mathrm{~h}\end{array}$ & $01: 10$ & 10.5 & Spherical & $13-22$ \\
\hline
\end{tabular}


Table 6: Preparation of silver nanoparticles with citric acid and their size and shape

\begin{tabular}{|c|c|c|c|c|c|}
\hline & Silver nanoparticles preparation & & & & \\
\hline $\begin{array}{l}\text { Sample } \\
\text { ID }\end{array}$ & Description: Preparation of silver nanoparticles with citric acid & $\begin{array}{l}\text { Ratio } \\
\mathrm{AgNO}_{3}: \mathrm{PVP}\end{array}$ & $\mathrm{pH}$ & Shape & $\begin{array}{l}\text { Particle size } \\
\text { distribution } \\
(\mathrm{nm})\end{array}$ \\
\hline B1 & $\begin{array}{l}0.4 \mathrm{mg} / \mathrm{mL} \text { of citric was adjusted to } \mathrm{pH} 9 \text { using } 1 \mathrm{M} \mathrm{NH}_{4} \mathrm{NO}_{3} \text { and } 1 \mathrm{M} \text { citric acid. } \\
0.4 \mathrm{mg} / \mathrm{mL} \text { of } \mathrm{AgNO}_{3} \text { was added into citric acid solution. The mixture was then } \\
\text { exposed to the light ( OSRAM Vitalux lamp ) for } 3 \mathrm{~h}\end{array}$ & 01:01 & 9 & Spherical & $38-91$ \\
\hline B2 & $\begin{array}{l}2 \mathrm{mg} / \mathrm{mL} \text { of citric was adjusted to } \mathrm{pH} 9 \text { using } 1 \mathrm{M} \mathrm{NH}_{4} \mathrm{NO}_{3} \text { and } 1 \mathrm{M} \text { citric acid. } \\
0.4 \mathrm{mg} / \mathrm{mL} \text { of } \mathrm{AgNO}_{3} \text { was added into citric acid solution. The mixture was then } \\
\text { exposed to the light ( OSRAM Vitalux lamp ) for } 3 \mathrm{~h}\end{array}$ & 01:05 & 9 & Spherical & 5 \\
\hline B3 & $\begin{array}{l}4 \mathrm{mg} / \mathrm{mL} \text { of citric was adjusted to } \mathrm{pH} 9 \text { using } 1 \mathrm{M} \mathrm{NH}_{4} \mathrm{NO}_{3} \text { and } 1 \mathrm{M} \text { citric acid. } \\
0.4 \mathrm{mg} / \mathrm{mL} \text { of } \mathrm{AgNO}_{3} \text { was added into citric acid solution. The mixture was then } \\
\text { exposed to the light ( OSRAM Vitalux lamp ) for } 3 \mathrm{~h}\end{array}$ & $01: 10$ & 9 & Spherical & $4-9$ \\
\hline B4 & $\begin{array}{l}4 \mathrm{mg} / \mathrm{mL} \text { of citric was adjusted to } \mathrm{pH} 9 \text { using } 1 \mathrm{M} \mathrm{NH}_{4} \mathrm{NO}_{3} \text { and } 1 \mathrm{M} \text { citric acid. } \\
0.4 \mathrm{mg} / \mathrm{mL} \text { of } \mathrm{AgNO}_{3} \text { was added into citric acid solution. The mixture was then } \\
\text { exposed to the light ( OSRAM Vitalux lamp ) for } 1 \mathrm{~h}\end{array}$ & $01: 10$ & 9 & Spherical & $22-40$ \\
\hline B5 & $\begin{array}{l}4 \mathrm{mg} / \mathrm{mL} \text { of citric was adjusted to } \mathrm{pH} 9 \text { using } 1 \mathrm{M} \mathrm{NH}_{4} \mathrm{NO}_{3} \text { and } 1 \mathrm{M} \text { citric acid. } \\
0.4 \mathrm{mg} / \mathrm{mL} \text { of } \mathrm{AgNO}_{3} \text { was added into citric acid solution. The mixture was then } \\
\text { exposed to the light ( OSRAM Vitalux lamp ) for } 2 \mathrm{~h}\end{array}$ & $01: 10$ & 9 & Spherical & $11-18$ \\
\hline B6 & $\begin{array}{l}4 \mathrm{mg} / \mathrm{mL} \text { of citric was adjusted to } \mathrm{pH} 6 \text { using } 1 \mathrm{M} \mathrm{NH}_{4} \mathrm{NO}_{3} \text { and } 1 \mathrm{M} \text { citric acid. } \\
0.4 \mathrm{mg} / \mathrm{mL} \text { of } \mathrm{AgNO}_{3} \text { was added into citric acid solution. The mixture was then } \\
\text { exposed to the light ( OSRAM Vitalux lamp ) for } 3 \mathrm{~h}\end{array}$ & $01: 10$ & 6 & Spherical & $11-31$ \\
\hline B7 & $\begin{array}{l}4 \mathrm{mg} / \mathrm{mL} \text { of citric was adjusted to } \mathrm{pH} 10.5 \text { using } 1 \mathrm{M} \mathrm{NH}_{4} \mathrm{NO}_{3} \text { and } 1 \mathrm{M} \text { citric acid. } \\
0.4 \mathrm{mg} / \mathrm{mL} \text { of } \mathrm{AgNO}_{3} \text { was added into citric acid solution. The mixture was then } \\
\text { exposed to the light ( OSRAM Vitalux lamp ) for } 3 \mathrm{~h}\end{array}$ & $01: 10$ & 10.5 & Spherical & $5-14$ \\
\hline
\end{tabular}


Table 7 (A1 to A7) and Table 8 (B1 to B7) show the outcomes of the AgNPs cytotoxicity assessed by XTT assay. The highlighted numbers are the most toxic concentrations of AgNPs to the $S$. cerevisiae cells and the un-highlighted ones are the non-toxic concentrations of AgNPs.

Table 7: Toxicity of AgNPs prepared using PVP as dispersing agent

\begin{tabular}{|c|c|c|c|c|c|c|c|c|c|c|}
\hline \multirow{2}{*}{$\begin{array}{c}\text { Sample } \\
\text { ID }\end{array}$} & \multirow[b]{2}{*}{ \%Survival } & \multicolumn{9}{|c|}{$\mu \mathrm{g} / \mathrm{ml}$ AgNPs } \\
\hline & & Control & 0.78125 & 1.5625 & 3.125 & 6.25 & 12.5 & 25 & 50 & 100 \\
\hline \multirow[b]{2}{*}{$\mathrm{A} 1$} & Mean & 100 & 102 & 103 & 101 & 102 & 99 & 27 & 20 & 17 \\
\hline & SD & 4 & 4 & 6 & 4 & 2 & 2 & 2 & 0 & 1 \\
\hline \multirow[b]{2}{*}{$\mathrm{A} 2$} & Mean & 100 & 102 & 98 & 96 & 98 & 100 & 34 & 21 & 19 \\
\hline & SD & 8 & 7 & 5 & 7 & 5 & 8 & 1 & 1 & 0 \\
\hline \multirow[b]{2}{*}{ A3 } & Mean & 100 & 101 & 101 & 105 & 104 & 104 & 101 & 72 & 20 \\
\hline & SD & 3 & 3 & 3 & 4 & 3 & 4 & 5 & 26 & 1 \\
\hline \multirow[b]{2}{*}{ A4 } & Mean & 100 & 106 & 102 & 99 & 23 & 20 & 19 & 17 & 14 \\
\hline & SD & 3 & 1 & 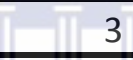 & 2 & 1 & 0 & 0 & 2 & 1 \\
\hline \multirow[b]{2}{*}{ A5 } & Mean & 100 & 106 & 105 & 106 & 53 & 24 & 22 & 21 & 18 \\
\hline & SD & 3 & 2 & 2 & 2 & 2 & 0 & 1 & 2 & 2 \\
\hline \multirow[b]{2}{*}{ A6 } & Mean & 100 & 108 & VE 107 & TY 109 & 107 & 68 & 26 & 24 & 23 \\
\hline & SD & 4 & 4 & 4 & 2 & 2 & 3 & 1 & 1 & 2 \\
\hline \multirow[b]{2}{*}{ A7 } & Mean & 100 & 99 & 99 & 90 & 23 & 13 & 12 & 10 & 8 \\
\hline & SD & 5 & 2 & 2 & 3 & 3 & 3 & 1 & 1 & 1 \\
\hline
\end{tabular}

Table 7 shows results of the toxicity of the synthesized AgNPs on S. cerevisiae. The results show clearly that higher concentrations of AgNPs are toxic to S. cerevisiae cells. At AgNPs concentrations above $6.25 \mu \mathrm{g} / \mathrm{ml}$, the most toxic particles start their killing effect. And this assays shows A4, A5 and A7 to be the most toxic AgNPs in this series. Following that is A6, which kills at $12.5 \mu \mathrm{g} / \mathrm{ml}$, and A1 and A2 that show toxicity at $25 \mu \mathrm{g} / \mathrm{ml}$. the least toxic particles in this series A3 starts killing cells only at concentrations as high as $50 \mu \mathrm{g} / \mathrm{ml}$. The cytotoxic data suggest that particles synthesise by different means demonstrate different toxicity levels on the cells. This means in synthesizing AgNPs for particular applications, the method of synthesis needs to be carefully investigated and optimised. 
Table 8: Toxicity of AgNPs prepared using citric acid as dispersing agent

\begin{tabular}{|c|c|c|c|c|c|c|c|c|c|c|}
\hline \multirow{2}{*}{$\begin{array}{c}\text { Sample } \\
\text { ID }\end{array}$} & \multirow[b]{2}{*}{ \% Toxicity } & \multicolumn{9}{|c|}{$\mu \mathrm{g} / \mathrm{ml} \mathrm{AgNPs}$} \\
\hline & & Control & 0.78125 & 1.5625 & 3.125 & 6.25 & 12.5 & 25 & 50 & 100 \\
\hline \multirow[b]{2}{*}{ B1 } & Mean & 100 & 101 & 99 & 98 & 97 & 97 & 97 & 98 & 90 \\
\hline & SD & 5 & 2 & 3 & 1 & 4 & 3 & 4 & 3 & 4 \\
\hline \multirow[b]{2}{*}{ B2 } & Mean & 100 & 112 & 114 & 115 & 114 & 100 & 103 & 100 & 29 \\
\hline & SD & 4 & 8 & 5 & 3 & 4 & 2 & 11 & 25 & 1 \\
\hline \multirow[b]{2}{*}{ B3 } & Mean & 100 & 110 & 115 & 114 & 79 & 18 & 22 & 19 & 19 \\
\hline & SD & 4 & 2 & 2 & 2 & 4 & 1 & 0 & 0 & 1 \\
\hline \multirow[b]{2}{*}{ B4 } & Mean & 100 & 112 & 109 & 103 & 116 & 109 & 20 & 21 & 20 \\
\hline & SD & 2 & 1 & 2 & 16 & 2 & 3 & 0 & 1 & 1 \\
\hline \multirow[b]{2}{*}{ B5 } & Mean & 100 & 95 & 92 & 98 & 97 & 99 & 101 & 104 & 67 \\
\hline & SD & 9 & 2 & 5 & 1 & 3 & 2 & 4 & 3 & 2 \\
\hline \multirow[b]{2}{*}{ B6 } & Mean & 100 & 96 & 95 & 99 & 98 & 99 & 98 & 93 & 27 \\
\hline & SD & 5 & 1 & 1 & 4 & 1 & 1 & 3 & 1 & 1 \\
\hline \multirow[b]{2}{*}{ B7 } & Mean & 100 & 101 & 102 & 112 & 47 & 22 & 20 & 20 & 18 \\
\hline & SD & 2 & 2 & 10 & 7 & 3 & 0 & 1 & 1 & 2 \\
\hline
\end{tabular}

The results obtained in Table 8 showed no cytotoxicity in sample B1 while B2, B5 and B6 are cytotoxic to $S$. cerevisiae at concentration of AgNPs as high as $100 \mu \mathrm{g} / \mathrm{ml}$. However, B4 starts showing cytotoxicity at concentrations above $12.5 \mu \mathrm{g} / \mathrm{ml}$ whilst B3 and B7 on the other hand, show cytotoxity from concentration of $6.25 \mu \mathrm{g} / \mathrm{ml}$. The observations showed that different parameters used to prepare AgNPs differ in their cytotoxicity and cytotoxicity increased in the following order $\mathrm{B} 1<\mathrm{B} 2$; $\mathrm{B} 5$; $\mathrm{B} 6<\mathrm{B} 4<\mathrm{B} 3$; B7. Comparatively, the A1-A7 series shows more cytotoxic effect on the S. cerevisiae cell than the B1-B7 series but both are cytotoxic at different concentration to the cells. 


\subsection{General Conclusion}

The task of this research was to investigate the toxicity of silver nanoparticles (AgNPs) on

S. cerevisiae cells as a model organism for eukaryotic cells. The results are to contribute to the knowledge required for the preparation of AgNPs water treatment strategy for poor communities. To accomplish this task, AgNPs were synthesized successfully by photochemical reduction of $\mathrm{AgNO}_{3}$ in the presence of PVP and in the presence of citric acid. The formation of AgNPs was confirmed by UV-Vis absorption spectra analysis. The UV-Vis absorption spectra showed the Surface Plasmon Resonance (SPR) band characteristics of AgNPs in the range of 400-500 nm. TEM was also used to confirm the formation of AgNPs and to view their sizes and shapes and to verify the size distribution of the synthesised particles. TEM images showed that the AgNPs were in spherical, needle-like and decahendrons shape depending on the method of synthesis applied. The particles obtained using PVP were shown to be bigger in nano-size than those synthesized using citric acid (Table 5 and 6). The concentration of PVP and citric acid, time of light exposure and $\mathrm{pH}$ of reaction mixture affected the formation of AgNPs in unique ways.

Cytotoxicity of the synthesised AgNPs was evaluated using the XTT assay which assesses cell viability upon exposure to different concentrations of AgNPs. The assay showed that high concentrations of AgNPs $(12.5,25,50$ and $100 \mu \mathrm{g} / \mathrm{mL})$ were toxic to the cell. The cell killing effect was greater with the PVP synthesised AgNPs than those from citric acid. It was also observed that the methods of preparation of the AgNPs influenced their toxicity. These observations were consisted with previous research on related topic (Braydich-Stolle et al., 2005, Carlson et al., 2008) which showed that AgNPs are toxic to mammalian cells, and that the sizes of the particles influence their toxicity but contrary to their conclusion, this study showed that larger AgNPs are more toxic to $S$. cerevisiae than small particles. AgNPs 
prepared and tested in this work were used in their crude form. Further investigation on this subject may consider purifying the AgNPs before proceeding to toxicity tests.

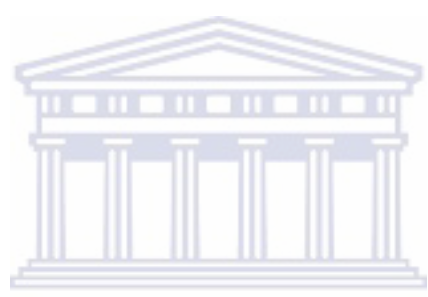

UNIVERSITY of the 


\section{References 3}

1. Braydich-Stolle, L., Hussain, S., Schlager, J.J. and Hofmann, M.C. In vitro cytotoxicity of nanoparticles in mammalian germlinestem cells. Toxicological Science.(2005); 88:412-419

2. Carlson, C., Hussain, S. M., Schrand, A. M., Braydich-Stolle, L. K., Hess, K. L., Jones, R. L. and Schlager, J. J. Unique cellular interaction of silver nanoparticles: size-dependent generation of reactive oxygen species. Journal of Physical Chemistry. (2008); 112:13608-13619.

3. Hussain, S. M., Hess, K. L., Gearhart, J. M, Geiss, K.T. and Schlager, J. J: In vitro toxicity of nanoparticles in BRL 3A rat liver cells. Toxicology in vitro. (2005); 19: 975-983.

4. Jun Sung, K., Eunye, K., Kyeong, N.Y., Jong-Ho, K., Sung, J. P., Hu, J. L., So, H. K., Young, K. P., Yong, H. P., Cheol-Yong, H., Yong-Kwon K., Yoon-Sik, L., Dae, H. J and Myung-Haing, C. Antimicrobial effects of silver nanoparticles. Nanomedicine: Nanotechnology, Biology, and Medicine. (2007); 3: 95- 101.

5. Kuhn, D. M., Balkis, M., Chandra, J., Mukherjee, P. K. and Ghannoum, M. A. Uses and limitations of the XTT assay in studies of Candida growth and metabolism. Journal of Clinical Microbiology. (2003); 41: 506.

6. Kuhn, D. M., George, T., Chandra, J., Mukherjee, P. K. and Ghannoum, M. A. Antifungal susceptibility of Candida biofilms: unique efficacy of amphotericin B lipid formulations $\quad$ and $\quad$ echinocandins. Antimicrob Agents Chemother (2002); 46:17731780.

7. Mosmann, T. Rapid colorimetric assay for cellular growth and survival: application to proliferation and cytotoxicity assays. Journal of immunological Methods. (1983); 65: $55-63$. 
8. Panyala, N. R., Pena-Mendez, E. M. and Havel, J. Silver or silver nanoparticles: a hazardous threat to the environment and human health? Journal of Applied Biomed. (2008); 6: 117-129.

9. Prabhu, S. and Poulose, E. K. Silver nanoparticles: mechanism of antimicrobial action, synthesis, medical applications, and toxicity effects. Prabhu and Poulose International Nano Letters. (2012); 2:1-1-10.

10. Reidy, B., Haase, A., Luch, A., Dawson K. A. and Lynch, I. Mechanisms of silver nanoparticle release, transformation and toxicity: A critical review of current knowledge and recommendations for future studies and applications. Materials. (2013); 6: 2295-2350.

11. Soto, K., Garza, K. M. and Murr, L. E. Cytotoxic effects of aggregated nanomaterials. Acta Biomater. (2007); 3:351-358.

12. Soto, K. F., Carrasco, A., Powell, T. G., Garza, K.M. and Murr, L. E. Comparative in vitro cytotoxicity assessment of some manufactured nanoparticulate materials characterized by transmission electron microscopy. Journal of Nanoparticle Research. (2005); 7:145-169. 